\title{
The Implementation of Communicative Focus-on-Form Activities in EFL: Young Adolescents' Initial Perceptions and Classroom Issues in Japan
}

by

\begin{abstract}
Ritsuko Honda
A thesis submitted to

The Faculty of Graduate Studies and Research in partial fulfilment of

the requirement of the degree of
\end{abstract}

Master of Arts

School of Linguistics and Applied Language Studies

\author{
Carleton University \\ Ottawa, Ontario \\ January 2004
}

CCopyright 2004, Ritsuko Honda 


\author{
National Library \\ of Canada \\ Acquisitions and \\ Bibliographic Services \\ 395 Wellington Street \\ Ottawa ON K1A ON4 \\ Canada
}

Bibliothèque nationale

du Canada

Acquisisitons et services bibliographiques

395 , rue Wellington Ottawa ON K1A ON4 Canada
Your file Votre référence ISBN: 0-612-93903-0

Ourfile Notre référence ISBN: 0-612-93903-0
The author has granted a nonexclusive licence allowing the National Library of Canada to reproduce, loan, distribute or sell copies of this thesis in microform, paper or electronic formats.

The author retains ownership of the copyright in this thesis. Neither the thesis nor substantial extracts from it may be printed or otherwise reproduced without the author's permission.
L'auteur a accordé une licence non exclusive permettant à la Bibliothèque nationale du Canada de reproduire, prêter, distribuer ou vendre des copies de cette thèse sous la forme de microfiche/film, de reproduction sur papier ou sur format électronique.

L'auteur conserve la propriété du droit d'auteur qui protège cette thèse. $\mathrm{Ni}$ la thèse ni des extraits substantiels de celle-ci ne doivent être imprimés ou aturement reproduits sans son autorisation.
In compliance with the Canadian Privacy Act some supporting forms may have been removed from this dissertation.

While these forms may be included in the document page count, their removal does not represent any loss of content from the dissertation.
Conformément à la loi canadienne sur la protection de la vie privée, quelques formulaires secondaires ont été enlevés de ce manuscrit.

Bien que ces formulaires aient inclus dans la pagination, il n'y aura aucun contenu manquant. 


\begin{abstract}
This research explores the possibility of implementing communicative focus-on-form (FonF) activities (e.g., Fotos, 2002; Harley, 1998; Spada \& Lightbown, 1993) conducted in only English to Japanese young adolescents, particularly focusing on their initial perceptions and responses to the activities. The research process examined a 2 -week period of communicative grammar teaching carried out by the researcher in five classes of junior high school students $(n=170)$. The research also included observation of 1 week of a traditional grammar class in Japanese by a regular teacher. The data was collected through i) student questionnaires administered before, in the middle of, and after the communicative teaching, ii) student group-interviews, iii) questionnaire and interview with 6 teachers, and iv) the researcher's reflective diary. The results provide evidence that students approved of and could understand the activities. The students successfully interpreted teacher's talk by use of various strategies and resources such as knowledge of loan words katakana and contextual cues. In particular, the importance of "key students" is identified as crucial in creating certain classroom interactions which lead to the contextual cues for the other students. Moreover, there is evidence that the communicative activity interactions provide the students, including slow learners and fidgety "problematic" students, with a chance to actively participate in the class, in addition to promoting their autonomy. The research concludes that such teaching requires certain conditions and suggests various classroom implications.
\end{abstract}




\section{Acknowledgements}

I am indebted to all the people who have supported me for this research project and my studies at Carleton. First of all, I would like to express my sincere gratitude to my thesis supervisor, Professor Devon Woods, without whom I could never have completed this project. Despite his extremely busy schedule, from the very beginning of planning the project to the last moment of editing the paper, he was always available and supportive for me. I thank him for his unprecedented assistance and guidance, dedication, patience, and encouragement. I would also like to thank my second reader, Professor Janna Fox, for her generosity and valuable comments on my draft. I would also thank ESL teachers, Stephanie Pinnacle and Linda Librande, who allowed me to observe their class and gave me advice and creative ideas for designing communicative FonF activities for beginners. I am thankful to all my ESL teachers, who empowered me and helped me establish my fundamental skills and knowledge to survive this academic life. I am thankful to Emily Woods for her great help with editing the paper in a short time.

I am deeply grateful to all the participants, the teachers and the students, who welcomed me with open arms and allowed me to carry out the project. I am also grateful to the former vice-principal and my colleagues for their understanding and valuable suggestions and information for my project. They made a number of arrangements for me to obtain the approval from the school and the city educational board.

I would like to thank my friends, Asifa Akba, Yi Peng, Mike Dodson, and Liz Freestone, who not only always encouraged me but also helped me make a video of teaching material. My thanks also go to my new friend, Younhee Choi, for her friendship and encouragement, and my old friends and colleagues for their encouraging words in innumerable e-mails from Japan.

My special thanks go to my dearest friends, Peter Langtvet and Prapapan Laokuldilok, for their sympathetic encouragement and constant support. Peter has always been there for me with his love and good humour, answering my incessant odd questions about English and giving me special care and warm advice. Pook has always been happy to share her knowledge and inspiration with me, taking care of me, listening to my problems, and cheering me up with a warm smile. Without their support, I would not even have started this project.

Finally, my very special thanks go to my family, my father, mother, sister, brother-in-law, and my Canadian mother Hilda Wynne, who have deeply understood me and infinitely supported my three-year study in Canada. 
To my amiable grandpa Totsue, my generous grandma Koto, and my humorous grandma Chiyoko, all of whom passed away during my study in Canada 


\section{Table of Contents}

Abstract

Acknowledgements

Dedication iv

Table of Contents $\quad v$

List of Tables and Figures viii

\section{Chapters}

1. Place for Communicative Focus-on-Form (FonF) Introduction 1

1.1. The Junior High School EFL Context in Japan 2

1.2. Place for FonF 9

1.3. Research Questions 11

2. Issues Related to Communicative FonF for Japanese Young Adolescents Introduction 14

2.1. The Age of Adolescence 15

2.2. Explicit and Implicit Teaching in Japan 17

2.3. Explicit and Implicit Knowledge 20

2.4. Attention and Noticing in Learning Language 25

2.5. Motivation in Learning Language 27

2.6. Focus on Form 29

2.6.1. 'Focus on Form' and 'Focus on FormS' 30

2.6.2. Communicative Focus on Form $\quad 32$

2.7. Teaching in the Target Language $\quad 37$

Conclusion $\quad 40$

3. Research Methodology

3.1. Design of Project 42

3.1.1. Project Class Location and Time 43

3.1.2. Participants 44

(1) Students 44

(2) Teachers 45

3.1.3. Design and Characteristics of Communicative FonF Teaching Materials 46

(1) Conducted Mainly in English to Maximize Input 48

(2) Organized with Thematic FonF Activities 51

(3) Combined with Lots of Non-Linguistic Input 52

(4) Requiring Physical Responses $\quad 52$ 
(5) Putting No Pressure on Students to Speak Up in English 53

(6) Stimulating Intrinsic Motivation 55

(7) Including Lots of Pair/Group Work 56

(8) Providing with Lots of Aural Modeling 56

(9) Completed with Homework $\quad 57$

3.2. Data Collection $\quad 58$

3.2.1. Methods $\quad 58$

$\begin{array}{ll}\text { 3.2.2. Project Procedures } & 60\end{array}$

3.3. Data Analysis 61

4. Current Situation: Students' Previous English Experiences and Perceptions Introduction $\quad 63$

4.1. At Elementary School 64

4.1.1. Students' English Experiences $\quad 64$

4.1.2. Students' Perceptions of English Experiences 66

4.2. At Junior High School $\quad 68$

4.2.1. Students' Current Knowledge about English $\quad 68$

$\begin{array}{ll}\text { 4.2.2. Regular English Class } & 71\end{array}$

4.2.3. Students' Perceptions of Regular English Class 75

4.3. Outside of School $\quad 77$

$\begin{array}{ll}\text { Conclusion } & 81\end{array}$

5. Students' Perceptions and Responses to Communicative FonF Activities $\begin{array}{ll}\text { Introduction } & 83\end{array}$

5.1. Students' Perceptions of Communicative FonF Activities 86

5.1.1. Favourable Perceptions $\quad 86$

$\begin{array}{ll}\text { 5.1.2. Unfavourable Perceptions } & 91\end{array}$

5.2. Students' Ability to Understand Communicative FonF Activities 93

5.2.1. Students' Perceptions of the Ability to Understand the Class 94

5.2.2. Teachers' Perceptions of Students' Ability to Understand the Class 97

5.2.3. Strategies and Resources Used to Understand the Class 99

(1) Strategies Used to Understand the Class 101

(2) Resources Used to Understand the Class 104

1) Use of Own World Knowledge and Contextual Cues 104

2) Use of Prior Linguistic Experience 113

3) Use of Key Students 120

4) Use of Explicit Form Instruction 122

5.3. Outcome from Communicative FonF Activities 129

5.3.1. Students' English Use in Communicative FonF Activities $\quad 130$ 
6. Discussion: Classroom Issues and Implications

Introduction

6.1. Students' Relationships with Teachers and Peers

6.1.1. Teacher-Student Relationships

6.1.2. Student-Student Relationships

6.2. Disciplinary Interventions and Encouragement

6.2.1. Disciplinary Interventions

6.2.2. Encouragement

6.3. Teacher Deficiencies

6.3.1. Organizational Instructions

6.3.2. Activity Instructions

6.3.3. Evaluation and Correction of Students' Performance 


\section{List of Tables and Figures}

\section{Tables:}

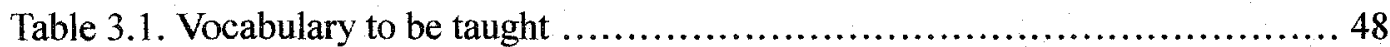

Table 4.1. SQ1-3(5) 1) Reasons for "Yes"..................................... 67

Table 4.2. SQ1-3(5) 2) Reasons for "No"

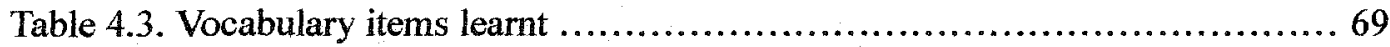

Table 4.4. Basic greetings learnt ..............................................69

Table 4.5. Classroom organizational language learnt ............................... 69

Table 5.1. TQ-1 ......................................................... 97

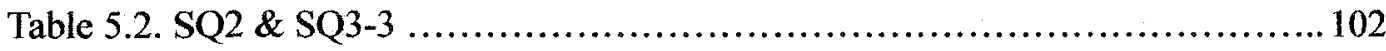

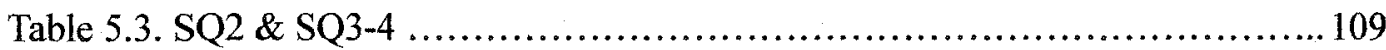

\section{Figures:}

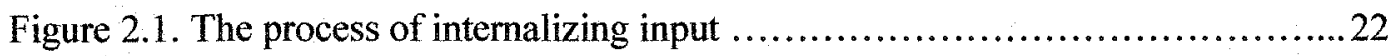

Figure 2.2. Types of knowledge and processing .................................23

Figure 2.3. Dichotomy of explicit and implicit knowledge and range of noticing .....224

Figure 2.4. Multistore model of memory ........................................25

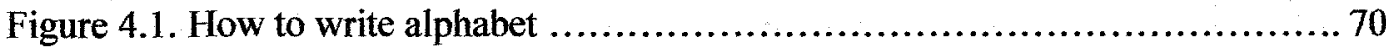

Figure 4.2. Two ways of writing " $\mathrm{M}$ " ........................................ 71

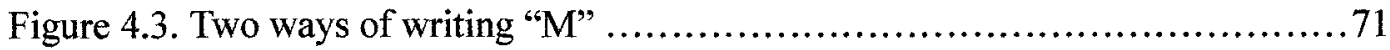

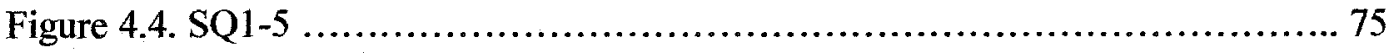

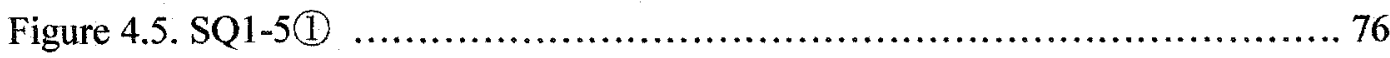

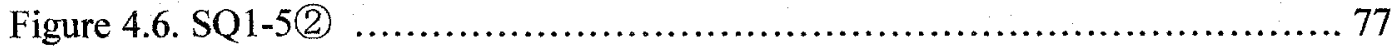

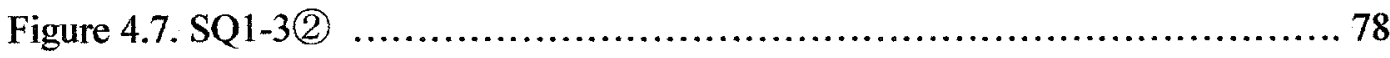

Figure 4.8. SQ1-4(2)(3) ...................................................... 79

Figure 4.9. SQ1-4(4) .................................................... 80

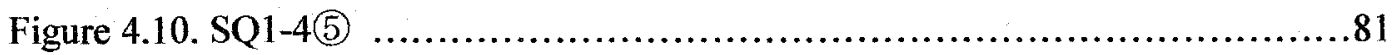

Figure 4.11. SQ1-4(6) ......................................................... 81

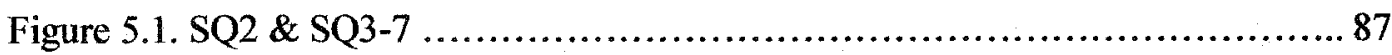

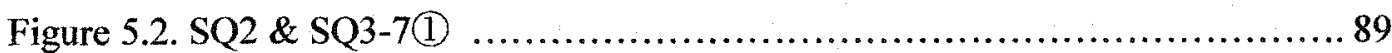

Figure 5.3. SQ2 \& SQ3-6 .................................................. 90

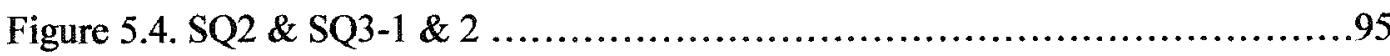

Figure 5.5. Picture cards for Karuta Activity .................................... 125

Figure 5.6. A dialogue in Skit Activity ..................................... 137 


\section{CHAPTER}

1

\section{Place for Communicative Focus-on-Form (FonF)}

\section{Introduction}

The most common approach to teaching English in Japan has been for teachers to present English texts to students, explain them from a grammatical point of view, word by word and sentence by sentence, using only Japanese. According to LoCastro (1996, p. 52), the aim has been 'to make English 100\% comprehensible in Japanese' (italics added). In 1989 , the Japanese government began to attempt an innovation in language classroom practice by issuing a new curriculum adopting a communicative language teaching (CLT) approach. However, most teachers, after trying to adopt it, have found themselves stupefied at such a dramatic change and faced the disappointing conclusion that CLT does not work in an EFL (English as a foreign language) context (Cortazzi \& Jin, 1996; Gorsuch, 2000; Fotos, 2002; Li, 1998; LoCastro, 1996). As a result, they returned to teaching grammar in Japanese. However, this reaction of the teachers needs to be investigated further. It is true that, as these teachers argued, the EFL context to which CLT is to be applied is completely different from the ESL (English as a second language) context in which it was developed. Yet the success of traditional grammar-based teaching in Japan has been very limited. Perhaps, a different context requires a different approach.

The purpose of this study is to examine the possibility of implementing a new approach to English teaching, that is, a combination of CLT and grammar teaching called communicative Focus-on-Form (FonF), in a Japanese junior high school context. Before discussing the study, let me elaborate on what a CLT approach implies. I will borrow the definition of CLT characterized by Li (1998): 


\section{CLT is characterized by}

1. a focus on communicative functions;

2.a focus on meaningful tasks rather than on language per se (e.g., grammar or vocabulary study);

3. efforts to make tasks and language relevant to a target group of learners through an analysis of genuine, realistic situations;

4. the use of authentic, from-life materials;

5. the use of group activities; and

6. the attempt to create a secure, nonthreatening atmosphere (p. 679).

Based on this definition, I will first provide an illustration of the EFL teaching context in Japanese junior high schools, which allows us to understand the constraints in adopting CLT in such a context. The constraints are also a rational explanation that communicative FonF is more suitable in the EFL context rather than the so-called pure CLT. In the second section, I will briefly explain what FonF means. Theoretically, it is believed that FonF, which works for adults and children in the ESL or immersion context, or adults in the EFL context, can work for adolescents in the EFL context. However, there is little empirical research on adolescents in such conditions. Can EFL teachers implement communicative FonF for young adolescents? Research questions will be addressed at the end of this chapter.

\subsection{The Junior High School EFL Context in Japan}

It is laid down in a commentary on junior high school education guidelines (1999) that 'English is a required subject at lower secondary school, based on awareness of the fact that it is becoming necessary for all students to acquire the basic practical communicative competence as to have a daily conversation and exchange easy information through a foreign language, and that English is world-widely used as a means of communication' (pp. 2-3). That is, EFL education starts at the age of 12 or 13 and continues for three years in junior high school. 
Since the Ministry of Education or Monbusho (1989) released a new curriculum or a course of study, which required English teachers to enhance students' communicative competence, the teachers have been expected to 'move in the direction of adoption of the CLT approach' (LoCastro, 1996). Yet, the teachers have found it difficult to adopt because of a number of constraints as seen in other Asian countries (Cortazzi \& Jin, 1996; Gorsuch, 2000; Fotos, 2002; Li, 1998; LoCastro, 1996). In 1998 a further new course of study (Ministry of Education, Science, Sports, and Culture, 1998a) was issued in which not only was communicative competence looked upon as more important, but also, many parts of the course such as the content, or what to be taught, and school hours dramatically changed. At each school, various preparations and experimental attempts were made towards the implementation date in April 2002. Nevertheless, the innovation has not yet seemed successful, considering that the teachers' struggles with the same constraints have remained.

It can be said that these constraints are mostly derived from the typical Asian EFL teaching and learning context and can be broken down into at least the following seven:

1) the confusing new curriculum, course of study (Ministry of Education, Science, Sports, and Culture (Monkasho), 1998a),

2) a prescribed structure-based textbook or non-authentic teaching materials,

3) extremely limited time and few opportunities for students' exposure to English inside and outside classrooms,

4) communicatively deficient teachers,

5) large class sizes,

6) the learning and teaching culture, and

7) mainly grammar-oriented high school entrance examinations.

First of all, in some Asian cases, the curriculum itself is the constraint, as 
pointed out by Li (1998). Japan is not the exception. The most serious problem in the Japanese new curriculum is that, in spite of great emphasis on fostering students' communicative competence, there is no clear description about the methodology that teachers should use. Rather, there are numerous descriptions about the content, or what is to be taught, prescribed at the level of vocabulary and grammar. There are currently three main documents issued by Monkasho (formerly Monbusho) that are relevant to the curriculum and English education in Japan: 1) a course of study (Ministry of Education, Science, Sports, and Culture (Monkasho), 1998a); 2) a commentary on junior high school education: Foreign languages (Ministry of Education, Science, Sports, and Culture (Monkasho), 1999) which provides interpretations of the course of study from the government perspective; and 3) National Curriculum Standards Reform for Kindergarten, Elementary School, Lower and Upper Secondary School and Schools for the Visually Disabled, the Hearing Impaired and the Otherwise Disabled - Synopsis of the Report (Ministry of Education, Science, Sports, and Culture (Monkasho), 1998b, hereinafter referred to as National Curriculum Standards Reform). While all three documents place great emphasis on fostering students' communicative competence, none has any clear statement of what kind of methodology or approach should be used.

National Curriculum Standards Reform briefly mentions the approach to be used as a means of instruction:

At lower secondary school, daily situations where the target language is actually used will be introduced, and functions of such discourse as "greeting", "making requests" and the like will be demonstrated. Adopting this approach, lower secondary schools will provide various activities in order for students to use the target language in context (p.1).

This document seemingly encourages using a situational approach, but refers to a 'functional syllabus' as well. Because of no clear definition of what this approach refers to, there could be a number of interpretations of the curriculum, which could result in 
confusion for the implementers or teachers.

Furthermore, in sub-section 3, 'design of teaching syllabi and instruction of the teaching contents' (pp. 87-89) in the new course of study, the use of pair and group work is encouraged. It seems to suggest CLT with reference to Li's (1998) definition, but again what kind of instruction or approach is intended is not clear. As pointed out in Gorsuch's (2000) research about the former curriculum, the new course of study (1989) is also very ambiguous in terms of intended instruction. Breen and Candlin (1980) state that the communicative curriculum would place content within methodology and provide it with the role of servant to the learning-teaching process' (p. 102). In this sense, the course of study, which does not include a state of methodology but the content, can cause teachers to assume that the curriculum does not require them to adopt CLT.

In contrast, most parts of the course of study are still occupied by numerous detailed descriptions of grammatical features and sentence structures to be taught with examples. After all, the new curriculum still remains content-oriented. Hence, under the centrally controlled curriculum, teachers have had no choice but to systematically teach the grammar, rather than wait for students to naturally 'pick it up' (Krashen \& Terrell, 1983, p. 18).

Furthermore, some parts of the documents can be interpreted to refer to 'audio-lingual' method. The sub-section 'speaking' indicates that the objective is 'to get familiar with the characteristics of basic English sounds such as accents, intonations, and pauses and to pronounce properly' (p. 81, emphasis added). As the interpretative explanation of this section, the commentary adds that 'other than theoretical explanations, it is necessary to consider to repetitively practice [those sounds] by actually pronouncing and balancing pronunciation practices with communicative activities' (pp. 15-16, emphasis added). Its aim in proper pronunciation and repetitive practices is not of the CLT but likely of the 'audio-lingual' method. 
As discussed above, the course of study contains a long list of detailed content to be taught and includes exercises and repetitive practices aimed at students' accurate production. It does not suggest using task-based activities or procedural activities that Breen (1987) advocates. It may be the case that the curriculum makers intend to introduce a combination of the 'functional syllabus' and the 'audio-lingual' method. If this is not the case, the curriculum makers' understanding of CLT and communicative curriculum is in question.

The second constraint that teachers must struggle with is the structure-based and mostly non-authentic textbooks, which consist of the vocabulary and grammatical items prescribed in the curriculum. Even if teachers create their own teaching materials rather than rely on the textbooks, it is still difficult to find authentic materials in EFL countries, especially listening materials appropriate for the beginning level.

The third constraint is both the limited time and the few opportunities that learners are exposed to English, both inside and outside of classrooms. In the case of Japanese junior high school, there are only three 50-minute sessions per week. In fact, in such EFL contexts where there tends to be a "poverty of input," the effectiveness of a purely meaning-based CLT is doubted (Fotos, 1993; 1994; 2002).

The fourth constraint teachers must struggle with is often their own inability to communicate in English (Li, ibid.). Since they have never been taught nor have they had a chance to be retrained in a communicative way, most teachers simply are not confident enough to communicate using English in classrooms. With regard to pre-service training, in order to obtain an English teaching license, university students must earn two kinds of credits: 1) for courses related to knowledge about the language such as phonetics and general knowledge about education such as educational psychology, and 2) for a two-week practicum in a junior or senior high school. However, the courses do not provide concrete pedagogy or methodologies as applied linguistic or TEFL courses in 
ESL countries do. Consequently, the students' knowledge about the pedagogy appears to be greatly influenced by the pedagogy of their field supervisor in the practicum who may not have a working understanding of CLT.

With regard to in-service training, Monkasho has begun to change the system and offer teachers more opportunities to get retrained, but in many cases, it backfires; teachers have become increasingly busy and overwhelmed with additional work. On the one hand, Monkasho has required teachers to implement this completely new and unfamiliar teaching approach and regulated their participation in retraining workshop. On the other hand, teachers, with no reduction of their workload, must find the time to participate in the compulsory workshop. There is very little remaining time and energy to study the new approach and devise creative teaching materials after attending the workshop and commuting back and forth between there and the school. Moreover, these opportunities and the system regarding in-service training are different, depending on prefectural educational boards. In the case of Osaka prefecture, teachers can apply for a six-month to three-year sabbatical only for study purposes, but there is no financial support offered from the prefecture; that is, teachers receive no salary during the period. And, even worse, in many prefectures, as of yet there is no such sabbatical system. Teachers, who wish to upgrade their knowledge and skills for the profession, cannot help but give up the profession or take an evening course. In either case, the opportunities are available to only a handful of teachers who can find the time and for whom it is financially feasible. LoCastro (ibid.) argues that the change of the new curriculum has positively influenced teacher training, but at the individual teacher's level, in fact, nothing has changed. The great majority of the teachers have groped their way without any helpful guidance or support.

The fifth constraint, the large class size, makes it even more difficult to conduct the class in a communicative effective way. Usually, there are approximately $\mathbf{4 0}$ 
students in a Japanese junior high school class. It is already difficult to pay attention to 40 students at once, but controlling them in a language that the teachers do not feel confident with is even more overwhelming.

The fourth and fifth constraints are also intertwined with the sixth: the sociocultural issues of learning and teaching. LoCastro (ibid.) regards Japanese teachers as 'the commentator, as the knower of all information, imparting that knowledge to learners, enlightening them, out of the belief that without that role being performed the learners would be unable to understand' (p. 53). That is, teachers should know everything, and thus should not show their deficiency in using the English language as it could cause them to lose their authority.

The last constraint on adopting CLT is what Gorsuch (2000) recognizes as the most influential: the grammar-oriented entrance examinations. Gorsuch reveals in her statistical research of teachers' perceptions of CLT that the main reason for the teachers' hesitation in adopting CLT is existence of grammar-based entrance examinations for university, which require students to be accurate in their performance. Her study dealt with senior high school contexts. However, even though the educational level is different, since high school entrance examinations are also mainly grammar-oriented, her conclusion can be applied to junior high school contexts as well. In order to prepare students for the examinations, teachers cannot ignore grammar, but must expose students to grammatical points by systematically teaching them.

These are all the practical reasons that Japanese teachers of English have adhered to the teaching of grammar. As discussed above, they have many constraints that may encourage them to shy away from adopting CLT in the EFL teaching context. Due to these constraints, it is practically impossible to simply adopt a purer form of CLT that has been used in ESL countries. Instead, it is necessary for the EFL countries like Japan 'to 
develop their own language teaching methods that take into account ... the EFL situations in their countries' ( $\mathrm{Li}, 1998$, p. 698), that would be Focus-on-Form (FonF) instruction. In the following section, I will briefly explain this new approach.

\subsection{Place for FonF}

As illustrated above, EFL teachers have been struggling with the constraints in adopting CLT, going back and forth between CLT and grammar teaching. Meanwhile, more recent theoretical discussions of CLT have emphasized the importance of some grammar focus integrated into the communicative framework. According to Schmidt (1990), consciousness-raising, or "noticing" is crucial in the process of language acquisition; therefore, it would be necessary for teachers to provide learners with chances to somehow "notice" incidental input, whether explicitly or implicitly (Hinkel \& Fotos, 2002a). As argued by many contributors to the volumes by Doughty and Williams (1998) and Hinkel and Fotos (2002b), it is only when teaching grammar is integrated within a CLT context that teachers can effectively allow learners to notice what is to be learnt from the input. Such teaching is called 'focus on form (FonF)' (Long, 1991) instruction. Originally, Long (1991) defines FonF as a focus on a facet of a target language, such as vocabulary or a grammatical feature, which incidentally occurs in a meaning-focused activity. Nevertheless, in this approach with incidental FonF, the problem of incidental versus planned learning items still exists.

However, many of the studies following Long (1991) introduce a different kind of FonF, one which is no longer incidental but pre-selected and proactive. This type of FonF requires two elements: One is providing formal features to be taught as input so that students can repeatedly be exposed to the features until they naturally "pick them up." In other words, this FonF allows teachers to make, in advance, a plan of classroom activities designed around formal features that teachers want students to "notice" and "pick up". In 
this sense, FonF could work within a centrally controlled curriculum. The other requirement for Fon $F$ is providing a large quantity of communicative input, which has been one of the essentials for the traditional CLT as well. However, input with FonF does not necessarily have to be outside of the classroom; rather, teachers can prepare an "acquisition-rich" (VanPatten, 1993) environment by providing an enormous amount of input in the classroom. This may still be difficult for communicatively deficient teachers of EFL to deal with, but using FonF, that is, controlling input by planning a class with a focus on a few main grammatical features, will help EFL teachers in overcoming this difficulty (Lightbown, 1992). Perhaps this newly evolving version of CLT will have more of a place in the EFL situation.

Contrary to the fact that most research on FonF concerns acquisition by adults and argues that children cannot be subject to the metalinguistically oriented focus-on-form, a number of researchers (e.g. Harley, 1998; Herman \& Flanigan, 1995; Spada \& Lightbown, 1993; White, 1998) have found some benefit when FonF was applied to children. These researchers take into account the students' interest and input salience, and adapt task-based activities which require students' attention to the relevant language features (e.g. Loschky \& Bley-Vroman, 1993).

However, all of these studies concern an ESL or French-immersion context. Considering that there are a number of critical differences between ESL and EFL contexts as indicated in the previous section, one cannot expect to reach the same conclusion for an EFL context. Moreover, junior high school students are no longer children but young adolescents who may bring different results or effects than those in the studies of children or adults. Based on these points, in the following section, I will address research questions. 


\subsection{Research Questions}

Unfortunately, there has been little empirical research with regard to 1) FonF in EFL situation, and 2) FonF with young adolescents or junior high school students, especially regarding their perceptions of communicative FonF instruction. Firstly, there are numerous issues that must be taken into account since all aspects of teaching, such as teachers, students, classroom situations, teaching and learning culture and so forth, are different in the EFL context than in the ESL context. FonF, which works in ESL classrooms or French-immersion classrooms as mentioned above, might not work in an EFL setting. What would happen to such a classroom where FonF was implemented? What would be the problems for its implementation in an EFL setting?

Secondly, unlike children in the research above, adolescents are generally considered to be at an awkward age and more difficult to deal with. They may react to a new style of language teaching differently than children or adults. They may not participate in activities, they may not use all information available to them in order to make sense of what the teacher is saying in English, or they may simply not accept the approach of a teacher who attempts to implement such teaching. It seems that the way in which a new approach is initiated can make a big difference in the responses of the students, and in the ultimate success of the approach. As a junior high school teacher, I am particularly interested in the initial stages of implementing this new approach. How would young adolescent students react to this new approach of teaching grammar communicatively? Would they be able to make sense of the class taught in this manner? Would they try to? If so, what strategies would they use? What would actually happen in the classroom at the initial stage of its implementation? Therefore, the research questions of this study are: 
1) What are the students' initial perceptions of classroom communicative language activities with a grammatical focus (FonF activities) conducted in only English at public junior high school in Japan?

2) Do the students understand the English-only communicative FonF activities? If so, how do they come to understand and respond to the activities?

3) What issues arise in attempting to implement such teaching?

In order to explore the research questions, a two-week project teaching with the communicative FonF activities took place in five classes of first-year (grade 7) public junior high school students (approximately 170) in an urban city in Japan. The data was collected from observations of regular classes and project classes, questionnaires and interviews administered to students and teachers in Japanese, and researcher's reflective diary and field notes.

Before dealing with the project and the data analysis, Chapter Two will discuss some theoretical issues that need to be taken into account, that is, age factors, implicit-explicit learning and teaching, noticing and attention, focus on form, and teaching in the target language. These elements are the foundation for designing communicative focus-on-form activities involved in the research project.

After the theoretical discussion, Chapter Three will illustrate the design and method of the project, including descriptions of the participants, the procedure, and the teaching materials, or the communicative focus-on-form activities used.

Chapters Four to Six will describe and discuss the findings. Chapter Four will examine the students' current situation by describing their previous English experiences and their perceptions of these experiences. This will be based on the information from the observation of the regular English class and their responses in the first student questionnaire, as well as some of the student interviews. This chapter confims that the students are total beginners with almost no knowledge of English nor any previous 
exposure to live English.

Chapter Five will present an analysis of the outcomes from implementing the communicative FonF activities in the total beginner class. The focus of the analysis will be especially on students' perspectives, that is, 1) students' perceptions of the activities, 2) students' ability to understand the activities, and 3) students' responses to the activities.

Finally, Chapter Six will explore the negative outcomes of the implementation of the communicative FonF activities, and the classroom issues that arise in implementing the activities. Also, some possible classroom implications will be discussed from the teacher's perspective. The focus of this chapter will be on the following four elements: 1) students' relationships with teachers and peers, 2) disciplinary interventions and encouragement, 3) teacher deficiencies, and 4) pressure for time. 


\title{
CHAPTER
}

2

\section{Issues Related to Communicative FonF for}

\author{
Japanese Young Adolescents
}

\section{Introduction}

The research of French immersion programs for Canadian children in the last two decades or so has found that the productive skills of immersion students remains below the level of native-speakers whereas their receptive skills can reach an equal level (Kowal \& Swain, 1998). After observational studies of immersion students' strengths and weaknesses, the researchers started suggesting 'a need for balancing experiential and analytical approaches to L2 learning' (Kowal \& Swain, ibid, p. 285), approving of FonF. However, this does not mean that we are heading back to the traditional grammar-translation teaching. Rather, what many researchers have emphasized is that FonF should be integrated into natural, meaning-centered communication (e.g., Ellis, Basturkmen, \& Loewen, 2001; Harley, 1998; Kowal \& Swain, 1998; Spada \& Lightbown, 1993; White, 1998).

However, English is taught all over the world, and in most cases the teaching or learning classroom situation is not one in which it be expected that students will have a rich English environment outside the classroom. In such a situation, the suitable approach must be different from the original one developed in the ESL situation; yet, attempts to simply adopt the original communicative language teaching have resulted in failure.

In this respect, Thompson's (1996) misconception about CLT can cast a new 
light on the teachers' concerns. He claims that 'the exclusion of explicit attention to grammar [is] never a necessary part of CLT' (p. 10). The teachers do not have to give up teaching grammar; rather they can combine it with communicative teaching, that is, communicative FonF, but Thompson does not include how it would be done, especially in teaching adolescents. There are a number of factors that should be taken into consideration with regard to teaching grammar to adolescents in an EFL classroom setting. Clarifying these factors will help the EFL teachers understand what communicative FonF is, and consequently dare to implement this new evolving type of CLT in teaching practice.

In this chapter, in order to figure out what would be a beneficial way of using communicative FonF for Japanese young adolescents, I will consider some theoretical issues that need to be taken into account, exploring the age of adolescence, explicit-implicit teaching and knowledge, noticing, motivational factors, types of FonF activities, and teaching in the target language.

\subsection{The Age of Adolescence}

In Japan, language learning starts at the age of 12 or 13 , which is universally categorized as the period of early adolescence or puberty. In the research field of second language acquisition, it is considered that this particular period in a child's life might be an important turning point for the acquisition of a new language. Some researchers such as Fathman (1975), Scovel (1981, 1988, 2000), Seliger (1981), Singleton(1995), and Tovell and Hawkins (1994) call the span of time from birth until about this age 'critical period'; others such as Bialystok (1994), Patkowski (1980) and Oyama (1976) prefer the term 'sensitive period.' Considering differences among individuals as Scovel points out as 'plus or minus two years, depending on individual and environmental factors' ( $p$. 184), the period of Japanese junior high school education which is from the age of 12 to 
15 would have both two types of leamers who are psychologically and cognitively characterized as almost children and almost adults.

According to Scovel, 'the critical period hypothesis is the notion that language is best learnt during the early years of childhood, and that after about the first dozen years of life, everyone faces certain constraints in the ability to pick up a new language' (p. 2). He claims that 'a great deal of exposure to consistent and accurate models' of a target language during the period enables one 'to acquire all the phonetic, phonological, and paralinguistic features necessary to sound exactly like a native speaker' (p. 184) of the language, although there is no evidence to support the existence of a critical period for syntax or vocabulary. Scovel claims that the critical period ends at around the age of 12 , by citing Tahta, Wood, and Loewenthal's (1981) research regarding ages of acquisition and emergence of accents of 109 immigrants of Great Britain. The result indicates that after the age of 11 , the rate of accent-free students dramatically decreases from $50 \%$ until almost $0 \%$ (Scovel, 1988, pp. 119-120).

Similarly, Fathman (1975) reveals in oral productive tests that 'there may actually be different critical periods which are optimal times for learning different aspects of a second language' (p. 251), that is, the 6-10 years for phonology and the 11-15 years for morphology and syntax. She also assumes that after puberty learners may more fully develop the ability of system-learning such as learning rules, making generalizations, or memorizing patterns. What she refers to as system-learning is "explicit learning", which will be discussed in the following sections.

With regard to the relationship between age and acquisition of grammaticality, Tovell and Hawkins (1994) cite an interesting study of 46 Chinese and Korean speakers of English administered by Johnson and Newport (1989). The researchers interpret the results as "beyond the age of around seven years learners are not going to be as successful as pre-seven-year-olds at acquiring all its grammatical properties' (p.15). 
However, it is possible to put another interpretation on Figure 1.1 about Mean percentage of errors on 12 types of English rules (Tovell \& Hawkins, ibid, p.14). There seems to be an significant distinction of the results between groups aged native, 3-7, and 8-10 and ones aged 17-24 and 25-39; the three younger groups make very few errors while the two older groups make many errors. In the mean time, it is difficult to categorize a group between the ages of 11-15, the same age as Japanese junior high school students, as either a younger or an older group; on some grammatical properties, the group of these adolescents performed similarly to the younger groups, and on others they performed similarly to the older groups. In brief, the acquisition of native-like grammatical knowledge gradually declines during early adolescence.

From an educational perspective, the declining rate of language acquisition during adolescence refers to the fact that there is a broad range in the students' ability to pick up a language; some can still acquire it just like preteens do whereas others are already close to the level of adults'. Considering this point, it would be crucial to provide both "explicit rules," which it is believed that is probably necessary for adults, and a natural communicative setting, which is essential for children to pick up a language.

\subsection{Explicit and Implicit Teaching in Japan}

Nick Ellis (1994), in the introduction of Implicit and explicit learning of languages, defines implicit and explicit learning as follows:

Implicit learning is acquisition of knowledge about the underlying structure of a complex stimulus environment by a process which takes place naturally, simply and without conscious operations. Explicit learning is a more conscious operation where the individual makes and tests hypotheses in a search for structures (p. 1).

In this sense, it can be said that Japanese people have learnt language explicitly rather 
than implicitly. They have learnt English through the grammar-translation method as Europeans learnt Latin in the past. The teachers explicitly provide students with detailed information about new language features that they translate into Japanese. This method is sometimes called 'yakudoku' in Japan (Hino, 1988), which means 'reading by translation.' In this 'yakudoku' method, students simply need to analyze the reading text, word by word, and understand what it is saying through translated Japanese, rather than use English per se. It has nothing to do with listening and speaking skills.

In most English classes at junior and senior high school level, the 'yakudoku' method has been used even after the government issued the new curriculum that required teachers to enhance students' communicative competence. In a typical class, a teacher first presents new vocabulary with Japanese meanings and explains new grammar points or sentence structures. Second, the teacher lets students listen to a tape on which a short text from a textbook containing the vocabulary and the grammatical features has been recorded by native English speakers, then practice reading it aloud a few times. Third, the teacher analyzes and translates the text into Japanese for students, word by word, or asks them to do so. In addition, these 'yakudoku' activities are followed by written grammar exercises such as fill-in-the-blanks, multiple-choice, inflection, translation, backward-translation (from Japanese into English), and so on. The worse thing is that all these activities are generally conducted in Japanese. It is very rare that teachers conduct classes in English.

Thus it is obvious that language input the students can obtain in this kind of explicit teaching is extremely limited. In the case of junior high school, all that students are exposed to is the short text they read and analyze with their teacher, which usually consists of only about 10 to 15 sentences for one lesson, the same audiotaped sample text they listen to once or twice, and several sample sentences preceding each grammar exercise. This amount of input is a long way from what is needed in such a 
communicative class as Krashen and Terrell (1983) refer to.

They advocate The Natural Approach in which 'learning' a language with explicit rules in a conscious way differs from 'acquiring' it, that is, genuinely learning or getting familiar with using it in a subconscious way. In this way, language is not to be consciously 'learnt' by means of rule learning and application of grammatical forms, but rather subconsciously 'acquired' in meaningful contexts. They emphasize that providing students with enough input in natural, communicative contexts, or teaching implicitly, is of primary importance in language classrooms. The acquisition then gradually emerges when acquirers are ready:

Spoken fluency in second language is not taught directly. Rather, the ability to speak fluently and easily in a second language emerges by itself, after a sufficient amount of competence has been acquired through input. It may take some time before any real spoken fluency develops (p. 20).

Besides, the Input Hypothesis (Krashen, 1982, 1985, 1994; Krashen \& Terrell, 1983) claims that it is essential that listening comprehension and reading should be 'comprehensible $\mathbf{i}+1$.' Students need to understand messages, which is a little beyond the students' 'interlanguage,' or current level of competence, from the context.

If there was plenty of time to wait for students to understand input containing $(i+1)$ vocabulary and structures that are part of the next stage, purely implicit teaching like The Natural Approach would be an ideal way of teaching language. In the Japanese EFL context as discussed in Chapter 1, however, using only implicit teaching is not efficient mainly because of the lack of time for exposure to English and grammar-oriented entrance examination on which students need explicit linguistic knowledge to 'monitor' (Krashen, 1982; Krashen \& Terrell, 1983) their written answers, or detect and correct errors in their output. Even Krashen and Terrell (ibid), who clearly state that explicit grammar learning is not helpful for acquisition, admit the benefit of 
grammar teaching for monitoring:

Knowledge of conscious rules can be helpful in situations other than formal grammar exams. In writing and in prepared speech, performers do have time to apply conscious knowledge of the second language and can use this knowledge to improve the form of their output by Monioring (p.19).

On the other hand, it is also true that the explicit teaching classroom in Japan is an extremely impoverished acquisition environment due to the lack of input. The most suitable way of teaching language would therefore be a combination both explicit and implicit teaching. In order to consider a beneficial compound way of teaching, in the next section, I will consider distinction of explicit and implicit knowledge which students obtain by the two types of language teaching.

\subsection{Explicit and Implicit Knowledge}

Whenever the topic of grammar teaching arises, researchers discuss whether language should be taught explicitly or implicitly (Krashen, 1999, for review). However, there is 'no consensus on where the line is to be drawn' (Schmidt, 1990, p. 134) between explicit knowledge obtained by learning about language and implicit knowledge obtained by acquiring language.

According to R. Ellis (1994), the key to distinction between the explicit and the implicit is an awareness of the rules:

[E]xplicit knowledge involves awareness, whereas implicit knowledge does not (p. 86).

In other words, one who possesses explicit knowledge knows not only a certain rule or vocabulary, but she also knows that she possesses this knowledge and consciously uses it; the other, who possesses implicit knowledge, may know a rule or vocabulary because 
she uses it to speak fluently but probably does not know she knows it, and thus uses it subconsciously.

Moreover, Ellis considers explicit knowledge as 'analyzed, abstract and explanatory language features' (p. 84), which is developed by memorizing or problem solving. Thus, Ellis refers to articulated metalinguistic knowledge, that is, if called upon, the learner will be able to say what it is that he or she knows' (p. 84). In this sense, the learner must have understood the language features deeply enough in order to explain them. However, explicit knowledge could also be unarticulated linguistic knowledge because it exists in the language representation of learners' mind separately from its articulation, as Ellis cites Bialystok (1981). The learner may have perfectly understood the language features, but simply cannot explain them.

Meanwhile, it is assumed by Ellis that implicit knowledge consists of unanalyzed chunks of actual instances, which are developed by internalizing linguistic features as part of interlanguage. In the process of internalizing (see Figure 2.1.), first the acquirer's brain notices a new feature by comprehending input, then compares a gap between the feature and her interlanguage which is old knowledge she has already possessed, and finally integrates the feature into the interlanguage system. At the stage of noticing and comparing, input becomes 'intake' (p. 93) which is placed in short-term memory storage. When integrated, this intake becomes implicit knowledge and is placed in long-term memory storage. According to Schmidt (1990), this process may take place subconsciously. Although the language feature may 'register' the learner may be unaware that she has 'noticed' it and may be even unaware of the existence of this feature. For example, in acquiring a new word 'dog,' an infant, or part of her brain should notice relationship between the word and the object, that is, a concept of the word, or the language feature itself. However, she must be unaware of the fact that she has noticed it and got the word in her brain. The word exists only in the subconscious 
part of her brain and becomes implicit knowledge.

Figure 2.1. The process of internalizing input (adapted from Ellis (1994, p. 93))

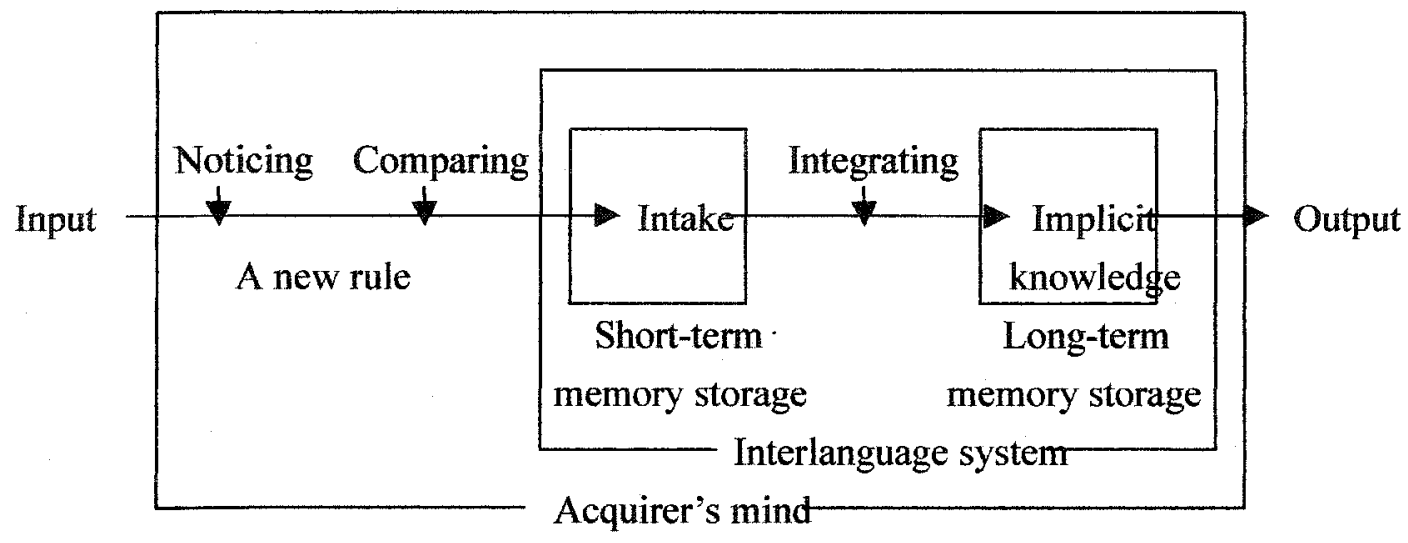

Ellis also approaches the distinction of knowledge from the procedural point of view - 'controlled and automatic processing'(p. 85). He argues that in a controlled manner of processing, the learner needs a sufficient amount of time and effort in order to access a language feature, whereas in the automatic processing the learner is unlikely to need as much time and effort. It is also assumed that the automatic processing is developed through many trials of making sense of the same input.

These two types of processing can occur as both explicit and implicit knowledge (See Figure 2.2.). The Type A of knowledge occurs when one has noticed a new rule in the input and used it in the output in a subconscious way, that is, the input is internalized as discussed above. However, accessing the knowledge is not done quickly at this point.

This is exemplified by the cases of children learning a second language and infants learning their mother tongue. They first acquire this type of knowledge and gradually automatize it into type B of knowledge over many trials. Type B occurs when one has acquired a rule or vocabulary naturally. The acquirer uses the knowledge in a subconscious and natural way without any effort or attention; the knowledge flows out fluently and smoothly. Type $\mathrm{C}$ is found when one consciously learns a rule in a grammar 
class. The learner needs enough time to access the knowledge. After practicing accessing over times, it can become type $D$ of knowledge, which the learner can access relatively easily and smoothly. However, since explicit knowledge, even automatized, operates in a conscious way, there seems to be a limitation on learner's capacity to process and access knowledge. On the other hand, for implicit knowledge the operations can be much faster than for explicit knowledge.

Figure 2.2. Types of knowledge and processing (adapted from Ellis (1994, p. 86))

\begin{tabular}{|c|c|c|c|}
\hline \multirow{2}{*}{$\begin{array}{l}\text { Type of } \\
\text { knowledge } \\
\text { Type of } \\
\text { Processing }\end{array}$} & \multirow[t]{2}{*}{$\begin{array}{l}\text { Implicit } \\
\text { An unanalyzed chunk } \\
\text { of linguistic features } \\
\text { is used subconsciously }\end{array}$} & \multicolumn{2}{|c|}{$\begin{array}{l}\rightarrow \text { Explicit } \\
\text { An analyzed abstract } \\
\text { of linguistic features } \\
\text { is used consciously }\end{array}$} \\
\hline & & unarticulated & articulated \\
\hline Controlled & $\begin{array}{l}\text { A : A new implicit rule } \\
\text { is used subconsciously } \\
\text { but accessed slowly }\end{array}$ & \multicolumn{2}{|c|}{$\begin{array}{l}\text { C: A new explicit rule is used consciously } \\
\text { and with deliberate effort }\end{array}$} \\
\hline $\begin{array}{l}1 \\
\text { Automatic }\end{array}$ & $\begin{array}{l}\text { B: A thoroughly learnt } \\
\text { implicit rule is used } \\
\text { subconsciously and } \\
\text { without effort }\end{array}$ & \multicolumn{2}{|c|}{$\begin{array}{l}\text { D: An old explicit rule is used consciously } \\
\text { but with relative speed }\end{array}$} \\
\hline
\end{tabular}

Due to the nature of type B knowledge, in terms of accessibility and capacity, it can be said that implicit automatic knowledge is what all language learners are attempting to obtain. However, because implicit knowledge is assumed to naturally emerge by itself when the learner is ready as discussed above, it cannot be intentionally learnt or taught. The controversy in this matter is whether or not explicit knowledge learnt or taught intentionally in language classroom situations can be converted into implicit knowledge. Taking a non-interface position of converting knowledge, for example, Krashen strongly claims that explicit learning differs from implicit acquisition, 
and that explicit knowledge can never turn into implicit knowledge. Similarly, Bialystok (1994) claims that 'language that is explicit does not become implicit' (p. 567). She explains that the change that occurs is in the type of procedure, or the access speed to the knowledge. She emphasizes that the nature of representation of knowledge must not be confused with access to the representation.

In contrast, R. Ellis (1994), taking a weak interface position, claims that 'explicit knowledge can be converted into implicit knowledge in the case of non-developmental grammatical rules...[and] in the case of developmental rules' (p. 89) for which the learner has psycholinguistically reached the stage of acquisition. Moreover, he believes that 'explicit knowledge may facilitate the process of noticing-the-gap' (p. 98) of implicit knowledge in Figure 2.1, and also points out the necessity of opportunities for using implicit knowledge in natural communication in order to automatize it. Therefore, in classroom situations where even intentional learning takes place (by providing analyzed explicit knowledge), learners may need to experience unanalyzed features and access the noticed gaps over times so that they can internalize the features.

Figure 2.3. Dichotomy of explicit and implicit knowledge and range of noticing

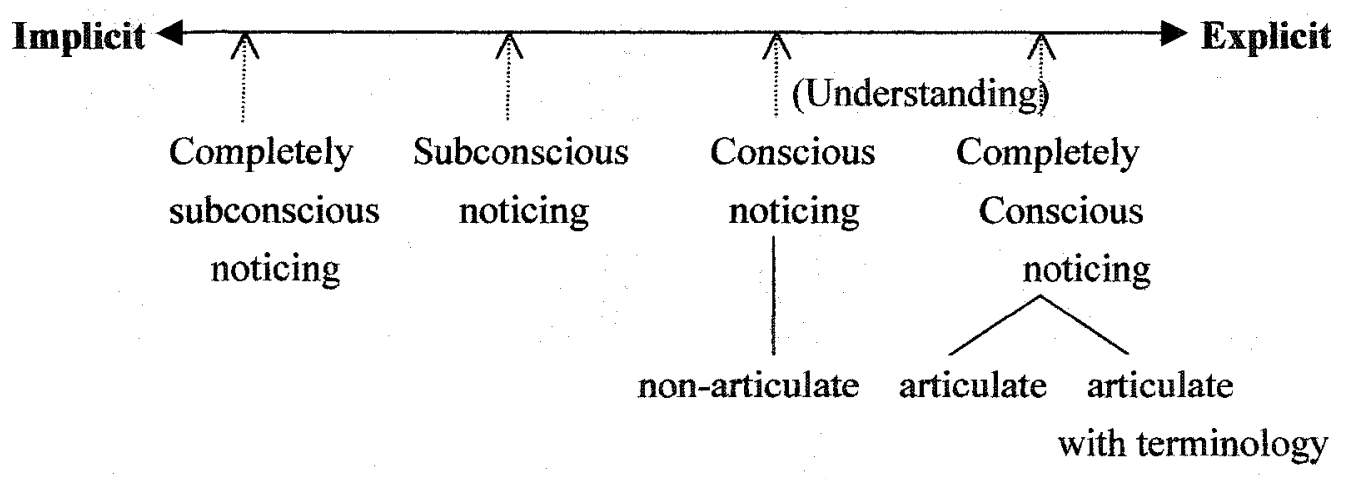

It seems that explicit and implicit knowledge form a dichotomy, and the distinction between them depends on the extent to which learners 'notice' a grammatical feature (see Figure 2.3.). Thus, there is, on the one hand, subconscious 'noticing' which 
is implicit knowledge, and on the other hand, there is conscious 'noticing,' or 'understanding,' which is explicit knowledge.

At the beginning of this section, there was a discussion of awareness being the key to the distinction of these two types of knowledge; however, 'noticing-the-gap' seems to be the precise point associated with the distinction. In the next section, the definition of 'noticing' and 'understanding' will be discussed.

\subsection{Attention and Noticing in Learning Language}

Schmidt (1995) identifies four types of learning associated with consciousness, that is, learning without 'intention;' 'attention;' 'noticing;' or 'understanding.' He defines the terms 'noticing' as a low level of awareness, or 'conscious registration of the occurrence of some event' and 'understanding' as a higher level of awareness, or 'implies recognition of a general principle, rule or pattern' (p. 29). According to Schmidt, while it is possible to learn without intention (for example, incidental acquisition), it is impossible to learn without attention and noticing. Conversely, one must first pay attention to and notice what is to be learnt in input so that the noticed item will be converted into intake.

Figure 2.4. Multistore model of memory (adapted from Schmidt, 1990, p. 135)

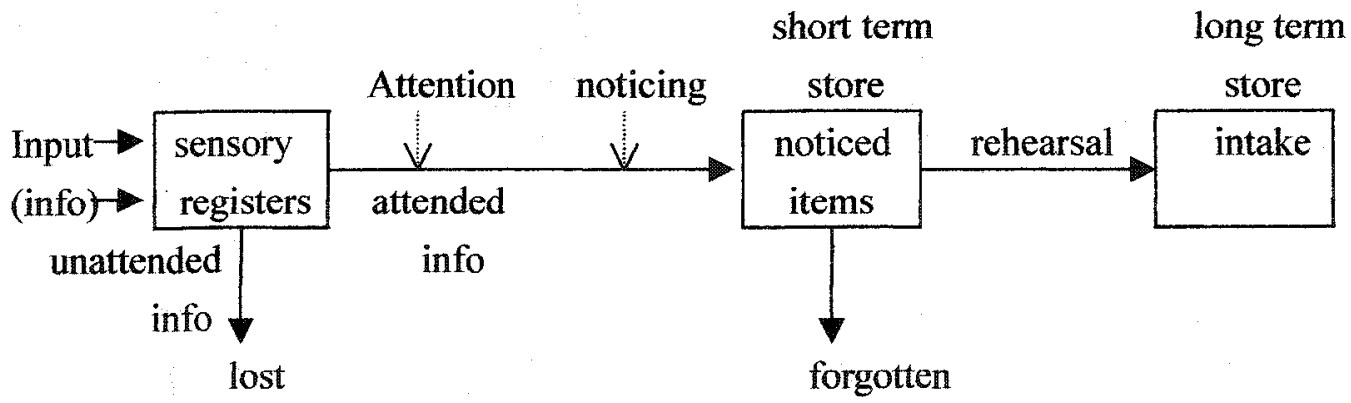

In order to explain the mental mechanism regarding attention, noticing and intake, Schmidt (1990) simplifies 'multistore model of memory' (p. 135) which has 
been proposed in several psychological studies. Schmidt's model is similar to Ellis's illustrated model in the previous section, but he focuses more on the process preceding 'noticing' (see Figure 2.4.). In the model, information, or input, goes through 'sensory registers' where the information is divided up between what is to be attended and what is to be unattended and lost. The attended information becomes a noticed item and is stored as a short term memory, and then finally turns into a long term memory, or intake, by being accessed several times, or through 'rehearsal.' Schmidt claims that 'processing in short term memory is necessary for permanent storage' (p. 136), that is to say, noticing through paying attention to what is to be learnt is critical for learning. From teachers' point of view, facilitating the students' 'noticing' of new items is an important part of their role as a teacher. Thus, how one can focus learners' attention on new items would be central to efficient language teaching.

While Schmidt's notion that noticing is an essential element for any kind of learning, including acquisition, attention is a critical tool for this noticing. Tomlin and Villa (1994) view attention as three separable functions: 'alertness,' 'orientation,' and 'detection.' In their view, alertness refers to 'an overall, general readiness to deal with incoming stimuli or data' (p. 190), and if increased, it may be better able to enhance noticing. They point out that although 'specific instructional activities such as a teacher's loudness and charisma may assist second language acquisition by heightening the alertness of the learner' (p. 197), other subjective factors such as motivation, language interest in L2 and classroom readiness to learn are more likely to be connected with alertness.

Tomlin and Villa refer to 'orientation' as 'the specific aligning of attention on a stimulus' (p. 191) and explain that orientation facilitates the third function 'detection' by orienting attention towards a stimulus. It might not be essential but could save much time and effort to detect information. 
Of great importance for learning is 'detection' which is 'the process that selects, or engages, a particular and specific bit of information' (p.192). The detecting process requires the most attention among the three functions, and without detection, any further processing could not take place. Therefore, it can be said that detection is crucial for learning.

Furthermore, Tomlin and Villa (ibid.) indicate that these three functions are interrelated to each other as follows:

[D]etection, which does not require awareness, is necessary for learning; detection can be enhanced when the learner is somehow more alert (e.g., motivated by a more provocative presentation) or when the learner is oriented to a particular kind of alternation (p. 197).

Thus, in order to promote detection, classroom teachers' role would be to help students to be more alert and oriented to the information at hand. In the next section, I will consider motivation, which Tomlin and Villa have suggested as an element that facilitates in the increase of alertness.

\subsection{Motivation in Learning Language}

Motivation, especially intrinsic motivation, is also considered one of the most important factors in focusing students' attention on what is to be learnt. Harley (1998) argues that '[n]oticing requires attention, and $\cdots$ it seems clear that attention is dependent on the intrinsic interest of the learning activities involved' (p. 170). That is to say, if learners are intrinsically motivated to learn, then they are more likely to pay attention to what is to be learnt, or the specific information in input.

According to Dörnyei (2001), there are two main types of motivation: intrinsic and extrinsic motivation. Intrinsic motivation involves three subtypes: to learn, to achieve a goal, and to experience stimulation. The first type of motivation is for 
"understanding something new, satisfying one's curiosity, and exploring the world." The second motivation is for achieving a personal goal, such as "surpassing oneself, coping with challenges, and accomplishing or creating something." The third motivation is for experiencing "pleasant sensations" (p. 28).

Moreover, Dörnyei explains that typically extrinsic motivation has often been considered to 'undermine intrinsic motivation' (p. 28). However, there is evidence to show that extrinsic motivation can be "internalised," and can turn into intrinsic motivation (Deci and Ryan, 1985, as cited in Dörnyei, 2001). Thus, it can be said that offering extrinsic rewards, which can be easily 'internalized', would be a teachers' role.

In a Japanese classroom setting, for the first type of motivation, it is possible that teachers provide students with activities that include new information and will stimulate their curiosity and interest. Teachers can also provide not only the information per se, but also opportunities for students to detect and explore the information through their learning process. Similarly, for the second type, it would be important for teachers to arrange opportunities for students to think about their own goals and ways in which they can achieve the goals. For the third type, teachers can not only make the class enjoyable but also encourage students and praise them for the effort they have made. In fact, generally teachers tend to give students negative feedback rather than positive encouragement as Dörnyei quotes Covington's (1992) claim:

For those students who are already insecure, tying a sense of worth to ability is a risky step because schools can threaten their belief in their ability. This is true because schools typically provide insufficient rewards for all students to strive for success. Instead, too many children must struggle to avoid failure (p. 74).

In this sense, it would be very important for teachers to remember the decisive role of rewards as a means to stimulate intrinsic motivation.

Although Harley (ibid.) posits the importance of intrinsic motivation to 
primary school children, all that has been discussed above should also hold true for adolescents. Sarantou (1998) reports the popularity of communicative activities based on games, which are thought to stimulate intrinsic motivation, among even senior high school students in Japan. Cheung (2001) argues that the use of popular culture such as television, pop songs and movies, comics, gossip magazines, fashion, and computer games is effective in motivating Hong Kong secondary students because not only is it enjoyable and interesting for them but also '[it] can often have a significant impact upon the lives and attitudes of young people around the world, partly by providing them with some form of meaning and insight in a relevant and concrete way' (P. 56). These studies confirm the evidence that junior high school students need something that stimulates their intrinsic motivation, which subsequently heightens their alertness as well.

\subsection{Focus on Form}

In the last decade or so, many studies have investigated the benefit of focus on form (FonF) instruction provided within a communicative language teaching context (for example, Fotos, 2002; Harley, 1998; Herman, 1995; Spada \& Lightbown, 1993; White, 1998). The discussion of FonF in this chapter is not part of an analysis of effectiveness of FonF teaching in a Japanese setting, but rather to give the rational and basis for the design of the communicative FonF materials used in the project.

Although the studies have shown some benefit, the term 'FonF' has a different meaning depending on the researcher. According to Ellis, Basturkmen, and Loewen (2001), for example, 'FonF' originally characterized by Long (1991) occurred incidentally in a meaning-focused activity. Many of the studies presented later, as seen in the volume by Doughty and Williams (1998), introduce a different kind of FonF that is no longer incidental but preselected and proactive. Such 'FonF instruction' can consist of the combination of four teaching activities: 
1) a main task-based activity;

2) an explicit explanation on a grammar feature;

3) corrective feedback; and

4) an extra follow-up activity.

Out of the four activities, while the first and fourth should be proactive activities, the second and third can be either incidental or proactive. In incidental cases, students may ask for an explicit explanation regarding vocabulary or a grammatical feature that is not relevant to intentioned items, or teachers may spontaneously correct students' errors. In proactive cases, all the activities and instructions provided by teachers are preselected, planned and intentioned to be taught.

In order to clarify the relationship between the type of instruction learners receive and its benefit, which is usually measured by their performance, that is, what type of instruction might be beneficial, I will first identify the meaning of the term 'FonF instruction.'

\subsection{1. 'Focus on Form' and 'Focus on FormS'}

Sheen (2002) points out that there is a terminological confusion between 'focus on form (FonF)' and 'focus on forms (FonFS) and reveals, considering its components, that many of the cases are FonFS although the term 'FonF' is widely used by many researchers. According to Sheen's (ibid.) definition of the terms, 'FonF' should be 'based on an exposure to comprehensible input in natural interaction' (p. 303) which is just like the process of the first language acquisition, and a supplement for insufficient exposure to acquire the second language grammar. 'FonFS', in contrast, refers to separate grammatical features in separate lessons, which could be followed by a communicative activity aimed to integrate the learnt knowledge. He lists three stages 'FonFS' comprises: 
1. providing understanding of the grammar by a variety of means (including explanation in the $\mathrm{L} 1$, pointing out differences between the $\mathrm{L} 1$ and the $\mathrm{L} 2$ );

2. exercises entailing using the grammar in both non-communicative and communicative activities for both comprehension and production; and

3. providing frequent opportunities for communicative use of the grammar to promote automatic, accurate, use (p. 304).

On this view, only incidental attention to form within a communicative context would be considered as 'FonF', such as Long's (1991) original criteria, 'students' attention to linguistic elements as they arise incidentally in lessons whose overriding focus is on meaning or communication' (pp. 45-46).

However, if FonF is limited to incidental focus, there seems to be at least three fundamental difficulties in practice. First, it would be very difficult to address communicative classes with FonF instruction along with a curriculum that indicates what to be taught. This is seen in Long and Robinson's (1998) categorization of syllabi and form-, forms-, or meaning-focused methodologies, in which FonF is involved in Process Syllabus whereas FonFS in Structural/Notional-Functional Syllabuses.

Second, it would also be difficult to draw students' attention to such grammatical features which otherwise students might not need to make sense of in communication and thus tend to ignore, for example, the third person singular $-\mathrm{s}$. Harley (1998) assumes in her research of child acquisition of French gender distinctions that 'there is little apparent motivation to pay attention to distinctions that are of minimal import for the expression of meaning' (p. 159).

The third difficulty of incidental FonF in practice would be in terms of learners', especially beginners', processing capacity. If learners have to incidentally pay attention to and notice form, then they need to both think about form and comprehend meaning or communication at the same time; that is, they must pay to two different aspects simultaneously. VanPatten (1990) suggests that specific activities that draw 
attention to form are necessary for low-proficiency learners because 'attention to form in the input competes with attention to meaning' (p. 296). Williams (1999) found that the more proficient learners initiated attention to form more frequently than the less proficient; to beginning learners in particular, learner-generated attention to form is less likely to occur. She contends that teachers should structure activities to 'draw or attract attention to form-meaning connections' (p. 619).

Due to these possible difficulties, it might be reasonable to adopt FonFS defined by Long (ibid.), that is, FonF proposed by other researchers following him, although "a focus on form and focus on forms are equally effective" should be treated with some caution' (Sheen, 2002, p. 304, cited from Norris and Ortega (2000)). In the following section, I will examine some of the experimental studies dealing with this type of FonF.

\subsubsection{Communicative Focus on Form}

Although intentional and preplanned FonF should be considered as FonFS according to Long (1991), many studies have found its effect on second language acquisition. Those studies also show that there could be a variety of different components of FonF activities. I will examine several of the studies, as well as their effect, in terms of the four teaching activities mentioned in the introductory part of this section.

White (1998) examined the effect of minimized proactive FonF in her quasi-experimental study of francophone intensive ESL children. The children were provided with neither explicit explanation nor corrective feedback but a set of task-based reading activities. After reading stories in which target grammar features were typographically enhanced, that is, bold, italic, underlined, or enlarged, children were provided with questions requiring them to understand meaning of the stories and the target grammar. In addition, for the second experimental group in this study, White 
also provided extensive free reading and listening as extra follow-up activities in which children could be exposed to more meaningful (but not enhanced) usages of the grammar features. The children's progress was compared with that of a non-enhanced group provided with the same reading activities but with other grammar features typographically enhanced and as well as another non-enhanced, or non-instructed, group. The results showed that all three groups provided with the questions about the stories outperformed the non-instructed group regardless of the typographical enhancement. Moreover, the second enhanced group with extra reading and listening significantly outperformed other groups in both accuracy and frequency of the usages of the target features on the immediate posttest but not the five-week delayed posttest.

Similarly, Harley (1998) investigated the lasting effect of FonF instruction on early French immersion child acquisition, in which only task-based activities designed to draw children's attention to target grammar features (noun articles) were provided. She used terms such as 'an instructional focus on form' (p. 156) and 'the FonF instruction' (p. 162) for the input provided, but what she referred to was not the metalinguistic explanation. Rather, considering the nature of young children aged 7 or 8 , Harley emphasized the importance of naturally drawing children's attention to target grammar features without de-motivating them:

[I]nput salience, opportunities for focused output, and intrinsically interesting, age-appropriate tasks that cannot be performed without attention to the relevant forms are the principles underlying the instruction (p. 158).

The results of this experimental research reveal that the instructed children made significant, lasting improvement in choosing an appropriate article for familiar vocabulary but not in applying their learning to unfamiliar nouns. In other words, instructional activities can induce 'item learning' rather than 'system learning' of children. 
Meanwhile, Spada and Lightbown (1993) include corrective feedback as well as task-based activities as tools of 'FonF instruction.' The researchers focused on relationship between oral improvement of francophone ESL children and different types of corrective feedback provided by teachers within a meaningful interaction between the teachers and the students, both in and out of the activities. The researchers assumed from the results that sustained FonF instruction and corrective feedback, including implicit corrections in order to offer a considerable amount of exposure to target forms, would contribute positively to the child's second language acquisition. However, it is not easy to identify what kind of explicit instruction was given in the activities of this study. For instance, how and when was it given? Although Spada and Lightbown mention 'exercises' (p. 209) and 'approximately $5 \mathrm{hr}$ of explicit instruction $\ldots$ in the first week' (p. 210), there is no clear detailed description such as a formal presentation on target forms supplemented by written examples.

Unlike the three classroom researches above, Herman \& Flanigan's (1995) study examined the effect of FonF instruction including negative input on ESL literacy of children. Their 'explicit formal grammar instruction' (p. 2) refers to formal presentations on forms with written samples, text-based reading activities requiring learners to detect and correct errors, slot-filling exercises, and corrective feedback to assigned written work. None is actually integrated with a communicative activity though the instruction takes place within the communicative ESL tutorial; the instruction is isolated from the theme. The results on written tests show significant improvement on a relatively easy rule, but not the other complex one.

Finally, Fotos (2002), from an EFL perspective, suggested using a structure-based activity combined with an explicit teacher-centered explanation in her research about first-year university students. Besides explaining several constraints on communicative teaching in an EFL context like Japan, she pointed out two main 
characteristics of the context: extremely limited access to English, both inside and outside the classrooms, and the necessity of attaining accurate use for mainly grammar-based examinations. Fotos clearly claimed that it is crucial to use explicit explanation in order to fulfill these two conditions. Although her FonF class consisted of all four components of the teaching activities mentioned above, she does not seem to give input from corrective feedback an important position, since the feedback refers to self-correction on only a few written incorrect sentences made by students.

To greater or lesser degrees, all these research projects result in finding some effect of FonF instruction. In terms of the four types of the instruction, the researchers make various suggestions as follows:

First, to design appropriate task-based activities, which are supposed to be a main part of the communicative class, Harley's suggestion mentioned above would be crucial. Spada and Lightbown's activities seem more likely to be grammatical exercise activities rather than games that can attract young learners. It would be possible that the activities have not fulfilled such conditions as Harley suggests. Consequently, the focus of the research turned out to be on the effect of corrections rather than the activities per se; the activities might not have played an important role as the instruction. Harley suggests that FonF activities for young children should be not only interesting, visually attractive and with familiar materials, but also integrated with curriculum communicative themes. This would probably be applied to young adolescent learners as well. Furthermore, White points out the necessity to explain the purpose of visual salience in activities.

Second, for explicit explanations of grammar features, Harley claims that '[y]oung children of 7 or 8 years of age cannot be subjected to the kind of metalinguistically oriented focus on form that relies heavily on the transmission of abstract rules' (p. 158). Instead, her activities require children to label, categorize, 
highlight, and match genders of articles and nouns. In other words, the visual salience is not only provided by teachers, but also created by students themselves so that they likely notice the grammar features. On the other hand, White suggests that it would presumably need to offer explicit instruction such as a brief explanation of grammar features. Fotos also strongly recommends adding an explicit explanation especially in an EFL context. Moreover, she suggests placing an explicit explanation after a structure-based activity for relatively easy grammar features and prior to the activity for complex ones.

For corrective feedback and an extra follow-up activity that play a supplemental role in FonF instruction, suggestions are synthetic. Since students need enough 'input' for the language acquisition (Krashen \& Terrell, 1983), it is presumably true that the instruction should involve more sufficient positive input than negative input to facilitate the acquisition of grammar features. Herman and Flanigan, on the one hand, hypothesized that it would be necessary for teachers to add negative input in order to promote the literacy. However, the results showed that negative input did not help the participants to acquire the more complex grammar rule such as past tense. In this research, there might not have been enough positive input of the target feature which supports learners to access to 'noticing' until it is internalized (Schmidt, 1995). On the other hand, Harley's and White's activities provided students with only plenty of correct examples which was positive input. Implicit corrections suggested by Spada and Lightbown's can also be a good example for positive input. In addition, what Fotos suggests included in the EFL teaching is all positive input except for a few students' self-corrections.

In short, I have discussed the distinction between FonF and FonFS on the basis of Long's (1991) definition, and then, considering the three difficulties in adopting the concept of Long's incidental FonF in practice, examined the effectiveness of the 
communicative FonFS activities, which are regarded as FonF by the other researchers. Clearly, FonF is beneficial to children, and therefore beneficial to young adolescents as well; however, it requires several conditional elements. FonF instruction, especially for children, should be comprised of communicative, task-based activities that are interesting, well designed in order to repeatedly expose to target grammar features, and integrated with meaning-centred communicative themes. It can also include brief explicit explanation, feedback consisting mainly of implicit correction, or/and extra activities supplementing exposure to target features. However, teachers should always keep in mind that students should be provided with sufficient correct input. The following section will discuss teaching in the target language, which is related to the idea of providing sufficient input and integrating FonF within meaning-centred CLT.

\subsection{Teaching in the Target Language}

Turnbull and Arnett (2002) review a number of studies on the topic of teachers' uses of the target (TL) and first (L1) languages in SL and FL classrooms, and confirm that many researchers in the 60 's and 70 's found 'a direct correlation between FL achievement and teacher use of the TL' (P. 205). Regarding their finding as 'the most persuasive theoretical rationale' (P. 205), Turnbull and Arnett argue that teachers should use the TL in the classroom as much as possible. Many contributors to this topic (e.g.. Burden, 2000; Chambers, 1991; Cook, 2001; Duff \& Polio, 1990; Franklin, 1990; Macaro, 1997; Polio \& Duff, 1994; Rolin-Ianziti \& Brownlie, 2002; Turnbull, 2001) agree with this point that teachers should maximize the TL use in SL or FL classrooms. However, as pointed out by Turnbull and Arnett (ibid.), what one means by the term "maximize" may differ from what another means.

For instance, a maximal case of TL use is Rolin-Ianziti and Brownlie's (2002) study in Australia. They argue that French teachers' use of code switching with English 
words embedded in a French sentence may facilitate beginners' FL acquisition, but emphasize the point that it should be within the immersion approach, in which teachers basically use only TL. According to Chaudron (1988, cited in Macaro, 1997, p. 75), in Canadian classrooms, FL teachers use the TL about $90 \%$ in the French immersion and about $70 \%$ in the core French (standard FL classroom). The latter is described as quite a high level of TL use in a FL learning context.

On the other hand, Cook's (2001) argument supports a number of places for teachers' $\mathrm{L} 1$ use. He regards the $\mathrm{L} 1$ as a useful classroom resource for teachers to convey meaning of vocabulary and sentences, explain grammar, organize tasks, discipline students, and test, and for students to carry on the main learning activity in a collaborative way with peers. However, if a teacher uses the L1 for all of these classroom instructions suggested by Cook, what can be conducted in the TL? It is possible to imagine that using $\mathrm{L} 1$ for all these classroom functions can result in creating similar FL classroom situation as Japan has, that is, providing ' $100 \%$ comprehensible input in Japanese' (LoCastro, 1996) as quoted in the very beginning of this paper. Turnbull (2001) contends that in the case that teachers use SL or FL during only less than $25 \%$ of class time, they must be 'relying far too much on the L1' and cautions that it would be 'depriving students of valuable TL input' (p. 536).

For non-native teachers, however, there is no doubt that teaching in the TL is challenging (Franklin, 1990; Medgyes, 1994). Medgyes regards the "linguistic deficit" as the "dark side of being a non-native" (p. 33) whereas Franklin's study investigating Scottish secondary school teachers' TL use of French in the classroom reported that teachers' lack of "confidence in using TL" (p. 21) is one of the four categorized reasons for not using it. In fact, a national survey conducted in the U.S. in 1997 revealed that just over a fifth of secondary school teacher respondents used the TL most $75 \%$ to $100 \%$ ) of the time (cited in Turnbull \& Arnett, 2002, p. 210). The Japanese case is even 
worse; there are apparently very few secondary school teachers who use the TL extensively. According to my eight-year experience as a junior high school English teacher, most teachers' TL use is restricted to the greetings at the very beginning of class. Gorsuch (1993) illustrates what she had expected to see in a high school English class in Japan until she met a "brave" striking English teacher who used mostly English for the instruction as 'the long explanations from the teacher in Japanese about every conceivable linguistic point of the lesson - anything to delay having to actually use the language being studied' (p.9). This minuscule amount of TL use can be seen in LoCastro's (1996) illustration of classroom behaviour in Japan. He explains that '[i]n a great majority of cases (80-90\% according to some unpublished prefectural board of education surveys), Japanese is the language of instruction in the typically teacher-fronted, teacher-centred classes' (p. 49); therefore, TL is not the medium of teaching English in Japan.

Particularly in the FL context like Japan, considering that 'teachers are often the students' primary source of linguistic input in the TL' (Turnbull \& Arnett, 2002, p. 205), it must be true that teachers should use the TL as much as possible, especially at the beginner level. Macaro (1997) argues that even though the input classroom resource is a combination of the teacher, taped/written teaching materials, and peers, it is difficult to expect beginners to obtain sufficient amount of comprehensible input merely from the teaching materials given or from the peer interactions; beginners desperately need 'the constant stop/start, interweaving and overlaying of teacher's voice and materials' ( $p$. 61) and modified teacher input. In order to provide beginners with this type of input, there seems to be no other way but teachers' maximal TL use.

Students' perceptions, as well as teachers', of language teaching including teachers' language use must be important and taken into account since it is believed that their perceptions are greatly related to their language acquisition in terms of the 
motivational (Dörnyei, 2001) and affective (Krashen, 1982; 1985) factors. However, there is little empirical research with focus on students' perceptions about their teachers' TL use. Duff and Polio's (1990) research on university students from 13 classes in the U.S. found that most were satisfied with the amount of their teachers' TL use and mostly understood it regardless of the amount, which ranged from $10 \%$ to $100 \%$. As for Japanese university students, Burden (2000) found that they expected the teacher to use TL in communication but $\mathrm{L} 1$ in explanations of the TL usage whilst reserving the right to ask questions in the L1 as well. Macaro's (1997) study on 12- and 13-year-old children's perceptions about their teachers' TL use shows the similar findings; the students preferred their teachers to speak in the TL exclusively, but in the L1 when they did not understand their teachers.

Regarding Japanese junior high school students, there is a lack of research on their perceptions of both current English classes, in which mostly L1 is the medium of the instruction as mentioned above, and the ideal English class, in which TL use would be maximized. As reported in the Japanese context (Burden, 2000) and by the young adolescents (Macaro, 1997), if teachers mostly use the TL, then will Japanese young adolescents perceive their teachers' TL use as favourable? Can they understand the class with maximal TL use? The present study, in which the teacher cannot help but maximize the $\mathrm{TL}$ use in order to address the communicative FonF activities providing with acquisition-rich environment, as a consequence, will also deal with these questions.

\section{Conclusion}

In this chapter, I have discussed the crucial issues related to communicative FonF for young adolescents aged 12 to 15 , the distinction between explicit and implicit in terms of teaching in Japan and knowledge, the indispensability of attention and noticing in 
language acquisition, the motivational factor, and the teachers' important role as an input resource regarding their TL use. Considering these issues and the notion of the junior high school language classroom context in Japan discussed in the previous chapter, communicative activities need to be designed to focus students' attention on a particular feature and must be mainly conducted in the target language. The activities should also intrinsically motivate the students in order that they are more alert.

It is considered that the activities involved in Harley's (1998) quasi-experimental study fulfill these conditions although the subjects are grade 2 children. She makes several suggestions in terms of designing focus-on-form activities that might be applied to adolescents in the Japanese context as well. First, the activities used should be interesting and visually attractive to students so as to allow them to actively engage in the activities and to increase their alertness. Second, tasks required in the activities 'cannot be performed without attention to the relevant forms' (p. 158). Third, the same linguistic feature should be dealt with in several ways, or activities, as to provide students with a great number of chances to access 'noticed' features and integrate them into their interlanguage system. Fourth, the activities should be integrated with overall communicative themes. This last suggestion would be challenging in the Japanese school context where structure-based textbooks are used and thematic lessons have not yet been well introduced. Based on all these discussed issues and suggestions, in the next chapter, I will describe the research method including the design of the communicative FonF activities employed in the project. 


\section{CHAPTER}

3

\section{Research Methodology}

\subsection{Design of Project}

This research project was designed to answer the following research questions:

1) What are the students' initial perceptions of classroom communicative language activities with a grammatical focus (FonF activities) conducted in only English at public junior high school in Japan?

2) Do the students understand the English-only communicative FonF activities? If so, how do they come to understand and respond to the activities?

3) What issues arise in attempting to implement such teaching?

The research was carried out within five first-year (grade 7) classes $(n=170)$ in a middle-size (total students 524) public junior high school in an urban city in Japan. It took place over a period of four weeks from May through June 2003.

This project consists mainly of two types of teaching: teaching by a regular English teacher and teaching by the researcher. The former was observed and recorded as field notes by the researcher and the latter was videotaped and observed later, and both were analyzed and compared as the data from the observations. The research focus was on students' perceptions of and responses to communicative FonF activities; the data was also collected through questionnaires and group interviews with students. For the supportive purpose of enriching the researcher's analysis and adding different perspectives, questionnaire and interview were administered to teachers as well. 


\subsubsection{Project Class Location and Time}

The classes and the time of the project were selected on the basis of several criteria. First, this school was selected for the research site; it was expected that it would be relatively easy to get teachers' cooperation and understandings of the project since the researcher previously taught at the school and had known some of them as her colleagues. She also understood the school area and its situation or problems very well. In other words, the teachers would hopefully accept the researcher as a familiar colleague who was doing this research for the school in order to find out a way of helping them, rather than as a strange researcher who was visiting the school to do work for her own sake. Rounds (1996), admitting the fact that '[r]esearchers often describe the teachers they study as uncooperative, unhelpful, inflexible, untrusting, and even just plain obstructionist' (p. 45), suggests 'spend[ing] time getting to know the students, teachers, and issues of the research site well before implementing a research program involving the cooperation of school personnel' (pp. 57-58). In this sense, the researcher had already built up the fundamental part of the first step for the project to get started; the researcher had already had at least a basic knowledge of the research site and a good relationship with some of the teachers.

Second, the early part of the first year, which was about one month after a new school year started in April, was selected for three reasons. The first reason is that '[e]liminating [L1] use ... appears to be difficult once the students and teacher have become accustomed to it' (Duff and Polio,1990, p. 163). It was expected that the students participating had not yet established a firm routine of using L1. The second reason is to minimize possible negative influences of the project lessons on the mainly grammar-oriented entrance examinations that most students will take at the end of the third year. Usually, teachers prepare students for the entrance examinations by cramming the grammatical knowledge through repetitious grammar exercises. However, 
the project class did not include such exercises although the communicative activities used in the class were designed to teach certain grammar forms. The effectiveness of the activities on the examinations has not been tested; it has not been certain whether the kind of activities can help students learn the forms well enough to accurately perform in the examinations. For this reason, the researcher chose a period long enough to collect sufficient data but as early and short as possible. The third reason is that only the first-year students were continuously available throughout the period; that is, the other school-year students had a big school event going on then, for which classes would be suspended for a week.

The city educational board, the school principal, and the English teacher had approved the project and agreed to participate in advance. The ethics approval was obtained from the departmental ethics committee, and all the participants signed the informed consent form translated into Japanese.

\subsubsection{Participants}

All five classes of first-year (grade 7) students ( $n=170 ; 34$ in each class) and 6 teachers, including the regular English teacher of the classes, participated in the project.

\section{(1) Students}

Many of the students in this school are not in an easy situation in terms of their financial situation and/or family relationship. The school is located in a low-income residence area that is also comprised of a couple of factories, several small subcontract factories, markets, and many one-story houses in a row. Many who live in this area receive public assistance. Some have a single parent, while others have none and live with other relatives. One teacher reported that 15 students out of 34 have only a single parent in his 
class. (In Japan, a divorce rate is getting higher, but divorce and single mothers are not yet as common as in North America. Usually only a couple of cases are found in a class.) Many of the students do not have their own room or even enough space to study at home.

The school is also in an area that has been left behind in the city development project with many unpaved allays and no public library, whereas all other areas of the city have been quite well developed. This might influence the cultural life of the people living in this area, or the other way around; the people do not care about the cultural life and chose to live here. It is uncommon even to find a book or newspaper at the students' home; they have no way of having an access to written texts in a daily life. Thus, it is assumed that many of the students have not established the cultural standard that most other Japanese have. They do not have a habit of sitting still and reading. A few students are illiterate in the Japanese language, which is extremely rare in Japan where the literacy is as high as $100 \%$ in other parts. According to the researcher's 8-year experiences as a teacher in the city, many students in this school have a limited vocabulary compared to the average student in another school. In brief, many of the students have some sort of problem, be it financial, psychological, cultural-environmental, and/or literal, which affects their learning situation and/or attitude and aptitude.

\section{(2) Teachers}

The regular English teacher (referred to as Toyota ${ }^{1}$ hereafter), two other English teachers, and three teachers of other subjects (Japanese, science, and social studies) willingly participated in the research project. The English teachers are in their $20 \mathrm{~s}$ or

\footnotetext{
1 All names used in this paper are pseudonyms.
} 
30s with an English-relevant B.A. degree and a teacher's license and full-time "contract teachers ${ }^{92}$ whilst the others are in their late middle age and have more experiences as regular full-time public school teachers. All of the teachers are full of energy and progressive; for instance, they have been constantly trying to improve their teaching in one way or another, although the experienced teachers sometimes complain about the hardship of their job due to their age and some naughty students. That is why they willingly agreed to participate in the study, despite their busy daily workload. Therefore, it should be noted that the implementation of a new teaching methodology elicited a positive response from these teachers.

\subsubsection{Design and Characteristics of Communicative FonF Teaching Materials}

For this research project, communicative FonF activities were designed and employed as teaching materials. Aiming to create an "acquisition-rich" environment in the Japanese classroom context, the first fundamental theory for designing communicative FonF activities for the project is Krashen's (1982) Input Hypothesis. He claims that:

The effective language teacher is someone who can provide input and help make it comprehensible in a low anxiety situation (p. 32)

Ellis (1992) describes this naturalistic acquisition-rich environment with the following six features:

(1) Teacher talk is simplified to a level that makes it possible for the learners to process input for comprehension.

(2) Classroom interaction provides opportunities for learners to observe the way utterances are constructed in the process of building discourse and to manipulate chunks of language in the expression of meaning content.

2 A contract teacher refers to a public or private school teacher who has been qualified with a teacher's license but has not yet passed a prefectural examination to become a regular full-time public school teacher. 
(3) Referential questions which encourage learners to express their own content in their own way in extended responses are used.

(4) Learners have the opportunity to nominate their own topics and to control the development of theses topics.

(5) Learners are given the opportunity to participate actively in the classroom communication but are not required to produce until they are ready to do so.

(6) The use of the L2 is not restricted to pedagogic functions but is also used for organizational and social functions. (p. 48)

Furthermore, Ellis, recognizing the importance of some formal instruction, identifies an acquisition-rich classroom as 'one which provides both those experiences associated with communicating in natural discourse and those experiences derived from cognitive activities designed to raise the learner's consciousness about the formal properties of the L2 and their function in language use' (p. 49). That is to say, what Ellis suggests is to provide students with communicative FonF. Drawing on these points above, ${ }^{3}$ the definition of CLT (Li, 1998), and Harley's (1998) four suggestions discussed in Chapter 2, and considering the Japanese junior high school language classroom context, the researcher designed 14 communicative FonF activities for the communicative project class. The following are the activities:

1. Mapping Activity (preparation and listening)

2. Vocabulary Building Activity with real items or picture cards (PCs) (listening and speaking)

3. Vocabulary Building Activity with flash cards (FCs) (listening and reading)

4. Vocabulary Building Activity with handouts (listening and writing)

5. Chant (listening and speaking)

6. Matching Game (reading)

7. Blackboard Karuta (listening and speaking)

3 However, Ellis' fourth feature was excluded from the considerations for designing the communicative FonF activities due to the time limitation. Instead, a topic "school" was selected by the researcher, based on the students' necessity and familiarity. 
8. Skit Listening Activity (listening)

9. Skit Writing Activity (listening, reading and writing)

10. Question-Answer Activity (listening and speaking)

11. Karuta (listening and speaking)

12. Video Activity (listening)

13. Tape Dictation Activity (listening and writing)

14. Check-it-out Activity (listening, reading and writing)

The aim of the activities is threefold: i) to make the learners familiar with an English-only class through a variety of (mainly listening) activities, ii) to make the learners establish the concept or meaning of new vocabulary related mainly to "school" (Table 3.1.) and review learnt vocabulary through visual and aural simultaneous input, and iii) to make the learners aware of new grammatical features such as possessive first and second personal pronouns my, your, and our, and a sentence with demonstrative pronoun This is and That is.

Table 3.1. Vocabulary to be taught

\begin{tabular}{|lllc|}
\hline bag & blackboard/board & door & ruler \\
school & chair & friend & park \\
desk & classroom & teacher & hospital \\
eraser & window & pencil case & ticket \\
\hline
\end{tabular}

The following are nine characteristics of the project class with these activities:

\section{(1) Conducted Mainly in English to Maximize Input}

Many researchers, whether or not in favour of form-focused teaching, agree with the point that being exposed to sufficient input is crucial for language acquisition (e.g., Ellis, 
1998; Herman \& Flanigan, 1995; Krashen, 1982, 1985; Krashen \& Terrel1, 1983; Long, 1991; Loschky \& Bley-Vorman, 1993; Spada \& Lightbown, 1993; VanPatten, 1993; VanPatten \& Cadierno, 1993; VanPatten \& Sanz, 1995). In the meanwhile, it is hard to say that English classrooms at Japanese junior high schools are in the input rich environment; three 50-minute classes a week are not enough to get a sufficient quantity of exposure to input. Outside of the classrooms, it is a monolingual EFL setting where there is hardly a chance to make a trial use, both aurally and orally, of what students have learnt. In other words, students only the limited classroom time to obtain input. Thus, the researcher believes that language teachers should maximize students' opportunities to obtain input in the classrooms even if it may still not be enough time.

In order to do so, the researcher made three attempts. The first was to talk only in English so that students could receive a lot of listening input. The second was to use as much required vocabulary and as many required grammatical features as possible. The researcher used the same items repeatedly but in different activities in order to increase the opportunity for students to see and hear them in various situations. The third attempt was to introduce more new words associated with the theme than required, rather than forcing students to memorize the small vocabulary required in the national syllabus. The hope was that they would remember some of these words.

It was expected that the English-only class would be a little challenging to students who had learnt English only through Japanese for about one month prior to the project. The researcher conducted the class from the very beginning only in English, except for three handouts on which there were several Japanese words along with the English. One of the handouts (Appendix 1) was prepared for the initial brainstorming activity or Mapping Activity. Since students were not yet familiar with engaging in a 
brainstorming nor listening to an English-only class and understanding what they heard, it was expected that the handout written in Japanese would play a role in bridging their regular English class in Japanese towards the English-only class. Another type of handout (Appendixes 2 and 3) was made for their homework (used for Activities 4 and 9) in which students could see the Japanese meaning of new words and phrases they had just learnt, and then practice spelling them in English. Since the researcher did not provide any aural Japanese explanation, even for the meaning of new vocabulary, this type of handout was expected to compensate for conveying the meaning. The students worked on these handouts first within the class, and then were required to finish practicing the rest of it at home. The other type of handout (Appendix 4) was for a listening activity (Activities 13 and 14) in which students were expected to fill out a chart with information from listening tapes. Some spaces of the chart had a few Japanese key words in order to help them understand questions and move on within a group of students with a little teacher's help. Prior to providing these handouts, the researcher explained what they were going to do with the handouts so that they could first build up a concept or meaning of the English they had just heard. This was different from the usual method of understanding what to do by the Japanese given on the handouts, which is similar to the traditional translation method.

In sum, in order to obtain the maximum amount of input, students did not listen to Japanese from the researcher at all, but had a couple of chances to see some written Japanese on the given handouts. This was a minimal amount of Japanese but thought necessary in order to maintain the large class conducted only in English. 


\section{(2) Organized with Thematic FonF Activities}

In order to help the students become aware of the required grammatical knowledge and acquire communicative skills, the researcher organized the project class with a variety of communicative FonF activities. For example, in Activity 6, Matching Game, students worked in a group of two on matching PCs of items seen at school with word cards contained in an envelope. The purpose of this activity was to become familiar with the school vocabulary introduced in a previous listening activity (Activity 2) by reading the words.

Another example for the communicative FonF activities addressed in the project was Activity 11, Karuta, or a traditional Japanese card game in which students worked in a group of six and competed to pick up a PC matched with what the teacher read aloud. In this activity, the researcher intended to teach demonstrative pronouns this and that, and review possessive pronouns and all the school vocabulary learnt. The PCs used were illustrated to show different distances expressed with this and that; each PC showed a school item but there were two different sizes, a large item pointed to by an index finger and a small item drawn in a corner of the card and pointed to by an index finger from the diagonal corner so that the item looked as if it was far away.

Moreover, drawing on Harley's (1998) suggestion, all the communicative FonF activities were designed around the theme "school." Harley concluded her study by stating that focus on form in a primary immersion context was most successful when it was well integrated with overall curriculum themes (p. 171). However, since the project site was not in a primary immersion context, there was no curriculum theme shared with other subjects or even in the prescribed English textbook. Hence, based on 
the consideration that the research period was at the beginning of the school year and students, particularly the first-years, were getting accustomed to the school and new people, the researcher decided upon the theme "school."

In brief, the class was intended to teach certain required grammatical features and vocabulary surrounding the theme "school" in communicative activities.

\section{(3) Combined with Lots of Non-Linguistic Input}

Krashen (1982, 1985) and Krashen and Terrell (1983) argue that comprehensible input at an i (interlanguage) +1 level, or a little bit beyond the learner's current linguistic level is essential for language acquisition. However, it seemed extremely difficult to make the project students understand input that contained only verbal and nonverbal English because they were at the beginner's level with almost no knowledge of English.

In order to make input comprehensible for the students, linguistic input was always combined with a great deal of non-linguistic device such as pictures, drawings, real items, video tapes, as well as the researcher's gestures, body language and facial expressions. With these pictorial images, it was expected that students could pick up the concept or meaning of what was meant in English.

\section{(4) Requiring Physical Responses}

According to the Total Physical Response (TPR) proposed by Asher (1966, 1969), children acquire language through actions commanded by an instructor. Krashen (1982)

\footnotetext{
4 See Chapter 4 on current situation for whole discussion regarding students' current interlanguage.
} 
summarizes some advantages of the use of TPR that it 'insures the active participation of students, helps the teacher know when utterances are understood, and also provides contexts to help students understand the language they hear' (p. 142). The researcher's teaching consisted of many commands requiring the students' physical responses, such as "Move your desk to make a group of six," "Get your file out on the desk," "Say it again," and so forth. Even though the class did not consist of only commands, activities often required some sort of physical involvement. In Matching Game, for example, when students understood how to read a word written on a piece of paper, they could put the word card with a picture together; in order to participate in these activities, students needed to use part of their body.

Also, Krashen (1982) supports the use of TPR, claiming that it lowers students' anxiety because they do not need to produce in the language until they feel ready (p. 141). This point is discussed in the following characteristics of the project class.

\section{(5) Putting No Pressure on Students to Speak Up in English}

Throughout the project teaching period, the researcher did not push students to actually speak in English, although they had opportunities to say new words aloud in chorus and repeat phrases used in a couple of games. Even in Activity 10, Question-Answer Activity, which was possibly the only time in which they were asked to respond in English in a meaningful way in public, they were still allowed to use either Japanese or gestures. The purpose of all the activities was focused on understanding what they received rather than producing what they understood. Prior to the project, it was 
explained to all the classes that they would not be listening to any Japanese but they could reserve the right to use it themselves.

There were mainly two reasons for this. One was to avoid the students' possible refusal of this new way of teaching. One of the researchers' concerns in teaching the new students was whether they would regard the researcher as an acceptable teacher; it was quite possible that the students would refuse a temporary teacher like the researcher because of their difficult age, not because her poor quality of teaching. If they found the class too tough and hated the teaching style in the communicative way or the researcher per se, then the project may have had to be given up altogether. Therefore, the researcher was very careful not to put the students in a difficult or uncomfortable situation by forcing them to speak up in English.

Another reason was in relation to Krashen's Affective Filter Hypothesis (1982, 1985). According to his hypothesis, the lower the students' anxiety the better they acquire the language, and therefore, teachers should not force them to produce in a TL until they decide they are ready. As it was the first time for the project students to listen to only English during a 50 -minite-class period, it was thought that this was stressful enough for the students. The researcher thus attempted to minimize their affective filter and maximize their acquisition by avoiding asking them for production in English.

Therefore, in the project class, the students listened to English and spoke Japanese to their peers and the researcher who understood their Japanese and replied in English in return. As a result, the students could concentrate on trying to understand input through their aural and visual sense while the researcher concentrated on making the class comprehensible and enjoyable. 


\section{(6) Stimulating Intrinsic Motivation}

There is no doubt that highly motivated students tend to learn better. As discussed in Chapter 2, it is believed that, in particular, intrinsic motivation can turn students on to learning, or absorbing input. For the project class, the researcher attempted to lead students to the three types of intrinsic motivation categorized by Dörnyei (2001, p. 27): motivation for learning something new, achieving a goal, and experiencing pleasure.

For the first and third types of motivation, the researcher brought the class several different activities and teaching materials which were new for them in order to stimulate their interest and curiosity, including games, videos, lots of pictures of cartoon characters and so on. Besides, what the researcher was attempting to do was to make the class more open, relaxed, enjoyable, and comfortable. Traditionally in a Japanese classroom situation, students have been expected to sit still and straight, concentrating on their own work or the teacher's talk. Instead, the researcher put the students in a lot of group work or in pairs and welcomed their questions and chat in order to give them more opportunities to talk about what they had heard and make sure their guesses were right. The researcher smiled to students a lot as well.

For the second type, the researcher prepared small rewards such as tiny stickers to the winners of the games, and often encouraged and admired students even for the small effort they had made. Also, each activity was designed to have several small steps or sets to complete so that even slow learners could complete the first step or set and feel a sense of achievement as well as receiving some praise from the researcher. Meanwhile, what the researcher was attempting to avoid was giving students negative feedback, discouraging and scolding them, as well as pointing out what they 
did not do well; even when some students did not do their homework, all she did was encourage them to complete it later, instead of blaming them.

\section{(7) Including Lots of Pair/Group Work}

As has been mentioned above, the class often encouraged students to work in pairs or in a group. Generally, the purpose for pair/group work should be, for example, to increase interaction in the TL, but that was not in the case for the project class; the students were not expected to produce in the TL through the pair/group work since it was the very first time they had attended a communicative class.

The intention of using pair/group work in the project class was, instead, to allow students: 1) relax, 2) check their comprehension immediately, and 3) have "locus of control" (Peirce, Swain, \& Hart, 1993). First, group work makes a relaxing atmosphere because students face peers rather than their teacher at the front of the class. Second, this relaxing atmosphere encourages students to talk to each other even in Japanese in order to clarify what they heard. Third, in group work, students can control their learning to some degree, for example, the pace of proceeding the activity. Peirce, Swain, and Hart found that students, who were in the position of controlling a communication flow, could outperform those who were not. As a consequence, it was expected that students in group work would work better than when the teacher controlled the class.

\section{(8) Providing with Lots of Aural Modeling}

Some phonological features of English are completely unfamiliar to Japanese students 
because those sounds simply do not exist in the Japanese language system. As there are only 5 vowels and every consonant always requires a vowel's attendance English sounds unclear to Japanese students of English.

Considering this point, the researcher frequently modeled how to pronounce new words and phrases aurally so that students could catch them. At the same time, this became another chance for students to obtain repetitive listening input.

\section{(9) Completed with Homework}

Due to the extremely limited class time, there was no way to cover all four skills and give students enough time to practice them until they got automatized. Thus, reviewing new vocabulary and phrases in handouts became part of the student's homework every day. Mainly there were two types of homework; pronouncing words aloud shown in a PC handout (Appendix 5) and practicing spelling words and phrases (Appendix 2 and 3, see (1) above for explanations).

The former was meaning-centered as the students were required to recall vocabulary with a visual pictorial cue; the latter was nothing but repetition and drilling, which is considered peripheral in CLT (Finocchiaro \& Brumfit, 1983). The process of presenting the homework to students involved a certain amount of time explaining in English what and how to do the work, demonstrating how it was to be done, and letting students attempt some alone in order to help them understand and feel comfortable with doing it at home. In addition, in the next class, the researcher always checked their homework and gave individuals oral or written feedback. Therefore, homework activities were not isolated from the classroom communicative FonF activities, but 
rather, part of them.

\subsection{Data Collection}

\subsubsection{Methods}

Maykut and Morehouse (1994) recommended using multiple methods of data collection for qualitative research in order to increase the trustworthiness of the research findings. For this reason, the researcher chose four different methods such as observations, interviews, questionnaires, reviews from her reflective diary and field notes as means of collecting research data.

First, advocated by van Lier's (1988) statement that 'observation of classrooms is a central aspect of classroom research' (p. 39), the researcher did two types of observation, non-participant observation and participant observation (p. 40), as the main classroom research methodology. In other words, the former was done by observing regular English classes conducted in Japanese by Toyota and taking notes, and in the latter the researcher took part in the classroom interaction as a teacher addressing classes with communicative FonF activities in English, which were also videotaped. It is assumed that observing and comparing both the classes will be able to draw answers for the research questions above, in particular for the second and third.

Second, in order to draw out students' opinions, thoughts, feelings, and reasons for the behaviours observed, or answers for the first research question, the researcher addressed three questionnaires and semi-structured group-interviews with the students. These allowed the researcher to look classroom behaviour from a third perspective on top of researcher and teacher. 
Third, a questionnaire was given to six teachers who observed at least one class, including three teachers of other school subjects so that different interpretations of these behaviours would be collected from a broader range of perspectives. This would also help the researcher remain neutral (van Lier, 1988). The three English teachers were interviewed in-depth after the class observations. The interview was semi-structured, and its schedule was given to the teachers in advance so that they could have time to reflect on what they had seen in the observed class. Besides, the researcher constantly had an informal discussion with the original English teacher in terms of teaching materials, students' behaviours and reactions in class, and issues regarding classroom management and instruction. This discussion gave the researcher a sense of the teacher's teaching philosophy, beliefs, and personality. All the questionnaires, interviews, and discussions were administered in Japanese (see Appendixes 6 to 11 for the English language version; see section 3.3. on data analysis regarding translation of data).

Moreover, throughout the process of data collection, the researcher kept field notes and a reflective diary to record what was happening in class and other thoughts related to the class. It was also expected that this would help the researcher to 'identify important experiences, ideas, concepts, themes, etc...in the data' (Maykut \& Morehouse, 1994, p. 132) when analyzing the data later.

In sum, in order to explore the research questions, the researcher chose the following seven approaches for data collection: 1) observation of original classes, 2) conduct and record communicative FonF-activity classes, 3) questionnaires to students, 4) questionnaire to teachers, 5) group-interviews with students, 6) interview with teachers, and 7) the researcher's reflective diary and field notes. 


\subsubsection{Project Procedures}

The project was carried out over a period of four weeks.

The 1st week: The original English classes conducted in Japanese (3 lessons for each class, the total is 15 lessons) were observed. During the observations, the researcher kept field notes in relation to what the teacher did, how she organized classroom activities, what kind of teaching materials she used, which student would need special attention in order to control the class. At the end of the week, the explanation of this project and the first questionnaire about their English learning experience and perceptions of it were given to the students.

During this period, the researcher concentrated particularly on getting to know the students and building up good relationships with them, staying around their classrooms and talking to them during lunch breaks and after school for as long as possible. It was expected that this would help to reduce the students' anxiety and nervousness about having different classes than usual with a new teacher. This attempt continued throughout the project period, and the researcher participated in all school activities and events such as an assembly and a field trip just as other teachers did.

The 2nd and 3rd weeks: A communicative FonF lesson including the same content as the curriculum required was conducted in English by the researcher 6 times per class. The classroom interactions were videotaped, and some of the group activities were audiotaped. A questionnaire asking for the students' perceptions of the lessons was given at the end of each week (twice), and group-interviews after each lesson were given to the students who were interested in the project further. The teachers were asked to observe the classes (all classes for the original English teacher and at least one for the 
others) and answer the questionnaire for feedback and comments on their perceptions of the students' understandings, reactions and interactions.

The 4th week: The three English teachers were individually interviewed in-depth. The researcher interviewed the original English teacher for two hours and the others for half an hour. The teachers were asked to discuss what they thought about in terms of the students' understandings, reactions, and interactions with peers and the teacher during each activity, to what extent they thought that it would be possible to implement the activity in their own lesson, and why.

All the interviews for both the students and the teachers were audio taped and transcribed later. During the entire period of the project, the researcher took notes about the students' reactions and interactions with peers and teachers. A diary was also kept, reflecting on the researcher's intentions, impressions, and thoughts on the class activities and the students' perceptions.

\subsection{Data Analysis}

In the analysis of the data, the researcher was inspired by elements of Maykut and Morehouse's (1994) constant comparative method of data analysis, originally proposed by Glaser and Strauss (1967), and Lincoln and Guba's (1985) procedures for analytical induction. As explained by Ertmer (1997, p. 163), this study attempted to find answers to questions that were important but not yet answered by identifying and describing the commonalities and the plausible relationships among observed phenomena or sets of concepts. The interview tapes were transcribed, and all the data collected from the lessons, interviews, questionnaires, and researcher's field notes and reflective diary was 
typed, carefully read through, and then small units of meaning (or themes) in the data were identified. After "unitizing" the data in terms of themes, each unit was compared to recurring concepts or themes grounded in the data and all other units of meaning, and subsequently categorized and coded with similar units of meaning (Maykut \& Morehouse, ibid.).

As the stage of synthesizing all the analyzed data, the researcher took mainly a narrative form in the process of writing, which allowed her think freshly about the data and find new insights and understanding (Maykut \& Morehouse, ibid. p. 145). Moreover, as advocated by Maxwell and Miller (1992), graphic displays were used to report the data from the questionnaires. Although statistical data about students' responses to the questionnaires is included in this thesis, there was no attempt to do random sampling or carry out statistical analysis of the data, because the researcher's intention is not to generalize from the sample, but rather to investigate as a single case the overall changes in the five classes taught. All Japanese produced by the students and teachers in classroom interactions, questionnaires, and interviews was translated into English by the researcher. In this paper, the words, phrases, and sentences originally produced in English are presented in Italics. 


\section{CHAPTER}

4

\section{Current Situation:}

\section{Students' Previous English Experiences and Perceptions}

\section{Introduction}

Before presenting outcomes of the study as a request of implementing the communicative FonF activities, I will present the students' perceptions of their learning experiences related to English and other languages besides their mother tongue. This understanding of the students' current situation will allow the researcher to clarify and compare what is the same and what is new and different in terms of their classroom input experiences and the outcomes. In other words, it will provide the researcher with cues to determine whether students' reactions or responses to the communicative FonF teaching are purely derived from the new way of teaching or whether there is evidence that these reactions were previously there. Thus, the findings presented in this chapter will provide a foundation for the following chapters.

In addition to making assumptions based on her own previous teaching experiences, or interviewing the regular English teacher, the researcher collected data from the students themselves and from observations of their actual classrooms. The data were elicited by asking students about their previous experiences and perceptions of the learning through questionnaire and interview and observing what and how they were learning in their regular English class at junior high school. In brief, the findings presented in this chapter are mostly based on the data from the non-participant 
observation, Student Questionnaire 1, and Student Interview and Teacher Interview.

This chapter is divided into three sections. The first section deals with the students' language experiences before junior high school and their perceptions of these experiences, and describes the data from Student Questionnaire 1 and Student Interview. The second deals with the students' experiences and perceptions of their regular English class in junior high school, and describes data mainly from the non-participant observation, Student Questionnaire 1, and Teacher Interview. The last section deals with other language experiences, for example, traveling abroad and English education that the students have received outside of school. The data from Student Questionnaire 1 is used for analysis.

\subsection{At Elementary School}

Prior to the official introduction of English education at junior high school, most of the students had a several chances to taste an "experiential English lesson" organized with communicative activities at elementary school. However overall, the experience was limited in terms of the quantity and quality. The students have mostly a good impression of the enjoyable experience of the lesson, which included their regular homeroom teacher's translation of it into Japanese in order to make it understandable.

\subsubsection{Students' English Experiences}

In Japan, since English education starts at junior high school (grade 7), students do not officially have English lessons as a subject at elementary school. However, three elementary schools from which most participants graduated offer experiential English 
lessons inviting a native English-speaking teacher ${ }^{1}$, who had a contract with a private English conversation school, once or twice a week for a month or two at the end of the 6-year elementary education. Though the content and number of the lessons differ depending on school, each class had totally six to ten hours of this kind of lesson just before graduation.

The primary aim of this English lesson is to give pupils some international experience, and foster their interest and positive and active attitude toward communicating with people who speak different language and have a different culture, rather than to actually teach English language. On the basis of this aim, lessons are usually designed around communicative games and songs and conducted mainly in English. However, in many classes according to the students interviewed, pupils did not understand what the native-speaking English teacher was trying to say, or the teacher failed to make pupils to understand what to do, and then their regular homeroom teacher translated English into Japanese most of the time.

Student Interview 2B, June 10 (which means that this interaction was retrieved from the Student Interview Tape $2 B$ recorded on June 10. It will be referred to as SI2B, June 10 hereafter):

SA (refers to Student A): I didn't understand because Tracy-sensei (meaning "teacher") kept talking in English all the time.

SB: Oh, yes. I didn't understand at all either. At elementary school, a real teacher came to school!

$\mathrm{R}$ (refers to the researcher): Do you mean a real American? ...

SA: Yes. She was speaking English for the entire hour, wasn't she?

SB: And the classroom teacher was a translator, wasn't he?

$\mathrm{R}:$ Oh, then, did the classroom teacher translate for you guys?

SB: Yes, all the time, because she couldn't speak Japanese.

R: Then, did it seem that you were having half of her class in Japanese? Eh, always like that? Every time?

1 The information regarding his or her degree and teaching experience is not available. 
SB: Yes, maybe depended on class, though....

SA: We played so-called "Cross Game" etc. (Explaining the game.)

SB: We had to answer in English.

R: The teacher asked questions in English, and you had to answer in English, didn't you?

SB: Yes.

From the data available, what kind of English input the pupils obtained through the experiential classes is not clear, in terms of its quantity and quality. It is assumed that at least half of the class was conducted in English and, therefore, that although the pupils may have depended on Japanese translation by their homeroom teacher, they had a chance to listen to and try to understand English input. However, the input that they obtained seemed not have been tuned to their level by the teacher's modification since they claimed that they could not understand it.

\subsubsection{Students' Perceptions of English Experiences}

The students seemed to find the English class difficult, but eventually had a favourable impression of it with their homeroom teacher's translation. One student indicated a reason for her favourable impression in Student Question (SQ) 1-3(5) as follows:

SQ1-3(5):

It was fun. Japanese couldn't be understood, but I could think by myself and used my body to communicate, and it was good for me.

Nearly $80 \%$ out of 148 students, who had the English experience at elementary school, reported in SQ1-3(5) that they liked the class; $116(78 \%)$ answered "Yes" while $32(22 \%)$ answered "No" to the question "Did you like the English class?" Table 4.1 presents reasons for the response "Yes." Not surprisingly, considering their 
age, $59 \%$ of the favourable indicated as a reason for their answer "because it was fun" and $29 \%$ for "because I could play a game." On the other hand, it should be also important to state that the first reason for the unfavourable answer was "because it was too difficult to understand" ( 8 out or $32,25 \%$ ) while all the other reasons were indicated by one or two students (Table 4.2).

Table 4.1. SQ1-3(5) 1) Reasons for "Yes" ( $n=116)$

\begin{tabular}{|l|r|r|}
\hline I liked the English class at elementary school because: & Number & \multicolumn{1}{c|}{$\%$} \\
\hline It was fun. & 68 & 59 \\
\hline I could play a game. & 34 & 29 \\
\hline The teacher was good. & 13 & 11 \\
\hline I liked English. & 7 & 6 \\
\hline The class was easy to understand. & 6 & 5 \\
\hline I could talk to my friends. & 22 & 19 \\
\hline Other & & 3 \\
\hline
\end{tabular}

Table 4.2. SQ1-3(5) 2) Reasons for "No" $(n=32)$

\begin{tabular}{|l|r|r|}
\hline I did not like the English class at elementary school because: & Number & $\%$ \\
\hline It was too difficult to understand. & 8 & 25 \\
\hline I hated English. / The game was not good. / & 2 & 6 \\
It was boring. / It was annoying. & 1 & 3 \\
\hline The teacher was not good. / I got scold. / It was not fun. & 3 & 9 \\
\hline No reason. & & \\
\hline
\end{tabular}

It can be interpreted that a communicative class should be not only enjoyable but also understandable in order to obtain students' approval. 


\subsection{At Junior High School}

The English input the students received at junior high school in the one month before the communicative teaching project is extremely limited to some isolated written words and example sentences. With regard to aural input, the students had obtained almost nothing. The class sometimes required student output in a spelling practice or oral production activity. Nearly four fifths of the students stated that they liked the English class because of their cheerful teacher.

\subsubsection{Students' Current Knowledge about English}

The students entered this public junior high school at the beginning of April and started studying English as a school subject for the first time in their life. Due to several school events over an orientation period of the first one-month or so, there were approximately four school-weeks that the students had actually studied before the project begun on 19th of May; they had had 10 to 1250 -minute lessons prior to the project.

During this five-week period, including the first week of the project in which the researcher was observing the original regular classes, the students were taught the English alphabet, 22 vocabulary items (Table 4.3), a couple of basic greetings (Table 4.4), some classroom organizational language (Table 4.5), and structures of 'I am ...' and 'You are ...' and their interrogative forms, along with the use of a textbook ( $\mathrm{New}$ horizon English course 1, pp. 2-15) approved by Monkasho. According to Toyota, when introducing the new vocabulary items shown in Table 4.3 , she usually presented them by showing flash cards without pictures, explaining meanings in Japanese, modeling how to read them a few times and letting students practice reading aloud and spelling them. 
Table 4.3. Vocabulary items learnt

\begin{tabular}{|llllll|}
\hline cat & dog & bike & notebook & basketball & Canada \\
milk & plane & piano & book & tennis & from \\
bus & train & flute & pencil & soccer & \\
pen & boat & guitar & baseball & America & \\
\hline
\end{tabular}

Table 4.4. Basic greetings learnt

$\begin{array}{lll}\text { Hi. } & \text { Good morning. } & \text { How are you? }- \\ \text { Bye. } & \text { Nice to meet you. } & \text { Fine, thank you. And you? }\end{array}$

See you.

Table 4.5. Classroom organizational language learnt

$\begin{array}{lll}\text { Stand up. } & \text { Listen to the tape. } & \text { Good! } \\ \text { Sit down. } & \text { Look at the board. } & \text { Bad! } \\ \text { Raise your hands. } & \text { OK. } & \text { I don't know. } \\ \text { Open your books. } & \text { Come here. } & \\ \text { Close your books. } & \text { Be quiet. } & \end{array}$

Toyota also explicitly taught the greeting items, but in this case, students practiced saying rather than writing by chorally repeating after their teacher, and they used some of the items as a choral classroom greeting at the beginning of each class. With respect to the classroom organizational language, the students just went through items by listening to the tape and mimicking the gestures shown in the textbook without practicing saying or writing the items. Toyota carefully taught the other items step by step, providing the students with enough time to practice them, especially for spelling.

In Japan, as to minimize possibilities of being penalized due to their bad handwriting on entrance examinations, the students are first encouraged and trained to 
uniformly handwrite the alphabet, using a notebook with four lines (three dotted and one red) printed on (see examples in Figure 4.1.), instead of being permitted to produce their own unique handwriting.

Figure 4.1. How to write Alphabet

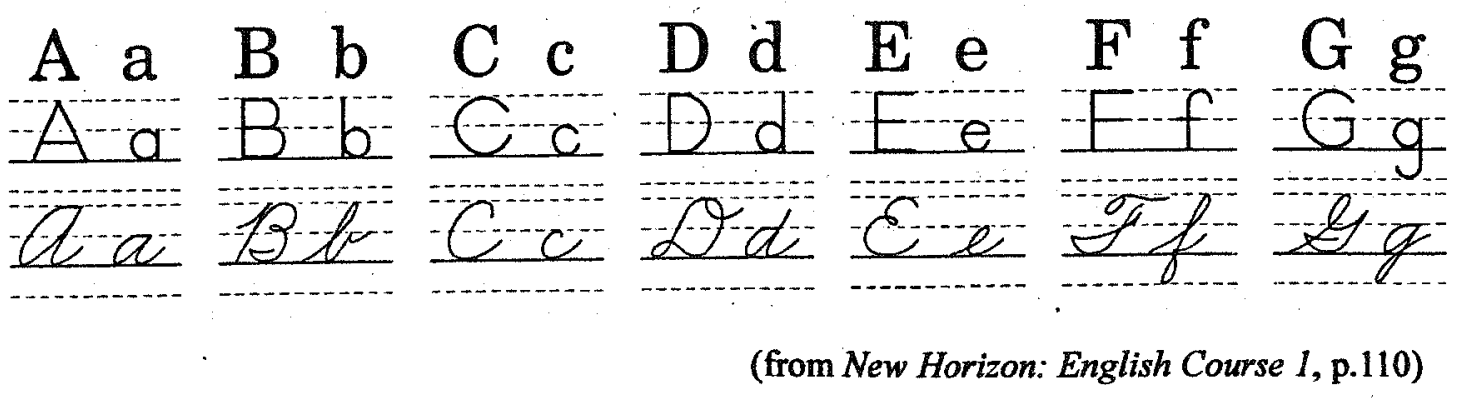

For a month or so, teachers also draw four lines on the blackboard in teaching the alphabet and spellings of new vocabulary items, and then eliminate the three dotted lines remaining the red, and eventually all the four as students become familiar with the alphabet. In this sense, Japanese English teachers provide a step-by-step scaffolding for spelling. However, there is no similar scaffolding for listening and speaking, nor even for creative writing. An interaction between a student and the researcher during the Skit Writing Activity (Activity 9) in a communicative lesson illustrated the rigorous manner in which they had been trained to handwrite. As soon as the researcher wrote a capital letter $\mathrm{M}$ on the lines (Figure 4.2.), a student came to the blackboard to correct it - as shown in Figure 4.3. - saying:

Class1-Lesson3-Period5 (which means that this interaction was retrieved from the Lesson 3 given to Class 1 in the 5th period of a day. It will be referred to as Class 1-3-5 hereafter):

S: Wait a second. Isn't that different from Miss Toyota's way? 
The researcher was not careful enough to identify such a detail and checked it in the textbook and found that the student was right.

\section{Two ways of writing "M"}

Figure 4.2.

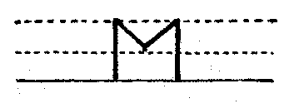

Figure 4.3.

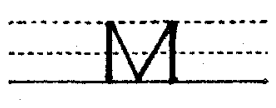

Through careful instruction in Japanese, Toyota had placed students' attention to how to write the alphabet and spell new words in details. Lots of time was spent for practicing as well as explaining. By contrast, the students hardly had a chance to listen to any English. In summary, the students' knowledge about English at the outset of the study was extremely limited, and the amount of input the students had received was limited to some written input.

\subsubsection{Regular English Class}

All five classes were taught by Toyota, a female teacher in her mid-twenties with a BA degree in English literature and an English teaching license in Japan. This is her fourth year of teaching; she has one-year of teaching experience at a senior high school and two-years at junior high schools. She claimed that she never learnt any concrete way of teaching English, whether communicative or not, in the course for the license except during the practicum at a junior high school. In addition, since she is not a permanent teacher employed by the prefecture government after passing a prefecture examination for public teachers, but a contract teacher employed by the city, she has not yet had an in-service teacher training for the first-year teachers which is offered by the prefecture 
government. Thus, Toyota's teaching philosophy is derived from her ex-colleagues at the previous school where there was some team-teaching. As a result, Toyota had the chance to teach in a sort of communicative way with another teacher. However, she emphasized that she actually did not know anything about communicative teaching; all she could think of and tried was to include some chances for students to use English in a sort of communicative activity although she was not sure whether it was a good activity.

From the one week of observation by the researcher, it seems that Toyota's class can be categorized as a typical Japanese English class with the Presentation-Practice-Performance (P-P-P) progression (Byrne, 1976, cited in Edge \& Samuda, 1980). For instance, one of her classes was conducted with a use of a handout including a review section from the 'I am ...' structure, an explanatory presentation section of a new 'You are ...' structure and its interrogative form, and a production activity.

In the Presentation stage, Toyota started her explanation about a new structure to be taught in Japanese, using a famous Japanese pop-singer's name for an example sentence:

Observation Class 5, May 21 (the English part is in italics):

T (refers to Toyota): Then, last time we all studied how to say about "me", but ... today we are going to study how to say about "you" in English. Sometimes people say to me, when passing by me, "Oh, you are Hamasaki Ayumi!" because I closely resemble her.

SS (refers to students): (Laughing) Who said that? Which part of you resembles Ayu?

T: Many people!! But anyway, if you want to say it in English, it will be like this. "You are Hamasaki Ayumi. You are Hamasaki Ayumi." You can write like this. (Writing "You are" on the blackboard so that students could fill in the space on the handout.) 
This Japanese conversation including this single model sentence in English was followed by the Practice stage:

\section{Observation Class 5, May 21:}

T: You can write and practice the same sentence one more time in the next line. (Giving a minute or two to SS.) You can also shorten "You are" like "You're". Write this one in the next space given on the handout, too. OK. Now, then let's read it together. You are Hamasaki Ayumi.

SS: You are Hamasaki Ayumi.

With respect to the interrogative sentence, the class also followed this pattern; that is, 1) teacher presenting a model sentence with a new structure, showing how to write it, with an explanation of how to change the affirmative sentence introduced into an interrogative one and how to answer, and 2) students' practicing a few times by repeating the same sentence after the teacher, verbally and/or in writing. In this section, however, there was no space for students to practice writing the new sentence structure. Instead, Toyota provided the class with another chance to verbally practice the structure, rather than only repeating after her; that is, a role play in which students asked Toyota "Are you ...?" with the singer's name and her real name in chorus, and responded by saying "Yes, I am. / No, I am not." to Toyota's question, "Are you Hamasaki Ayumi?" There seemed to be confusion among the students regarding what they were supposed to say during this small practice activity, especially when in their turn they were required to say "Yes" because the answer "Yes" did not make sense at all; none of them was the pop singer.

At the Production stage, Toyota had prepared a communicative activity in which the students chose a famous person to pretend to be out of 11 given on the handout. Then they had to find out who their partner was pretending to be and where 
he/she was from by guessing and asking "Are you ... ?" There were three types of groups in terms of their understanding during this activity. The first, consisting of about two third of the students, were those who were participating in the activity without any problem. The second group included most of the remainder who did not know what to say, particularly at the beginning, and gradually figured it out with a help of their partner or other peers. The third group included a few students who could not understand how to ask the question or answer in English, and who could not read the example sentence on the handout, or who were not confident enough to articulate the sentence.

From the observations of these classes, the researcher came up with several characteristics that described the regular English class. The regular class:

1) is organized with the P-P-P progression;

2) is conducted with a use of handout in Japanese;

3) provides extremely limited amount of input (only one or two model sentences);

4) provides situationally and quantitatively limited practice;

5) sometimes includes a communicative production activity; and

6) has almost no teacher-student interaction since it is one-way explanation except during the communicative activity in which there is student-student interaction.

Therefore, it can be concluded that at the time of the project, these students had received very little aural input but some written input, and had done some limited production practice as both verbal and written output. 


\subsubsection{Students' Perceptions of Regular English Class}

With respect to the students' perceptions, they generally had a favourable impression of English class because of the cheerful personality of Toyota. After observing four classes conducted by her, the researcher wrote down a comment on the class atmosphere in the reflective diary:

Reflective Diary, May 21st:

Most students seem to be interested in English class and the English teacher who has been making big efforts in making class fun or interesting; there are lots of laughter, jokes, and smiles on both teacher's and students' sides.

Figure 4.4. SQ1-5

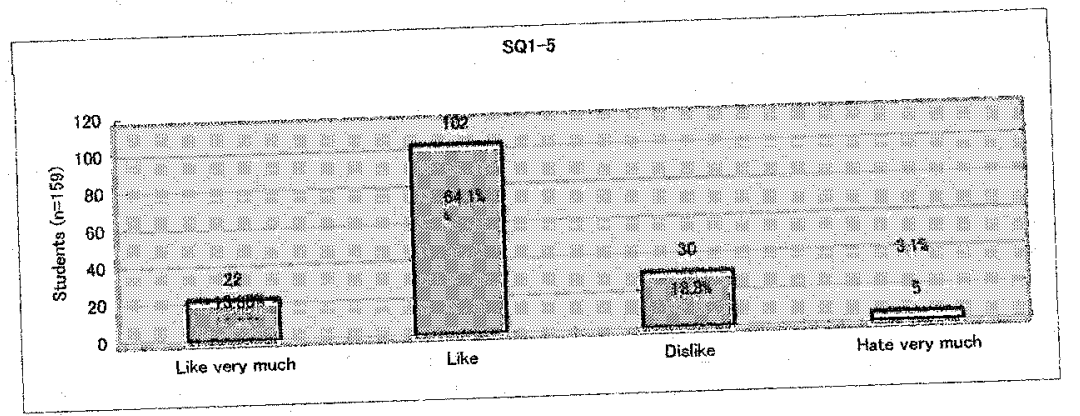

This is seen in the answers from SQ1-5 (Figure 4.4), in which the students are asked whether or not they like English class at junior high school. The total of 'Like very much' and 'Like' is $78 \%$ whereas the total of 'Dislike' and 'Hate very much' is $22 \%{ }^{2}$ Besides, the first reason that the most students, 90 out of 124 , chose is 'The teacher is good (funny or kind)' $(73 \%)$, and the second is 'Class is fun with games' (80 students, $65 \%$ ). All teachers probably agree that a funny class is not always good;

2 Note that these categories are translations of the Japanese terms, ‘大好き”, “好き”, ‘嫌い’, and ‘大 嫌い'。 
however, it must also be true that when students enjoy themselves, they learn more. In this sense, most students made a good start of learning English with a good impression. The rest of the reasons are shown in Figure 4.5.

Figure 4.5. SQ1-5(1)

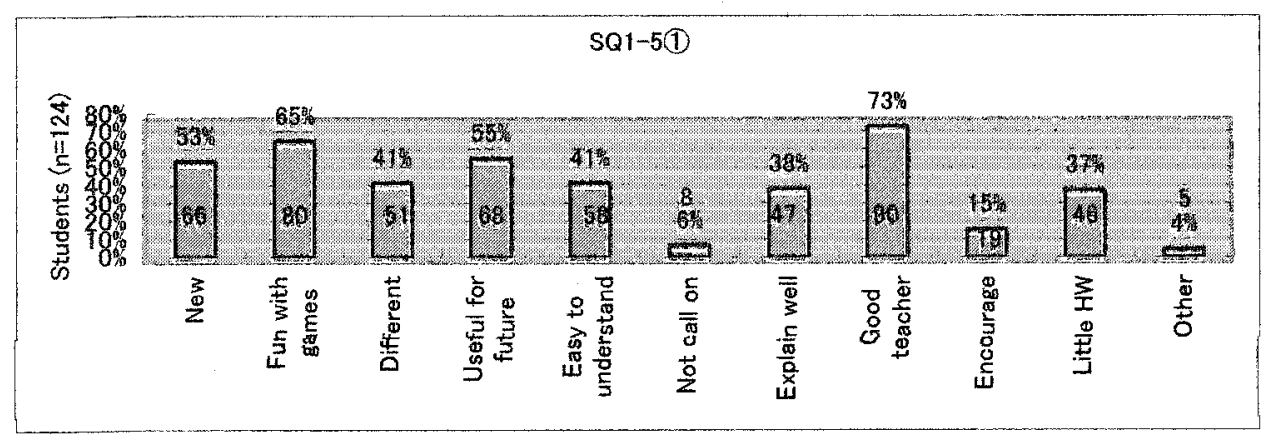

Meanwhile, nearly half of the students who did not like the class $(15 ; 43 \%$ out of 38) stated in SQ1-5(2) that the reason for their dislike was because 'it is not fun.' This is followed by 'the teacher is not good (funny or kind)' $(11 ; 31 \%)$ and 'it is difficult to understand' $(9 ; 26 \%)$. Furthermore, there are other notable reasons; they are 'I have to pronounce aloud' $(11 ; 31 \%)$ and 'the teacher often calls on a student' $(9 ; 26 \%)$. These show that at least some students do not like the class because of its production activities. With little input at the beginning level, they found it difficult to produce English. As Krashen's Affective Filter Hypothesis $(1982,1985)$ cautions, teachers probably need take these students' feelings into consideration. The result of SQ1-5(2) is shown in Figure 4.6.

After all, the majority of the students like the English class conducted in Japanese by their regular English teacher Toyota. The result of Student Questionnaire 1 reveals that the English class should be enjoyable and understandable from the 
perspective of the students who do not like it as well as the ones who like it.

Figure 4.6. SQ 1-5(2)

\begin{tabular}{|c|c|c|c|c|c|c|c|c|c|c|c|c|}
\hline \multirow{2}{*}{ 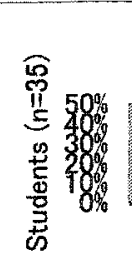 } & \multicolumn{11}{|c|}{ SQ1-5(2) } & \multirow[b]{2}{*}{ [1] } \\
\hline & [ & $\begin{array}{l}11 \% \\
178\end{array}$ & $\begin{array}{l}14^{\circ} \\
151\end{array}$ & $\begin{array}{l}17 \% \\
{[6]}\end{array}$ & {$[1$} & $\frac{28 \%}{\left[\begin{array}{l}28 \\
9\end{array}\right]}$ & $\prod_{0}^{26 \%}$ & $\frac{776}{\square}$ & [11\% & 6 & $\sqrt{109}$ & \\
\hline & $\begin{array}{l}\frac{5}{2} \\
+ \\
2\end{array}$ & $\begin{array}{l}\frac{3}{3} \\
\frac{3}{2} \\
\frac{1}{2}\end{array}$ & 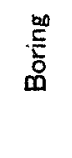 & 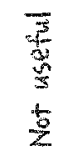 & 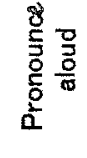 & 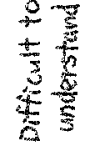 & 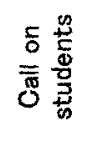 & $\begin{array}{l}\frac{5}{8} \\
\frac{1}{8} \\
\frac{1}{2} \\
\frac{0}{2}\end{array}$ & 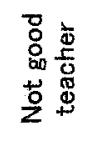 & 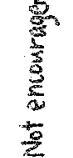 & 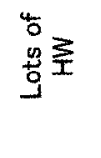 & $\frac{\mathbf{s}}{\underline{\mathbf{s}}}$ \\
\hline
\end{tabular}

\subsection{Outside of School}

Other than these English classes at elementary and junior high school, most students have hardly ever had a chance to experience English language and culture, especially a chance to communicate by listening to and speaking English. This can be found in SQ1-1 to 4 .

The result of SQ1-1, in which students were asked if they had been to a foreign country, shows that only $13 \%$ (one to six in each class) answered, "Yes." Even these students presumably were too young to pay attention to and try to communicate in a language spoken in the country during the short trip. However, a relevant implication from the statistic is the fact that only around one tenth of their family has finances and time available as well as interest in visiting abroad.

In SQ1-2, the students were asked if they had lived in any other country, and only two students in Class 2, out of 160, answered, "Yes" (a boy who had lived in Singapore for 9 years since he was born and a girl who had lived in U.S. for 1 year at her 
age of 9-10). Again, most students have had no exposure to any other language than Japanese.

In SQ1-3(1), the students were asked about their English learning experience before junior high school. This raw result (Yes: 148) includes the number of those who had an experiential English class at elementary school. After excluding responses who mention only the elementary class, the number of "Yes" turned into $58(36 \%)$ and whereas "No" turned into $102(64 \%)$. This number, over one third, refers to pupils who privately learnt English as a foreign language before actual education at school.

Figure 4.7. SQ1-3(2)

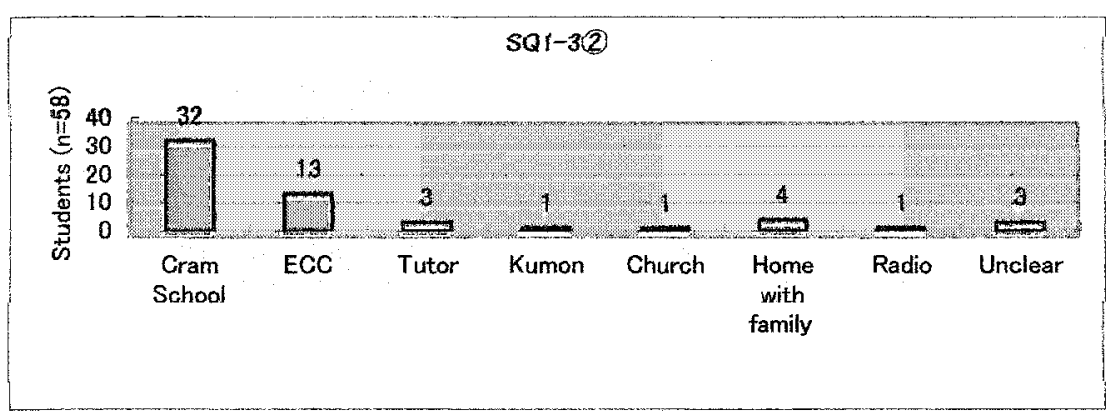

However, closely examining the result of the next question SQ1-3(2) in which they were asked where they had the learning experience, it becomes clear that most of them attended to so-called "cram school" or similar sort of institution where lots of grammar exercises were provided and probably did not have an exposure to English. The itemized answer of the 58 students can be seen in Figure 4.7. Among these items, only $\operatorname{ECC}^{3}(n=13)$, Church $(n=1)$, and Radio ${ }^{4}(n=1)$ have a possibility for students to have an

3 ECC stands for "English Conversation Circle," a chain cram school where students supposedly learn how to communicate in English through conversations in a small group with a Japanese teacher, who can speak English, but indeed the way of teaching depends on branch and teacher, and sometimes the class does not focus on conversation but plays a role of supplementary school. 
exposure to some English communication, although it is still not certain to what extent they could be exposed in a limited time (most said that their lesson was 1 or 1.5 -hour long a week).

Figure 4.8. SQ1-4(2)(3)

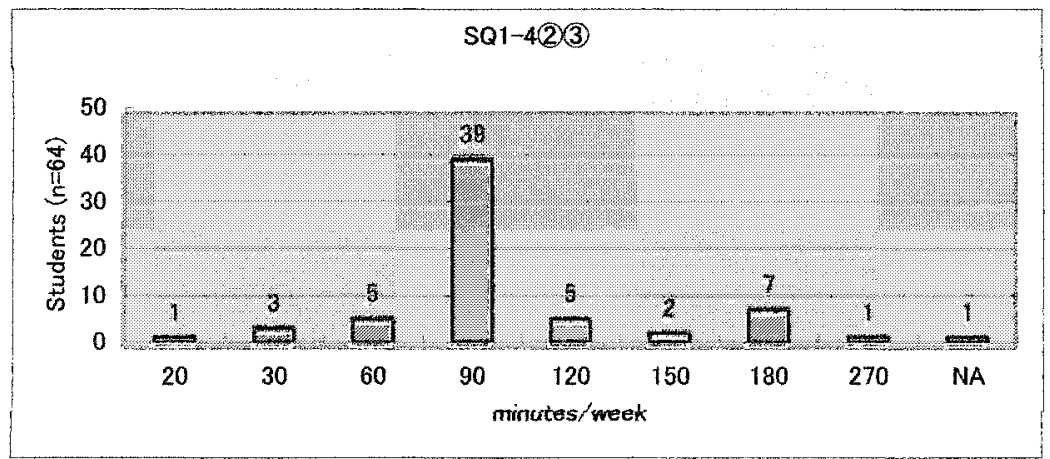

To SQ1-4, in which the students were asked whether they were taking any other English lesson besides ones at junior high school, 64 students (40\%) answered, "Yes" while $96(60 \%)$ answered, "No." The positive respondents were asked for further details. In SQ1-4(1), they were asked where they were taking the additional lesson, and the two tops of the result were again "cram school" with $44(28 \%$ out of the total 160$)$ and "English Conversation School (mostly ECC)" with $9(6 \%)$. The rest of the items chosen were: "with Tutor" with 1 (1\%); "Home with family" with $5(3 \%)$; and "Other" with $5(3 \%)^{5}$. In SQ1-4(2) and (3) regarding the quantity of the lesson, the researcher looked at both the answers simultaneously and converted into the way that showed how

${ }^{4}$ Here, Radio refers to "Radio Basic English Kiso Eigo," a 20-minute long radio program which is organized along certain grammar structures and explained in Japanese but which still provides a number of examples broadcasted by a Japanese moderating teacher and a few native English speakers.

5 "Others" included "Correspondence course of drilling" with 3, "Radio" with 1, and "Friend's mother" with 1. 
many minutes a week they studied (Figure 4.8 ). The result shows that $61 \%(n=39)$ of the students taking an extra English lesson reported that the lesson was 90-minute long per week. What is important to note in these questions regarding additional English learning experience outside school is that only a small number of students (at most, 9 attending English conversation school, and 1 listening to Radio) can possibly have an opportunity to listen to and speak English while most students do not have any such opportunity but just do grammar drills or exercise. In other words, for more than $90 \%$ of the students, English class at junior high school three times a week is all chance to be exposed to English.

Figure 4.9. SQ1-4(4)

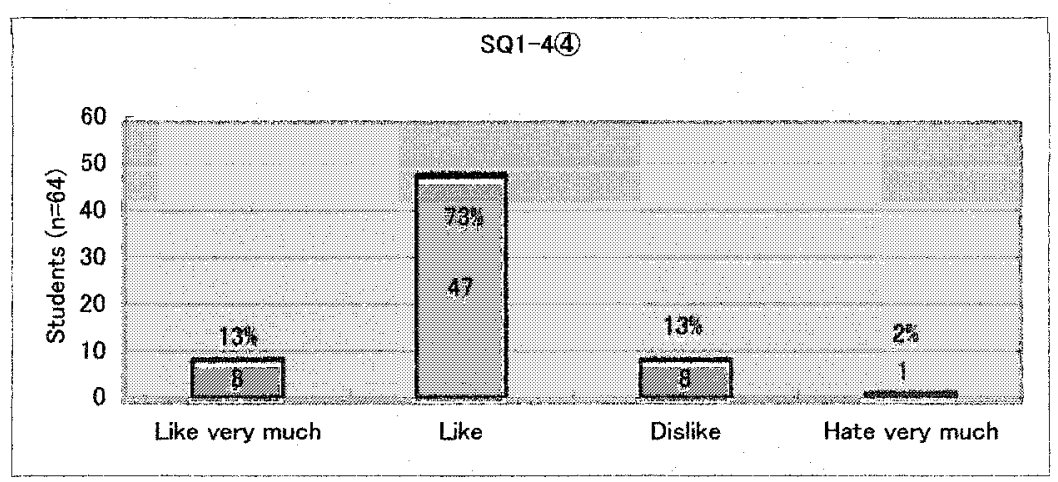

Moreover, in SQ1-4(4), the positive respondents were asked about their perception of the additional English class, and the reason for the perception in the following questions. The results are in Figures 4.9 to 4.11 . According to the results, 55 students (86\%) like the class, and their top criterion for judging the class is again whether or not it is fun. However, around half of the students are also looking at the quality of the class, which can be revealed in such items as "useful for school," "I can learn something new," "easy to understand," and "teacher explains well." For most of 
those respondents who do not like the class, the quality of the class is also as important as its fun.

Figure 4.10. SQI-4(5)

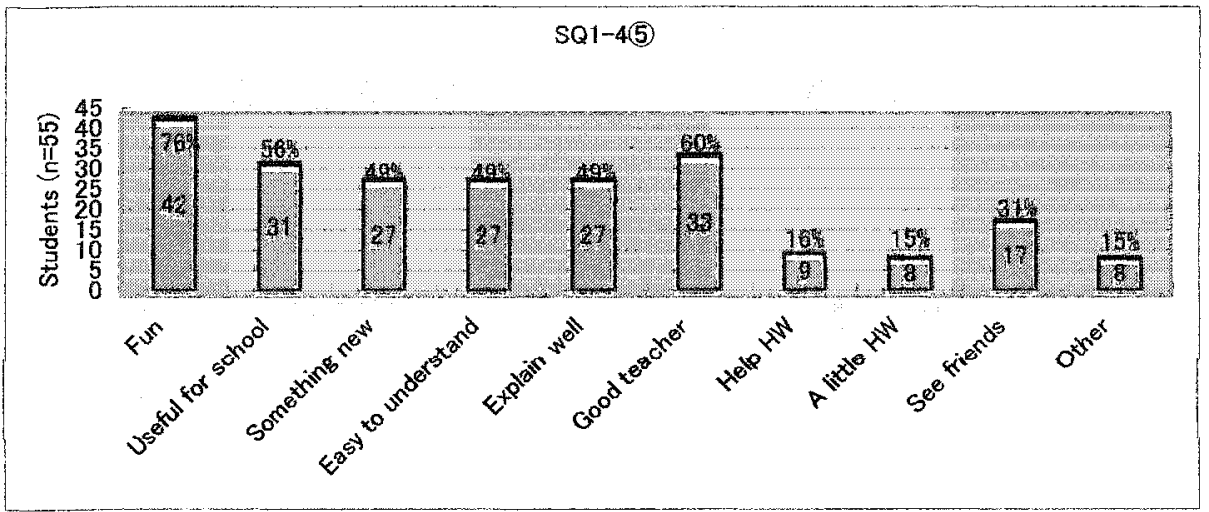

Figure 4.11. SQ1-4(6)

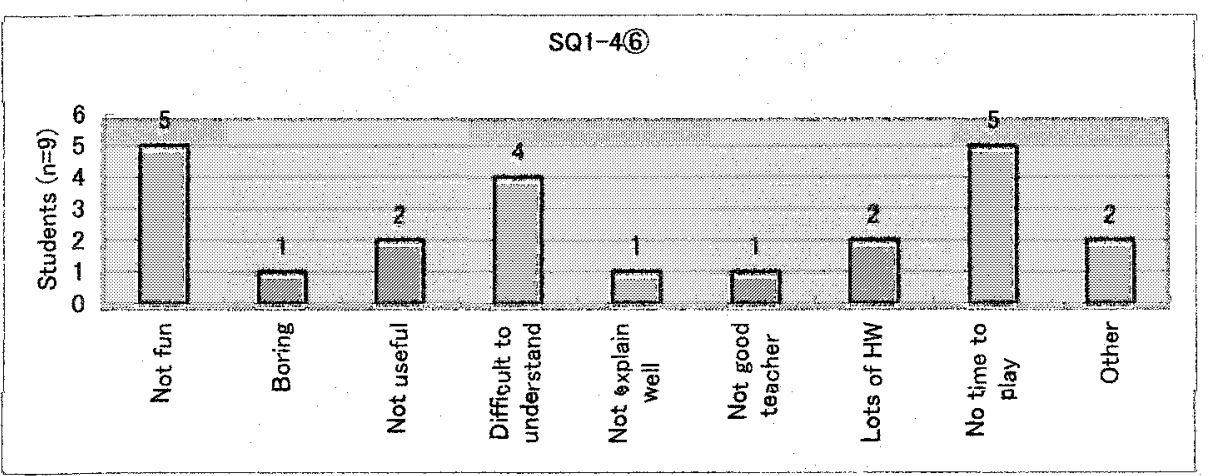

\section{Conclusion}

In this chapter, I have specified some characteristics of the students' current situation, exploring what they have experienced in terms of foreign language classes, mainly English, at elementary school and junior high school as well as outside of school, and how they have perceived the experiences. 
The students who participated in the project have had extremely limited access to English, especially situated "live English" that they can listen to, both inside and outside of school. However, most of the students have experienced up-to-10-hour communicative English class at elementary school although it was not conducted in completely English but with a help of Japanese translation by their homeroom teacher. Furthermore, $40 \%$ of the students have taken supplementary English lessons after school, most of which does not provide communicative class. Regardless what kind of English class students experienced and what kind of approach teachers used, most students have a positive impression of their English class. The students' most important criteria for judging their English class are whether the classes are understandable and fun. 


\section{CHAPTER}

5

\section{Students' Perceptions and Responses to}

\section{Communicative FonF Activities}

\section{Introduction}

The analysis of the patterns of student interaction in the classroom and the student perceptions elicited by the interviews produced two classifications of students in terms of their roles in the implementation of classroom activities by the teacher. One classification is in terms of students' opinions of what goes on in the classroom; the second is in terms of the degree of influence they have on other students in the class.

In terms of students' perceptions of the class, generally speaking, there are three types of students in a class. The first type is those who like whatever they are given at school, that is, whoever a teacher is, whatever kind of teaching approach and material the teacher uses, or however the teacher teaches. They always love the class, teachers, and school and are highly motivated. Leaving aside the question whether they are successful language learners, they are "excellent students" from classroom teacher's point of view because they just always like the class. Nothing changes these students' perceptions of the class. The second type is opposite of the first one, that is, students who never like whatever they are given at school. They may claim a reason for their hatred, but even if it were solved, they would find another reason. They dislike the class, teachers, and school and are de-motivated. In many cases, these students have other serious problems with, for example, their family background as explained in section 3.1 .2 , and these problems and 
their perceptions of a class or school are intertwined. Similar to the "excellent students", it is difficult to change the perceptions of these "problematic students" as well. The third type includes the remainder of the students, that is, those who are between the two extremes and who make up a majority of the class. Their perceptions of the class are changeable and depend on different elements of the class such as the teaching approach, materials used, a teacher, his/her personality, the manner of teaching and so forth. Depending on the conditions, they can become motivated or de-motivated. In implementing communicative FonF teaching, what is important for the teacher is to "win over" this group of students.

In terms of students' influence over other students in the class, students can be classified into two types: "key students" who have a different major role in contributing to the class flow, and other regular students who generally follow the class flow that is established. Since the key students are usually energetic, talkative, and active, they do not hesitate to ask questions in public, and consequently have lots of interactions with their teacher in public. These student-teacher interactions play an important role in the direction the lesson takes. Meanwhile, other regular students tend to listen to the interactions quietly and cooperatively participate in the activities. That is to say, the key students create a class flow and other students follow the flow. In this case, teachers need to win the key students in order to successfully implement communicative FonF teaching.

In this chapter, I will present an analysis of the outcomes from implementing the communicative Fonf activities conducted by the researcher, in particular focusing on students' perspectives; that is, answers to the first and second research questions: 1) what are the students' initial perceptions of classroom communicative FonF activities 
conducted only in English, and 2) how do they respond to the English-only communicative activities?

These perceptions and responses can be manifested in a number of ways:

1) what students state when they are asked;

2) how they come to understand the activities; and

3) how they respond to the activities in terms of their English use, their participation, and their autonomy.

I will divide this chapter into three sections. The first section will focus on students' perceptions of communicative FonF activities, and it will specifically trace the above-mentioned "middle students." What did students think about the class organized with the activities? How did they like the English-only class, and why? Which activity did they like or dislike, and why? Did their perceptions change at the end of the first and second week of the project teaching? The data for this section is retrieved mainly from Student Questionnaire 2 and 3, Student Interview, and the transcription of the 2-week project teaching.

The second section will consist of three sub-sections and examine students' ability to understand the English-only class, first, from students', and then, from teachers' and researcher's point of view. In the first sub-section, students' perceptions of their ability to understand the class will be focused on, looking mainly at Student Questionnaire 2 and 3 and Student Interview. To what extent did students think that they understood the English-only class? What did they think that was useful to understand the class? What did they think they did when they did not understand the class? In the second sub-section, teachers' and researcher's perceptions of students' ability to understand the class will be explored. What did teachers think of in terms of students' understanding of the class? How did students come to understand the class? What did students do when 
they understood and did not understand? What kind of 'form' did students notice? What did teachers see and think of from these students' reactions? In order to reveal answers for these questions, I will not only look at Teacher Questionnaire and Teacher Interview but also analytically examine the classroom interaction, especially between the teacher and key students. The researcher's reflective diary will be also used for analysis.

The third section will illustrate students' English use in the communicative FonF activities involved, which is language outcome from the activities. What kind of English did students use? When did they use it? In order to answer these questions, the data mainly from the classroom interaction will be closely examined.

\subsection{Students' Perceptions of Communicative FonF Activities}

Considering the existence of three types of students, or "excellent, middle, and problematic students" and the different possibilities of changing their perceptions, one of the crucial factors for successful teaching seems to belong to whether or not a teacher can grab the feelings of the "middle students." In this sense, the English-only communicative FonF teaching in the project can be characterized as successful at the initial stage of its implementation; the majority of the students including the "middle students" expressed their favour of the class, and after two weeks. In fact the number of the students who liked the class very much increased.

\subsubsection{Favourable Perceptions}

The students in the project generally stated that they considered the activities as enjoyable, interesting, or at least acceptable. At the same time, they approved the researcher as at least an acceptable teacher. These good impression of the new activities and the new 
teacher led the students perceive the class as favourable although the class, in which they were surrounded by ambiguous information, required students' considerable efforts, concentration, and tolerance.

This favourable perception can be seen in Question 7 in both SQ2, which was carried out at the end of the first communicative week, and SQ3, which was carried out one week later, or at the end of the project. In these questions, students were asked whether they liked the English-only class and to chose one out of four: 'T like it very much, 'I like it,' 'I dislike it,' or 'I hate it very much.' The result is found in Figure 5.1. This figure shows that the total of 'Like very much' and 'Like' accounts for more than $90 \%$ in both questionnaires. This number is much higher than the one for the original regular class (78\%; see Figure 4.4.). This means that the implementation of the communicative Fon $F^{1}$ did successfully draw some students belonging to the third group, in which the perception is changeable, into the first type, as mentioned at the beginning of this section.

Figure 5.1. SQ2 \& SQ3-7

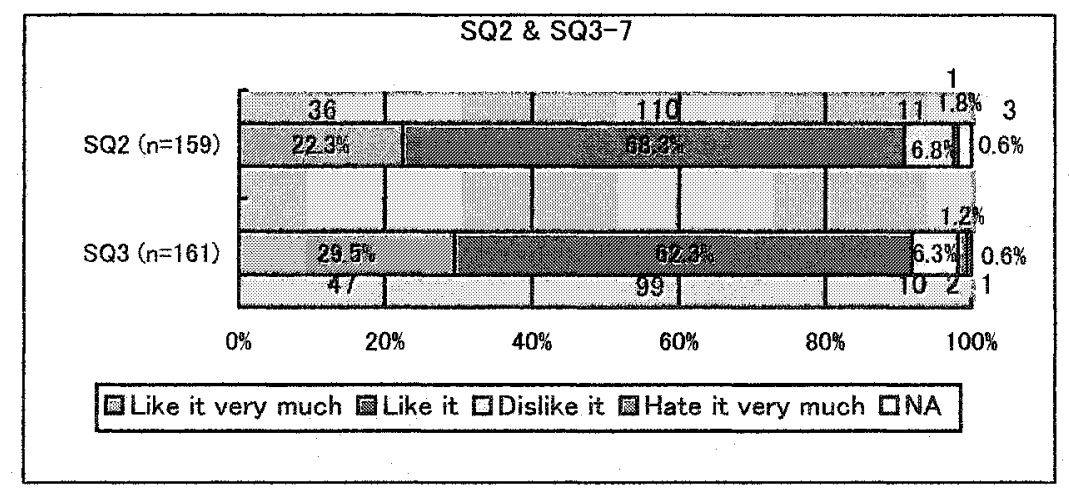

\footnotetext{
${ }^{1}$ The teachers can also be a variable, but it is unlikely to be this case because the difference of the reasons regarding teachers shown between SQ1-5(1) and SQ2/3-7(1) is very small (for the item 'the teacher explains well,' $29.5 \%$ in SQ1-5(1) to $30.3 \%$ for the average of $27.3 \%$ in SQ2 and $33.3 \%$ in SQ3), or even the result in SQ2 and 3 is slightly lower than SQ1 (for the item 'because of the good (funny/kind) teacher,' $50.3 \%$ and $55.9 \%$ in SQ2 and 3 and $56.6 \%$ in SQ1). Or, see other teachers' perceptions of the students' reactions on section 5.2.2.
} 
Comparing each ratio of 'Like very much' and 'Like' between SQ2 and SQ3, it can be seen that the total number of the two items did not change (both $146,90.7 \%$ and 91.9\%) but only the ratio of the two changed; the ratio of 'Like very much' increased from $36(22.3 \%)$ to $47(29.6 \%)$ while the one of 'Like' decreased from $110(68.3 \%)$ to 99 (62.3\%). The reason for this change can be that students' anxiety about the new unfamiliar approach decreased as they became familiar with it. Many students interviewed reported that they were nervous at the beginning of the first project-week, and gradually recovered their composure and came to comfortably participate in the class as they realized that they could understand the class. The followings are the comments from two girls in the Student Interview:

SI3A, June 10:

S: I became able to do something at my ease, for example, when we pronounced words seeing flash cards shown by the teacher.

R: You've hardly said something aloud in class before, have you?

S: I don't mean that. In Miss Toyota's class, which we have had many times, I've been used to it, but I was nervous at first [in the communicative class].

R: I see. Because the teacher was new, you were hesitating, weren't you?

S: Yes, exactly.

SI3A, June 10:

S: Oh, this is a good one. In Karuta, when I was not sure if I was right or not, I did not try at first. But, now, I would pick it up if I thought, "This one!"

R: Then, now you don't care you might be wrong, do you? Didn't you trust your hearing at first?

S: I thought I would be embarrassed if I made a mistake.

R: Now you are confident, aren't you? You can say, "I'm probably right," can't you?

S: Yes, I can. That's right.

Those who chose 'Like very much' or 'Like' were, then, asked its reason/reasons in the following question, SQ2/3-7(1). The result is shown in Figure 5.2. 
Figure 5.2. SQ2 \& SQ3-7(1) ( $n=161$ in $\mathrm{SQ2}, \mathrm{n}=159$ in $\mathrm{SQ3}$ )

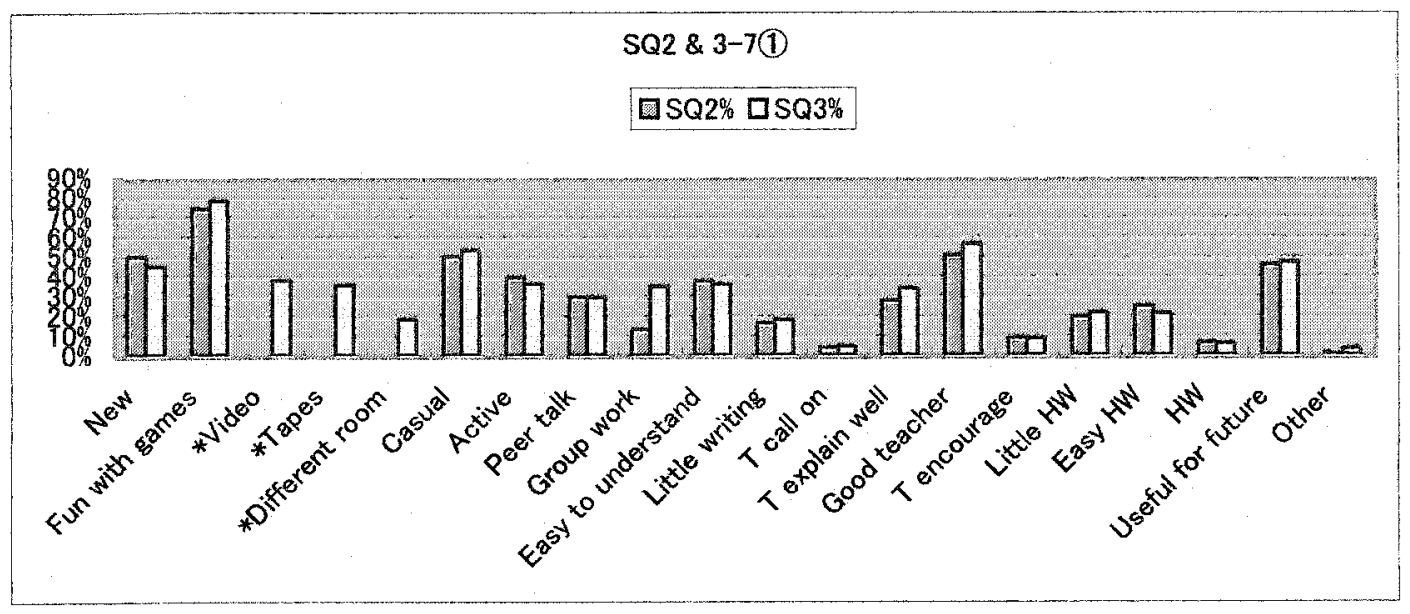

*The items of 'Video,' 'Tapes,' and 'Different Room' were not available in the classes during the first week, therefore, in SQ2.

The most distinguishable item among the reasons that students chose is 'because the class is fun with games.' This means that the most important aspect for a good class to students seems to be whether or not it is fun though that might not be true from a teacher's point of view. This result also confirms that the students accepted the communicative FonF activities as enjoyable as the researcher had intended in designing them. It is also a good sign that relatively a certain measure of students responded in other aspects of the communicative activities such as 'because the class is casual,' 'because I can work actively,' 'because I can talk to peers,' and 'because there is group work' in SQ3.

Another item that should be noted is the second distinguishable reason, that is, 'because the teacher is nice (funny/kind).' This item has nothing to do with the content or quality of the class. Rather, this result can be interpreted as the fact that students need a nice impression of, and then a good relationship with their teacher to consider the class as good. This seems more than other reasons such as 'the teacher explains well' or ' the class is easy to understand,' which are the next leading reasons. The teacher-student relationship will be discussed more in the next chapter. 
Figure 5.3. $\mathrm{SQ2} \& \mathrm{SQ3-6}$

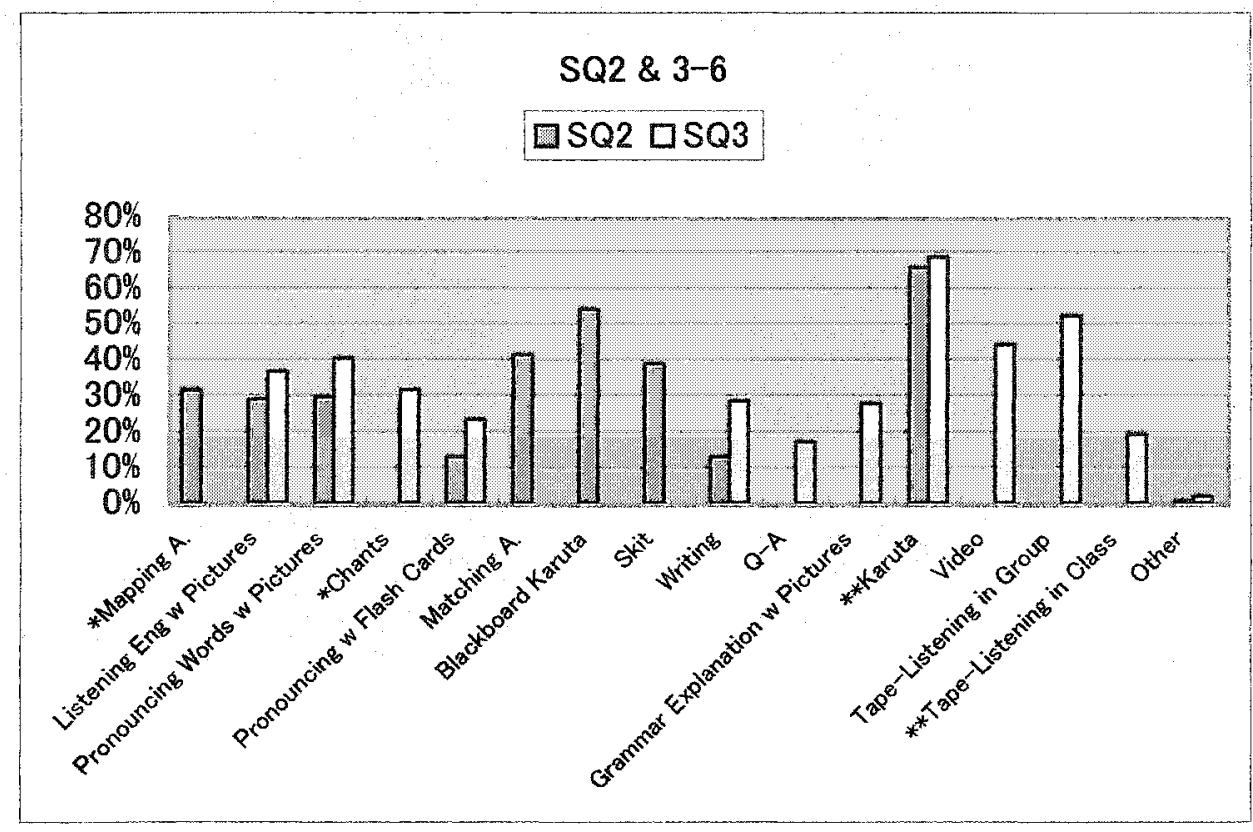

*For the items that has only either of the two categories, SQ2 or SQ3, for example, 'Mapping Activity' or 'Chants,' the activity was not available in class during the week.

**Karuta Activity during the first week was available only in Class 2 ; therefore, the result in $\mathrm{SQ} 2$ is within Class $2(\mathrm{n}=32)$. Likewise Tape-Listening in Class was available in Class 1 and $2(n=63)$.

An item which shows produces a difference between SQ2 and SQ3, is 'because there is lots of group work,' for which the number more than doubles, from $13 \%$ in SQ2 to $35 \%$ in SQ3. During the first week, there was only Matching Activity for which students shortly engaged in pair work; otherwise, the class was addressed mostly in a teacher-centered way although there were lots of classroom interactions between the teacher and students and among students, which students could use for confirmation of meanings. During the second week, on the other hand, the class engaged in group work, such as Karuta and Tape-Listening Activity, most of the time. It is likely to be that, as chances for students to engage in group work increased, more students came to identify group work as a reason for their favourable impression of the class. The reason for this 
can be that students were getting used to group work and became more comfortable with it, and/or simply the activities used in the second week were better and more favourable than the ones in the first week. Indeed, it is seen in SQ2/3-6 that Karuta and Tape-Listening Activity are students' favourite activities (Figure 5.3).

Another example of a favourable impression of an activity is found in a teacher-student interaction after Matching Activity on the first day:

\section{Class2-1-3:}

S: Miss, I've done!

R: Good. Good job. Great. Good. Good. (Checking their cards finished.) Very good. OK. Put them together and put them back in your bag.

S: It's fun, isn't it? This one!!

R: Do you like it? Good.

In sum, over $90 \%$ of the students approved the communicative FonF class, and many of them stated that the reason was that the class was fun with games. In addition, they expressed their favour of the group activities.

\subsubsection{Unfavourable Perceptions}

Meanwhile, of course, there are a few students in each class who do not like the communicative lessons. All the students $(n=19)$ who chose 'Dislike it' or 'Hate it very much' in SQ2 $(n=12)$ and/or SQ3 $(n=12)$ did not originally like English class at school, which is found in SQ1. However, 7 students out of $12(58.3 \%)$ who did not like it in SQ2 improved their perceptions and $5(41.7 \%)$ actually turned into favour in SQ3. This means that the communicative FonF teaching has seemingly "won over" a number of the possibly middle students who changed their perceptions. Even a student who never got up 
from his desk until the "curry trial" moment in the last lesson changed his perception from 'Hate very much' to 'Dislike., 2

Another student, besides choosing 'Not fun' and 'No good teacher,' clearly indicated that he did not like school itself as a reason that he did not like English class at school in SQ1 as follows:

SQ1-5(2):

Cram school is more fun than school. School itself is not fun. Doing anything at school nauseates me.

This student retained his answer 'Dislike' in SQ2, but finally in SQ3, in order to not choose 'Dislike', made a new category for himself: 'Neither like nor dislike'. It is possible to come to the interpretation that the communicative activities contributed to this student's changing his impression of his school English class a little for the better. However, there are many possible factors that might have affected him positively and it is not certain which factor was the major one in his change of mind.

Tatsuya is another example of a student who usually does not participate in classroom activities but did somehow in the communicative FonF activities. In spite of his answer of 'Dislike' the class in SQ3-7 (his perceptions of the class in SQ2-7 is not available because he missed the questions on this page), his response in SQ2-6 indicates that he is in favour of most of the activities except for Matching Activity and writing activities. His curiosity, interests, and willing participation were also seen particularly in Blackboard Karuta Activity for which he was helping the researcher by calling the words out. $^{3}$

2 The "curry trial" was part of Activity 14, Check-it-out Activity, in which the class had a chance to taste green curry paste which was one of the items introduced in the video and the tape in the previous class. More detailed description of this student, Koji, is in section 6.1.1.

3 More detailed description of this student, Tatsuya, is also in section 6.1.1. 
These behaviours of the students who expressed their unfavourable impression of the English class but participated in some of the activities or ultimately changed their minds can be evidence that communicative FonF activities can possibly play a role of a filler of gaps between the motivated "excellent students" and the de-motivated "problematic students." The activities can give a chance to students who tend to be left out in the regular class where they supposedly sit and listen to their teacher quietly because mostly they have a problem to understand and follow the class, by allowing them to easily get help from peers and/or somehow find an alternative way to participate in the class. However, as mentioned in section 3.1.2, these students also tend to have other background problems that may hinder their study. Unless the problems are resolved, it is difficult to expect a dramatic change in the class perceptions and attitude of the "problematic students."

\subsection{Students' Ability to Understand Communicative FonF Activities}

It sounds extremely difficult or even impossible to make complete beginners understand English-only communicative FonF class without any Japanese devices. Probably Japanese English teachers who conduct their class mainly in Japanese may have such concern identifying the beginning level as an impediment to implementation of such class. This had also been the researcher's primary concern before standing in front of the project class for the first time. However, most amazingly, these beginning students could mostly understand and follow the English-only classes with no Japanese. As time went on, although it was only for two weeks, the students came to feel more comfortable with taking the class.

This section will be divided into three sub-sections. Students' ability to understand the classes will be examined from students' perspectives in the first 
sub-section and from teachers/researcher's perspectives in the second. The data from Student Questionnaires 2 and 3 and Interviews for the first and Teacher Questionnaire and Interview for the second sub-section is used. In addition, the third sub-section will take into consideration what kind of strategies and resources students used to reach the understanding. Tracing the processes that the students followed to come to understand the class by revealing their strategies and resources available helps to confirm that they evidently understood the class, rather than assuming that from their self-report. It will also allow teachers to have some ideas for designing such classes and preparing for their implementation. Student Questionnaires 2 and 3, Student Interview, and the class interaction of the project teaching will be used for analysis.

\subsubsection{Students' Perceptions of the Ability to Understand the Class}

About $80 \%$ of the students reported that they understood the class "mostly". It is true that they still had some difficulties to understand English because of a lack of the input experience; however, through the experience of listening to English and gathering some related information from their surroundings, they became more comfortable with English, and the feelings positively affected their perceptions of their ability to understand the class.

In SQ2 and 3-1, students were asked to choose one out of six categories about their perception for the question "Did you understand what the teacher was saying?" The results show that nearly $30 \%$ "understood almost all (80-100\%)," and about $50 \%$ "generally understood it (60-80\%)." The following question 2 , in which students were asked whether they understood what to do in class although they might not have understood some English, reported their slightly better understanding. This is probably because they could use other resources in order to figure out what to do, for example, 
peers' behaviours, the teacher's gestures, pictures, and so forth (see section 5.2.3. for more discussion).

Moreover, as students became used to the class with time, they came to realization that they could understand what the teacher said and what they should do. This can be seen in that the total of those stating that they understood more than $60 \%$ of the class increases in both Question 1 and 2 in SQ3 (Figure 5.4).

Figure 5.4. SQ2 \& 3-1 \& 2

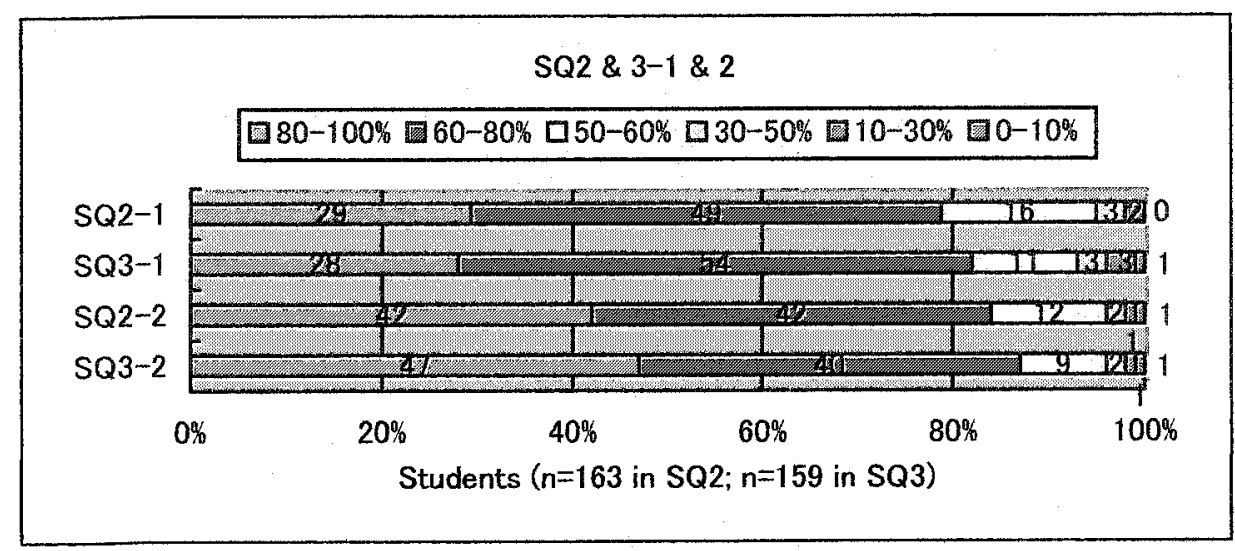

In Student Interview, also, some students reported that they could see their improvement when comparing their very first day and the last day. A student interviewed reported that she understood only $10 \%$ of the class at the beginning and needed friends' help but improved up to around $50 \%$ at the end. However, it is not certain that these students really improved over such a short period as two weeks because their interlanguage was not measured or tested; yet, what is clear is that they feel that they came to understand better over the period. It is assumed that this change in their perceptions may have resulted from both their linguistic experience and psychological change. Since the students had not ever been exposed to so much English input before, they were first shocked with the input; they did not know what to do and even what to try 
to listen to. Another girl from Class 1 reported her panicky feelings in the interview as follows:

SI2A, June 9:

S: First, I didn't understand what you were saying in English at all.

R: Then, what did you think you could do? On the first day, I came up to the class and said, "I'm going to use only English from today." What did you think?

S: I panicked thinking, "What the heck is she talking about? Did she say that she was going to teach only in English?" I was being really panicky myself. I was expecting you'd use a little bit Japanese too, but you didn't. Everything started in English. Ehhhhh!!! I've got into a panic.

However, she recovered her emotional stability as she participated in activities even on the first day. She continued:

SI2A, June 9, continued:

R: You didn't understand me, and then what did you do?

S: Then, I was just listening to you, and asked my friend, like "What did she say for "eraser" in English?" And, as listening to you pronouncing words, gradually I came to understand.

R: When did you begin to understand?

S: Probably around when we practice pronouncing words looking at pictures.

$\mathrm{R}$ : On the first day?

S: Right.

R: Wow, that's pretty fast. Weren't you panicky any more?

S: No. I realized I could understand you somehow. I was relieved.

As time passed, it is seemed that her aural function had to be tuned to the English input and her emotional stability helped her concentrate on listening in comfort.

Within the new teaching style or new learning environment in which there was only limited amount of language understandable and the students were required to use other strategies or sources such as peers and pictures, first, they did feel uncomfortable or 
uneasy. However, they seemed to adapt in an amazingly short time, and began to understand the class almost by "trial and error." At the same time, they developed the perceptions that they could "understand the class."

\subsubsection{Teachers' Perceptions of Students' Ability to Understand the Class}

In general, all six teachers participated in the project indicated that they were favourably impressed by the communicative FonF class and students' responses in the class. ${ }^{4}$ This result is shown in the responses to Teacher Questionnaire (TQ), administered after observing the project class. Five of them stated that they strongly agreed and one stated that she tended to agree with continuing this teaching approach in TQ-2.

Table 5.1. TQ-1

\begin{tabular}{|l|c|}
\hline The impressions of the class; I think that the class: & Number \\
\hline A. looks easy for students to get familiar with. & 6 \\
\hline B. looks easy for students to understand. & 4 \\
\hline C. is good because it is taking a participatory style. & 6 \\
\hline D. is good because it is what the new national curriculum is requiring. & 2 \\
\hline E. seems to prepare students for entrance examinations. & 2 \\
\hline F. seems to foster students' conversation competence for their future. & 6 \\
\hline G. is too casual. & 0 \\
\hline H. has a lack of seriousness. & 0 \\
\hline I. is noisy, and I'm afraid that it may bother other classes. & 0 \\
\hline J. does not seem to make students understand well enough. & 0 \\
\hline K. may not foster students' communicative competence. & 0 \\
\hline L. may not prepare students for entrance examinations. & 1 \\
\hline M. Other (specify) & 0 \\
\hline
\end{tabular}

${ }^{4}$ Note that all these teachers are progressive (see section 3.1.2.). 
In TQ-1, the teachers were asked about their impression of the class organized with communicative activities and conducted only in English (Table 5.1.). All impressions they chose were positive except for one who pointed out its uncertainty of effectiveness on entrance examinations. All the teachers admitted some of the characteristics of the class such as its familiarity and participatory style as well as its focus on fostering communicative competence. Another noticeable point in the responses is that 4 out of 6 consider the class easy for students to understand. This teachers' perception of students' ability to understand the class is confirmed in other questions such as TQ-4 and 7.

In TQ-4, which asked about students' reactions, three teachers stated that the students' reactions were very good and the other three stated good. The leading reasons for this impression are "the activities were enjoyable themselves" (for 5 teachers) and "the activities were clear" (for 4) whereas only one teacher for each chose the other three reasons: "the examples used were good," "the explanations and instructions were clear so that students could understand well," and "students were well motivated." This means that it is thought that the students' good reactions in the class are derived from the quality or characteristics of the activities used, but not variables in teacher or students' quality. In TQ-7, which asked teachers to what extent they think students understood teacher's instruction and what to do in class, it is also reported that three teachers had an impression that students seemed to "generally understand the class $(60-80 \%)$ ", and the other three had an impression that students seemed to "understand almost all (80-100\%)."

The male English teacher (ET) participated expressed his impression of the students' ability to understand the class as follows:

\section{TI1B, June 13:}

ET: Generally, the students were working really hard, I guess. I was impressed that they could understand even a difficult expression from a classroom flow. 
They can go with it. For example, when you said, "Today what we're going to do is play Karuta", none of the grammatical features or sentence structures used is what they've already learnt. But, some student responded to you in Japanese, "Wow, really? Can we play Karuta?" I was sort of shocked.

Toyota also confirmed that most of the students understood what to do in the class. She said that even when the researcher gave instructions for a game to students, which required them to understand a whole long process of the game, although some needed time to come to understand, they eventually came to understand what to do with supportive resources such as teacher's gestures, demonstration, and pictures. She exemplified instructions for Blackboard Karuta and claimed that there was no panic, no uncertainty or students who did not know what to do in terms of the rule.

These teachers' perceptions of the students' ability to understand the class agree with the students' perceptions of their own ability, which was discussed in the previous section. That is to say, most of the students, but not all, seem to have understood at least $60 \%$ of the class.

\subsubsection{Strategies and Resources Used to Understand the Class}

Keller-Cohen (1981) categorized the resources that child L2 learners may use to arrive at an interpretation into following: 1) general knowledge about the world; 2) contextual cues; 3) previously acquired linguistic generalizations. Among these three resources, Keller-Cohen argues, 'young children frequently have been found to rely on their knowledge of the world to interpret others' speech' (p.95).

However, in the classroom situation under study, it seemed that, although students use all of these, they seemed to use contextual cues more than world knowledge and linguistic background. The reason for this is related to social processes in the 
classroom, and the existence of "key influential students" noted earlier in this chapter. These key students can be described as those who tend to have lots of curiosity about something new or uncertain, be sensitive to contextual cues, guess for a connection from the cues to their world knowledge and what they need in order to understand the class. However, there is an additional important characteristic: they do not hesitate out of fear of making a mistake. Therefore, they often speak up and ask questions about whatever they are uncertain of or whatever connects to the world knowledge or to the cues that popped up in their mind. Their guess can be sometimes wrong, but since they do not care about being wrong, they can ask for clarification in public one after another, and eventually succeed to reach a certain understanding. They play a role of actively creating the class flow and leading the class to understand the teacher. The connection in their mind might be totally irrelevant to teacher's intention and sometimes interrupt the class flow, but most of the time it also contributes to the other regular students' process of reaching understanding.

Most students, on the other hand, usually neither ask a question to a teacher nor speak up in public; instead, they keep quiet and think about uncertain points by themselves, and, if they cannot find an answer, then they may go see the teacher to ask the question in person. They play a role in keeping the class calm and smooth, and collaborate in the progress of the lesson by not interrupting the flow.

In the communicative class, the key students are more actively involved in the classroom interaction than in a regular class where they must maintain a quieter presence. As a result, their interactions allow the other students to have access to many more contextual cues. In other words, the existence of the key students becomes part of the contextual "cue-making" for the other students. The regular students can see and listen to 
the key students' process of clarifying meanings, and reflect it on their own process of reaching understanding.

In this sub-section, I will focus on the resources students used to reach an interpretation or understanding, including the key students. What did they do when they did not understand something in the class? How did they arrive at an interpretation? What kinds of resources did they use in order to arrive at the interpretation? Pondering over these questions, the researcher carefully examined and compared the data from the classroom interaction and SI and attained four categories of the resources used, which were adapted from the Keller-Cohen's (1981) as mentioned above. The categories are: 1) students' own world knowledge and contextual cues; 2) students' prior linguistic experience, which is related to katakana, Japanese loan words, or one of three writing systems, in Japanese students' case; 3) key students; and 4) explicit form instruction. Since it is thought that the existence of the key students has one of major influences on students' ability to understand the communicative class through providing contextual cues, I will nevertheless deal with this category separately.

Before focusing on each of the specific resources students used to understand the communicative class, I will start with looking at general strategies used to understand the class, by examining the data from SQ2 and 3 and SI.

\section{(1) Strategies Used to Understand the Class}

SQ2-3 and SQ3-3 reveal that students used multi-strategies when they did not understand the English-only class (Table 5.2). On the average, they used more than two strategies (2.03 in SQ2 and 2.49 in SQ3). It is seen in these means that as time went by, students came to use more strategies in order to understand the class. This is also seen in that the number in all the strategies, except for 'I asked in English,' increased in SQ3. 
Table 5.2. SQ2 \& SQ3-3

$$
\text { ( } \mathrm{n}=163 \text { in } \mathrm{SQ} 2, \mathrm{n}=159 \text { in } \mathrm{SQ} 3 \text { ) }
$$

\begin{tabular}{|l|r|r|}
\hline Strategies used when you did not understand something; you: & SQ2(\%) & SQ3(\%) \\
\hline Carefully listened to teacher's English. & $71(44)$ & $75(47)$ \\
\hline Asked the teacher in English. & $2(1)$ & $1(1)$ \\
\hline Asked the teacher in Japanese. & $61(37)$ & $72(45)$ \\
\hline Asked peers. & $96(59)$ & $111(70)$ \\
\hline Watched what other peers were doing. & $53(33)$ & $78(49)$ \\
\hline Guessed by myself. & $37(23)$ & $50(31)$ \\
\hline Left it unsolved. & $7(4)$ & $7(4)$ \\
\hline Other (specify: Slept, Watched teacher's actions) & $4(2)$ & $2(1)$ \\
\hline
\end{tabular}

A close analysis of the strategies in Table 5.2. produces three interesting conclusions. The first is that, in the communicative class, that students seemed to interact more than in their regular class. Second, it seems that they focused more on the context for meanings than in their regular class. Third, they seemed to listen more carefully to the teacher more than in their regular class.

First, 'I asked peers' is the most popular strategy in both the questionnaires. The reason for this can be thought that asking peers is a handy and less stressful way of finding out prompt answers. It is assumed because the longer students engage in group/pair work, which is one of the design characteristics for the communicative FonF class, the more easily and the more chances students have to clarify and confirm uncertain points with peers. Second, the strategy 'I watched what other peers were doing' dramatically increased, from $53(33 \%)$ to $78(49 \%)$ in the second week. It is evidence that students started searching for any useful information contextualized in the class in order to understand what they had heard. Behind this increase, there could be an influence by key students, as noted above, because 'other peers' can refer to the key students. I will come back to this second point in the following sub-section. Third, impressively, many 
students consistently chose 'I carefully listened to teacher's English' (71 (44\%) in SQ2 and $75(47 \%)$ in SQ3). This can be taken as evidence that students' impatience to understand the class positively affected their classroom attitude. It is assumed that the fact that they could not rely on Japanese to figure out what to do motivated them to pay more attention to listening. This requirement for attention is argued as essential for learning by Schmidt (1990). Some of the students interviewed clearly stated the change of their attitude as well. The following is one of them:

\section{SI2A, June 9:}

S: Because Miss Toyota says in English and after that makes up for meaning in Japanese, I've never understood English itself relying on the Japanese. And in Miss Honda's class, which was conducted only in English, I could practice listening. And after listening, I could ask questions about what I couldn't understand. $\cdots$ [omission] $\cdots$

R: Do you mean that you are listening to this class more carefully than the former class?

S: Yes. When I was half-hearted, I came to not understand at all. In the first class, I first asked a friend of mine about what I didn't understand. And then, she said she didn't understand either, so I thought, "Oh, my...I should really buckle down to this, otherwise I will get lost." That's why I was super concentrating my attention on listening.

This example from SI and the responses in SQ discussed above show that students come to use multiple strategies to clarify uncertainty in the communicative FonF class. For example, students more often interact with peers even in Japanese, by asking questions about what are not clear, more carefully observe what peers are doing, and try to concentrate harder on listening to English uttered by the teacher in order to reach an interpretation of, and hopefully understand the class. 


\section{(2) Resources Used to Understand the Class}

The data presented in the previous sub-section confirmed that students used multiple strategies to understand the English-only communicative class; yet, it is not enough to find what kind of cues students were looking for. In other words, questions still remain: what resources did students use to understand the communicative FonF class and when and how did they use them? More specifically, in students' interaction, what specific points did students ask each other? Did they successfully clarify the points? If so, how? In observing peers, what kinds of cues did they particularly look for? Who were observed? In concentrating on teacher's talk, what specific cues did they look for? Which part of the teacher's talk was helpful for students to clarify uncertainty? In order to discover answers to these questions, the focus of discussion will move onto resources students used by analyzing the videotaped classroom interaction as well as SI and TI in the following sub-section. This sub-section will be divided into four.

\section{1) Use of Own World Knowledge and Contextual Cues}

There is lots of obvious evidence in the classroom interaction that students use both the knowledge about the world and context-embedded cues, especially visual cues as resources with which they can manage to interpret what the teacher says in English into something that makes sense to them.

The researcher started the first class with Vocabulary-Building Activity by picking up things that students could see around in their daily school life and asking names of the things as Krashen (1980) suggests as the 'here and now' principle (p. 172). After greeting, to present the topic "school" for the series of the communicative FonF 
class, the researcher first showed a picture of a school to the class, and started the totally English-only class as follows:

Class2-1-3:

R: Today we're going to study this one (holding a picture of 'school'). What's this?

These sentences did not contain words that students had already learnt in school; however, surprisingly, the right answer to the question emerged from several students, in either Japanese or even English. As soon as the picture was held up, a key student in this class said, "School!" in Japanese and several others, who might attend to cram school and know the English word, said, "School!" in English. However, none was likely to know the interrogative sentence used; even for those who attended cram school the sentence structure was more advanced. It was supposed to be taught much later - 19-pages ahead in the prescribed textbook. For this reason, it is assumed that the students got the right answer not because they understood what the interrogative sentence actually meant, rather because they reflexively uttered what popped up in their mind with the sight of the picture. In this case, students used a visual cue, that is, the picture describing an object called 'school' in Japanese, as well as the knowledge about the world, that is, the picture shown in class must have been related to what the teacher wanted to tell them. However, they probably had not yet established a connection between the picture and the teacher's utterance of the interrogative "What is this?" To these students' accidental correct answer, the researcher replied with positive evaluative words and repetitive use of the word 'school':

Class2-1-3:

R: Yes. 'School.' You know 'school.' Good. This is a school (pointing at the picture).

This is your school (pointing at the classroom where they were).

S: Yes. 

$\mathrm{R}:$ This is our school.
S: Yes.

After this first example, Vocabulary-Building Activity continued in the same pattern: 1) the researcher showed a picture or pointed at something in the classroom and asked for the name, 2) students replied with a Japanese/English word describing the picture, and 3) the researcher evaluated or repeated the English word. For items that the students had already learnt, many students replied in English in chorus while for unfamiliar items few students, mostly the "key students," replied in Japanese.

\title{
Class2-1-3:
}
$\mathrm{R}$ : What's this? (pointing at a desk.)
$\mathrm{S}: \mathrm{Ah}$, 'desk,' isn't it? 'Desk' (in Japanese).
R: Yes, 'desk.' 'Desk.' What's this? (picking up a notebook.)
SS: 'Notebook' (in English).

\begin{abstract}
As the Activity went on (it lasted for about 8 minutes), the more students gradually came to participate in the interaction with the researcher. At the same time, new knowledge about the world was established as a classroom habit in which whenever the researcher showed a picture or an object, she wanted to know a name of the object, and then, students would reply.
\end{abstract}

When a vocabulary item was abstract, rather than a name of a concrete object, it became obvious that students used the knowledge about the world more. To introduce and help to establish the abstract concept of a word 'friend,' the researcher used three sets of cartoon character pictures and a mascot from a TV talk show that everybody knew as follows:

\section{Class2-1-3:}

$\mathrm{R}$ : And, do you know who this is? (holding a picture of a cartoon character.)

SS: Maruko! 
S: Maruko. You're good at drawing.

R: And? (holding another picture.)

SS: (Laughing) Maruo!!

S: A good one.

R: Maruo is Maruko's friend. 'Friend.'

S: 'Friend'? I don't think so.

S: Miss, how about Miss Noguchi? ${ }^{5}$

R: Oh, sorry. I don thave Miss Noguchi. I just have Maruo and Maruko. Maruko is Maruo's friend. Maruo is Maruko's friend. Who is this? (holding another picture.)

S: 'Dog.'

S: 'Dog.'

SS: Shiro! Shiro! ${ }^{6}$

R: Yes!! That's right. Shiro. Do you know Shiro?

S: Shin-chan's dog.

R: Yes. Shiro is Shinnosuke's friend.

S: "furendo"?

R: Shinnosuke's friend. Do you know this? (holding another picture.)

SS: Hahahhah, Sanma's!! Mamma.

R: Yes, Manma. Manma is Sanma's...

SS: 'Friend.'

In order to understand what the researcher was trying to say with the pictures of the cartoon characters or the mascot, students needed to use the knowledge of the world (or in this case of their own culture), which was, in this case, "Maruko and Maruo are friends.' Toyota also mentioned this point by exemplifying other cartoon characters used in the Chants Activity in TI:

TI1B, June 13:

T: Students realized, "Oh, friend", didn't they? That was not through Japanese translation 'friend,' but a concept that 'Doraemon's friend is Nobita.'

$\mathrm{R}$ : I think it is challenging to introduce such abstract things that I cannot describe in a picture, or that doesn't directly help a word that popped up even if I could.

${ }^{5}$ Miss Noguchi is another friend of Maruko in the cartoon.

${ }^{6}$ Shiro is a dog's name in another famous cartoon in which Shinnosuke or Shin-chan is staring as well. 
T: But, then, when they saw a picture and wondered "Look! I don't understand what this is," they were extremely concentrating on listening. They should've known that the teacher didn't want to say 'Nobita' as a new word. Then, what does she want to say with this? They seemed to be interested in finding out what this was. That was different than seeing a picture of 'school' and saying 'school.' There was a question in seeing a picture of Nobita. That's why they came to try to listen, or they were longing for the answer.

What Toyota is saying here is that students tried to make a bridge from what they see to what they heard in English with what they have already had, that is to say, their knowledge of the world, but they do not know which part of the knowledge is necessary. In the process of succeeding in this task, they tend to pay attention to listening, and finally realize which part of the knowledge they need, that is, the concept of 'friend.' In other words, this kind of activity which requires students' knowledge about the world can promote students' concentration and motivation.

After these three examples with a use of pictures and the underlying knowledge about the world, the researcher used the classroom context to confirm the concept of 'friend' that the students had just established; she asked a question about their friend to ten individuals:

\section{Class2-1-3:}

R: You...Naoya? Naoya, is Akira your friend?

Naoya: Yes.

Some of the questions were expecting a negative answer as well:

\section{Class2-1-3:}

R: Kyoko. Miss Honda...

SS: No, no, no!

R: Is Miss Honda your friend?

Kyoko: No.

SS: (Laughing.) 
Since the individuals asked could answer and the class could react with a Yes/No answer correctly, rather than pretending they had understood the question and mimicking the answer 'Yes,' it was confirmed that they had established the concept of 'friend' and came to understand the question.

With respect to contextual cues, students relied on non-linguistic visual resources such as the researcher's gesture and demonstration, a map, the video shown in the fifth lesson, the skit played by classmates, the situation immediately before, as well as pictures. In particular, the pictures and the video were recognized by students as very helpful resources to understand the class in SQ2 \& 3-4 (Table 5.3).

Table 5.3. SQ2 \& SQ3-4

$(\mathrm{n}=163$ in SQ2, $\mathrm{n}=159$ in SQ3)

\begin{tabular}{|l|r|r|}
\hline Which is helpful to easily understand the class? & SQ2(\%) & SQ3(\%) \\
\hline Teacher's English & $64(39)$ & $72(45)$ \\
\hline Pictures shown by teacher & $124(76)$ & $128(81)$ \\
\hline Word cards (Flash cards) & $77(47)$ & $97(61)$ \\
\hline Talk with neighbours or peers in a group & $41(25)$ & $56(35)$ \\
\hline Games & $91(56)$ & $110(69)$ \\
\hline Video & NA & $81(51)$ \\
\hline Tapes & NA & $70(44)$ \\
\hline Other (Specify: Handout, Skit, None) & $2(1)$ & $13(8)$ \\
\hline
\end{tabular}

The following is an example for which students used the teacher's gesture as a resource to understand instructions with an unfamiliar phrase or word: 


\section{Class4-1-3:}

R: OK. Let's say English together. Say (with a gesture of 'something coming out of the mouth') English together (with a gesture of 'inviting all'). Please repeat after me. 'Pen.' Say (with the gesture).

SS: Pen.

R: Good. 'Pen, 'say.

SS: Pen.

When the researcher used the same gesture to make sure about the meaning of the instruction in the second lesson, it became obvious that the students had understood from an aside made by a student:

\section{Class4-2-6:}

R: 'Say.' 'Say' (with the gesture of 'coming out of the mouth').

S: (To a peer) We have understood it, haven't we?

For more complicated instructions, the researcher demonstrated what students should do by inviting a few demonstrative students to the front of the classroom and giving them step-by-step instructions of what to do as well as gestures. The following is one of such instructions for Matching Activity:

\section{Class2-1-3:}

R: Now, I will give you a small bag, a small envelope (showing an envelope for the activity). In this bag, you can see many cards (showing some cards) and pictures (showing some pictures out of the envelope). All right? Put together, pictures and cards (showing to put them together from apart). Put them together. All right?

SA: Do you mean to put them together?

SB: To match them?

$\mathrm{R}$ : Yes, that's right. For example, let's see... Where is the card? OK. 'School' (holding up a flash card 'school'). Ryuta, put this with a picture. Put them together (pointing at pictures posted on the blackboard). Where is a picture for this?

Ryuta: Eh? Should I go?

R: Yes. Go put together. 
Ryuta: (Walked to the blackboard and posted the flash card beside the picture card 'school.')

R: Yes, great! Good! 'Pencil.' Where is 'pencil'? (handing the flash card 'pencil' to another student.)

S: (Walked to the blackboard and posted the card on the picture 'pencil.')

R: Yes, that's great. Good, good! Very good. Like this, you can do this with your cards and pictures in this envelope. OK?

This evidence for students' understanding from the resources such as gestures and pictures can be found in SI as well. One of them is about the instruction for homework as follows:

SI2A, June 9:

SA: I can understand almost all, for example, what you are saying about homework. SB: Oh, yes. About homework, I can understand quite well because you showed the handout to us pointing and saying something like "Until here!"

SA: All of us understood that pretty well, didn't we? Homework, isn't it? It means 'do it at home,'

Another group also said:

SI3A, June 10:

R: How about the homework we did on the very first day? Did you understand what to do for your homework?

SC: I did. You drew a picture of a house on the blackboard. That helped.

SD: I understood it because you did all different things with your hands.

Moreover, students constantly look for any useful information available and embedded in the classroom situation where they are, especially in what has happened before. A good example for this is the situation in which the class was using picture cards posted on the blackboard but the wind blew them out several times. The researcher asked a student beside the window to close it: 


\section{Class3-3-6:}

R: Oh, Nao, could you close the window, please? (pointing at the window.) Nao: (Closed the window.)

It is not likely that Nao understood the researcher's English except for 'window' that the class had been learning in several previous activities. Even to the word 'window,' it is not certain whether Nao had had enough exposure since he skipped the first class and a half of the second and never did his homework. Yet, it seems that he understood the researcher's request from the gesture of pointing at the window and the situation in which many picture cards were blown out before. ${ }^{7}$

When the situation is more urgent to students, they are likely to understand English used better. Their reaction toward the phrase "Are you ready?" is an example for this. The phrase was used at least six times in Blackboard Karuta at the first time, for which only a few students in each turn answered with yes/no. For the second time, the phrase was used in starting Karuta Activity. After desks were arranged into groups of six, and a set of cards was handed to each group. The researcher was about to start to explain the rules of the game, but the students seem to have misunderstood thinking that the researcher was going to start the game, and several students immediately replied even in English, "No, no, no." After the explanation of the rules, when the students were getting impatient to start the game, they then reacted correctly and promptly in English:

\section{Class 1-4-4:}

SA: Now, please start!

R: $O K$. Ready?

SB: Yes!

R: Are you ready?

SS: Yes!!

\footnotetext{
7 More descriptions of Nao are in the section 5.3.2.
} 
Another example of students understanding better in an urgent situation happened when the researcher offered a taste of Thai curry paste in the last sixth lesson. The students seemed to sense what the researcher said from the whole context.

Class1-6-4:

R: Would you like to try? This is Thai curry. Thai green curry (showing the container to the class).

S: Miss, where did you bring it?

R: From Canada. (Opened the container.) Do you want to try?

S: Yes.

$\mathrm{R}$ : Who wants to try it? (holding up a spoon with the curry paste.)

SS: Yes. Yes. (Many students raised their hand.)

In this case, the researcher's interrogative sentence included no word that had already been learnt. Nonetheless, most of the students could understand it and resulted in the action of raising their hand. It is assumed that they exploited all the contextual cues including the researcher's gestures, things shown, and the situation such as the class flow and what they had just done before.

\section{2) Use of Prior Linguistic Experience}

Although students are considered almost complete beginners of English, in fact, they already know a large number of English vocabulary items but as Japanese words through the writing system of katakana. However it is a distorted knowledge of English.

Katakana is one of three Japanese writing systems and is used mainly for loan words from abroad. It is phonogram and does not describe meaning like Chinese characters do. There are 71 katakana letters which consist of a combination one consonant and one vowel. That is to say, a katakana letter always contains one syllable. This makes a problem to convert a foreign word including a consonant-only sound into 
katakana. For example, the word 'basketball' with three syllables is described as a six-syllable katakana バスケットボール “basukettobohru”, and the accent is on 'e' instead of the first 'a.' Another problem is also seen in this example; some consonants such as "1" in 'basketball' do not exist in Japanese language. To compensate these missing sounds, similar sounds are replacing, such as " $r$ " for "l" or " $\mathrm{s}$ " for "th." When this sport 'basketball' was introduced to Japan, the name of the sport was also adapted in katakana instead of translating it into Japanese. Numerous loan words are similarly used with Japanese pronunciation as Japanese.

In the project class, it was found that students' knowledge of katakana could both positively and negatively influence on their ability to understand the communicative English-only class. The positive influence is, of course, that the knowledge of katakana facilitates them to understand the researcher's utterances including original English words of such loan words. Meanwhile, the negative influence is that katakana confuses students because of its different pronunciation. In this sub-section, I will discuss the facilitative role and confusion of katakana based on the classroom interaction and Student Interview.

It is not merely an exaggeration but true that the Japanese society is inundated with loan words. This social phenomenon is seen in examining the compulsory words for junior high school students. Among the basic compulsory words, in particular, at the beginning level, there are lots of words which have already been familiar to students as katakana. Out of the 16 vocabulary items to be taught in the project (see Table 3.1. in section 3.1.3.), 10 are used as katakana in the daily life. ${ }^{8}$ Besides these compulsory words,

\footnotetext{
8 However, all of these 10 English words can also be translated into purer Japanese or more common version to use, other than loan words, since there have originally been existing these items in Japan before loan words were introduced.
} 
there are many katakana words derived from English, which helps students interpret English they have heard.

One of good examples that katakana plays a facilitative role in students understanding the English-only class is seen in the researcher's instruction as follows:

Class4-2-6:

R: Put the paper in your file.

S: "Fairu"?

R: Yes, 'file.' Put this paper in your file. Do you have a file?

S: (Pulled his file out of the desk and bound the handout in.)

R: Good. Very good.

In this case, it is seemed that the student identified the word "file" as "fairu" in katakana and consequently understood what the researcher was requesting him. Japanese people usually use the katakana word "fairu" for 'file,' and other than the word, there is no Japanese word describing the item.

There is another example that many katakana words are commonly used in the daily life and can play a facilitative role in understanding the class. It is found in Tape-Listening Activity. In this example case, six students in a group are working on the tape about a girl from Africa.

Class1-5-2:

SA: "amerika"? (for 'America')

SB: "afurika" (for 'Africa'), isn't it?

SA: "afurika"? I though "amerika."

SB: Let's listen once more. (replayed the tape again.) How can I write "afurika"?

SC: She said, "keiki" (for 'cake') and then said, "appuru pai" (for 'apple pie'), didn't she?

SB: I've just got "appuru pai." 
These English vocabulary items such as America, Africa, cake, and apple pie are all ones students have already known as katakana words and there is no pure Japanese word describing such things. That allows the students easily dictate the words and grab a general idea of what they heard. Besides these words, there were lots of new English vocabulary items in the Listening-Tape Activity from which students could predict the meaning due to the knowledge of katakana. The vocabulary includes 'fishing, poodle, cute, boy, nurse, doctor, China, dress, nice, curry, and green.' For most of these words there is also pure Japanese word besides the loan word; Japanese people use either the Japanese word or the loan word according to circumstances. In this case, students still easily find out a connection from an English word they have heard to a katakana word, and then to a Japanese word even though they pronounce the English word just like katakana. The following is such a case in which students succeeded to make the connection in their mind:

Class5-2-19:

R: What's this? (showing a picture of a ticket.)

SS: Ticket. "Chiketto." Ticket.

R: Yes! Yes! 'Ticket.'

SS: "Chiket."

Regardless of existence of a pure Japanese word for katakana, the prior knowledge of katakana definitely facilitates students to understand and establish a concept or meaning of new English vocabulary.

In the meantime, the knowledge of katakana sometimes causes students' minor confusion. There are two types of confusion found in the project, relating to different pronunciation between katakana and English words. One is in understanding the meaning

\footnotetext{
${ }^{9}$ Note that this is the second lesson in this class, but it is the first time to introduce new vocabulary items including this word 'ticket' since the first lesson was 20-minute long or so.
} 
of English and the other is in describing English in katakana. When the pronunciation of katakana greatly differs from the original English word, students sometimes have a trouble with making a connection between the English word and the knowledge of katakana. The following is a classroom interaction in Tape-Listening Activity, in which students are trying to dictate an English name 'Peter':

Class3-6-1:

$\mathrm{R}:$ What's his name?

SA: "Piro"? (mimicking the sound as he heard.)

R: Yes. 'Peter.' No. 1 [in the handout] is 'Peter.'

SB: It's not "Piro."

R: P-E-T-E-R. Yes. For No. 1, 'Peter.'

SA: Do I write this in English?

R: Yes.

SA: Can I write "Piro" [in katakana]?

R: That's OK too, but ...

SA: Should I write it in English?

R: Yes, that's right.

SA: (writing in English.)

R: Good. 'Peter. ' (To the class) If you say it in Japanese, you can say "pi:ta:", but that's Japanese. In English, you have to say 'Peter.' In English, his name is 'Peter.'

SA: Is that "Pi:ta:"? This is not "Piro," is it?

After this whole conversation, SA still remains confused; in his process of interpreting the English name, it is assumed that the sound 'Peter' he heard has not yet been connected to katakana "Pi:ta:". There has been a concept of the name in katakana in the student's mind, that is, "Pi:ta:" is an English male name, but he cannot consider "Pi:ta:" and 'Peter" as the same concept because they sound very different.

For the words with a consonant final such as 'south' and 'Liz', students also had a trouble with understanding. 'South' is described and pronounced as "sausu" and 'Liz' as "Rizu" in katakana. So, it would be hard to catch a final consonant without a 
vowel, and as a consequence, students failed to connect "sau" without "su" or "th" to the concept of "sausu" as a direction and "Ri" without "zu" or ' $z$ ' to the concept of "Rizu" as a female name.

Another example for students' confusion in identifying a concept of an English word occurred when there were more than two concepts for the word and students did not know either necessary in the situation. For example, the word 'green' has at least two concepts: a colour and a family name if started with a capital letter. To students, katakana "guri:n" is familiar as a colour while there is not a family name 'green' in Japanese and they seldom have a chance to hear foreigner's family name 'Green' in their daily life, whether in katakana "guri:n" or English 'Green' (although the pronunciations of katakana and English are similar in this case). For this reason, there was confusion relating to 'green' among the students when they were engaging in Karuta Activity, in which the researcher read aloud a sentence for a card:

\section{Class2-4-1:}

R: That's Ms. Green's pen.

SS: "guri:n"?

S: We don't have a green pen.

The picture card supposedly to be picked was of a pen with the possessor's name 'Green' on, but the one the students were looking for was of a green-coloured pen. They did neither have a concept of 'Green' as a name nor were they familiar to the title 'Ms.' which might have been able to lead them to notice the concept that 'Green' must be a name.

As seen in these examples, when English sounds quite different from its equivalent katakana, or when students have not had a necessary concept for the English word rather than one from katakana, the students need to clarify whether the English 
word they have just heard really means the katakana they can possibly think about from the English sound.

The other type of confusion is found when students attempt to put an English word in katakana writing. Since they had not yet learnt many English words, the reseacher often allowed students write in katakana if they did not know the spelling. In this way, students could at least keep a record what they heard and understood even though they did not know how to write it in English. However, because there are less vowels and consonants in Japanese language than in English and for even some of the Japanese sounds considered the same as English are pronounced with less stress, students have a trouble with describing English words in Japanese katakana. Some students claimed this trouble in the group work involved in Tape-Listening Activity:

Class3-6-1:

SS: 'Mitzie.'

SA: Eh? (replayed the tape.)

SA\&SB: 'Mitzie.' 'Mitzie', isn't it?

SC: 'Netzie'?

SD: It sounds like "ne."

SE: Mitzie. Should be OK even if we got wrong.

SB: Mitzie, Mitzie, sounds strange.

SA: Sounds strange (replayed the tape).

SS: Sounds like 'Mitzie' to me.

SA: A bit different one from "ne"...

SB: But it's got strange if we write in katakana.

SA: 'Nitzie, Nitzie.' I gave up!

As observed in the project, students' knowledge of katakana can cause confusion in some cases of understanding and describing English words. Nevertheless, compared to benefits students can obtain from the knowledge, the confusion is a trifle. 
The English-only communicative class can be made much more understandable with the utilization of the students' prior linguistic knowledge.

\section{3) Use of Key Students}

Every class usually includes a few key students as mentioned at the beginning of this chapter and the second section. It was observed in the original English classes that these students were very energetic and sometimes misbehaved as they chatted to neighbours; they were too energetic to concentrate on just the class and to keep quiet and sit still without any movement.

In the communicative class, on the contrary, the energy of the key students can be utilized to lead not only them but also other classmates to better understand the class. These students can release their energy in taking part in activities and their curiosity in asking questions in public to clarify uncertain points without hesitations that others have. Needless to say, the key students also use all different kinds of information available such as the knowledge about the world and contextual cues discussed in previous sub-sections and teacher's explicit instruction in the following sub-sections in order to arrive at an interpretation. However, the most different point between the key students and the other regular students is that the key students make approaches to clarifications or confirmations by themselves rather than wait for somebody else to do while the others do not. In other words, the key students are not passive but act on their own initiative. As a consequence, their existence activates classroom, especially teacher-student interactions and pushes the class flow ahead. The following is an example of this type of interaction. The researcher is providing the class with instructions for their first homework: 


\section{Class4-2-6:}

R: OK. Today's homework. Homework. When you go home, ... what's this? (drawing a picture of a house on the blackboard).

KS1 (refers to Key Student 1): A house?

$\mathrm{R}$ : Yes, your home. When you go home, at your house (pointing at the house), at your house, you have to read three times more (with a gesture of ' 3 '). OK?

$\mathrm{KS} 2$ : To read 3 times?

$\mathrm{R}$ : Three times more (drawing three flowers more besides the 2 flowers used in the former activity, which was a demonstration for the homework as well). Now you coloured two flowers. 1, 2, right? At your home, 1, 2, 3. Three times more. (Showing the handout) One time, 'pen, pencil, book, ...blabla... and tennis.' This is one time. And colour No. 3 flower. The second time. 'Pen, pencil, ... blabla... and tennis.' And colour No. 4 flower. Yes. 3 times at home. $O K ?$

KS2: Do you mean to read 3 times at home?

$\mathrm{R}$ : Yes, at home, at your home.

KS3: Homework, isn't it?

R: Right. Right. This is your homework. You have to read 3 times more. 3 times more. Your homework. OK?

KS2: $O K$.

In the next lesson, it was found that most of the students understood what to do for their homework - although they might have confirmed further by asking peers - read 3 times, and colour 3 flowers on the handout.

Moreover, the existence of these key students sometimes leads the class expand the interaction further, which results in increasing their exposure to aural input on the same topic. The following is taken from the 'Thai curry' episode in the Check-it-out Activity:

\section{Class2-6-4:}

KS1: Why is it green?

$\mathrm{R}:$ Oh, that's a good question, but I don't know, sorry. I don't know why it's green. They have green curry. And, they have red curry, red one. And, they also have yellow curry. Our Japanese curry is yellow. Our Japanese curry is yellow. 
KS2: Brown. ${ }^{10}$

R: Yes. It looks brown, but it's called yellow curry. And, they have green curry and red curry too. It's very, very spicy.

I have discussed that students use "key students" as part of contextual cues in order to reach understanding English-only communicative class. Key students constantly interact with the teacher clarifying questions and modifying the classroom input in public for their own sake, but this process also leads the whole class to come to understand the input and expand the classroom interactions. The existence of key students is, on the one hand, helpful for other students; from the teachers' point of view, on the other hand, it is useful or even necessary in order to carry on communicative class which requires interactions. In sum, in implementing communicative FonF activities, teachers should be aware of this function of key students, identify them, and let them actively participate in the classroom interaction with teachers, rather than try to make them hold their tongue.

\section{4) Use of Explicit Form Instruction}

In most of the communicative FonF activities involved, instruction of grammar points and vocabulary was done implicitly rather than explicitly, for example by modeling forms and illustrating with pictures. However, in some cases, specifically certain pronunciations which do not exist in Japanese language and the grammar point of 'this/that' which was necessary to play the game in the Karuta Activity were explicitly instructed. However, in providing explicit instruction, the researcher avoided abstract explanations; rather, concrete step-by-step explanations with teacher models were provided including concrete pictures or drawings to help students establish a pictorial concept of the grammar or a pictorial understanding of how to use their mouth for certain pronunciations in their mind.

10 Note that this utterance by the key student was even produced in English. 
For the pronunciation instructions, a focus was brought on sounds such as 'er' as in 'eraser', ' $a$ ' as in 'bag', 'th' as in 'thank you', and the pronunciation of some words pronounced differently in English compared to katakana, such as 'ticket' ("chiketto") and 'hospital' ("hosupitaru"). Through the instruction, students explicitly learned which part of the mouth or tongue to move in what way, watching the researcher's demonstration or/and explanations with a picture of the mouth and mimicking the researcher's sound and way of using the mouth. This is how the researcher instructed the 'er' pronunciation, that is, how students learned the new pronunciation through explicit instructions:

\section{Class 1-1-4:}

1. R: What's this? (showing a picture of a ruler.)

2. KS1: Let me see...it is a ruler, so...

3. R: Yes?

4. KS1: "johgi" (in Japanese but with a funny pronunciation pretending to speak English).

5. R: 'ruler'

6. SS: "ro:ra:"? Eh?

7. R: 'ruler'

8. SS: "ru:ra:"?

9. R: 'ruler'

10. SS: "ru:ru:"

11. R: Yes (drawing a picture of a mouth). What's this?

12. KS2: Teeth?

13. R: Yes.

14. KS3: False teeth? Bad teeth?

15. R: This is your mouth (drawing a tongue rolled up in).

16. KS3: A uvula?

17. R: This is your tongue.

18. KS3: A tongue.

19. R: Yes. Roll up your tongue. Roll it up. OK. Do this. 'er'.

20. SS: 'er' 'er'

21. R: Good. Very good. Very good!! 'Ruler'

22. SS: 'Ruler' 
The conversations from lines 4 to 10 show that while the researcher was keeping modeling the new word 'ruler', students tried to pronounce it in four different ways but failed to find out a right pronunciation. Then, the researcher decided to provide explicit instruction by drawing a profile of a mouth so that students could actually see a tongue position for the pronunciation (in lines 11 to 17 ). In line 19, the researcher was demonstrating the sound 'er' again, but this time with pointing at the profile. As a result, it can be seen that students were successfully mimicking the pronunciation 'er' in line 20 , and finally the word 'ruler' in line 22.

To correct the katakana-like pronunciation into an English one, in cases where to which the Japanese pronunciation system also includes a similar phoneme, it was relatively easier. 'Ticket' is one of those examples. The explicit instructions for 'ticket' was as follows:

\section{Class5-2-4:}

R: 'Ticket'.

SS: "Chiket".

R: Listen. Not "chiket". Not "chiket" (shaking the head), but 'ticket'. (Pointing at a tip of the tongue) Look at my tongue here. 'Ti' 'Ti' 'Ticket'.

SS: 'Ticket'.

R: Yes! Right.

This type of explicit instruction was definitely helpful for students who had no idea about the pronunciations to understand which part of the mouth and how to use in order to make these sounds. Their learnt skill, of course, has not yet been automatized for accurate and fluent productions since they have not had enough access to it although it is expected that students will be eventually able to produce these sounds mostly in a correct way or at least at an understandable level. However, it is expected that the basic 
understanding of the unfamiliar pronunciation will help students recognize the sound and understand what they have heard in English.

With respect to the explicit instruction of the grammar point 'this/that' for the game in the Karuta Activity, four strategies of instruction are identifiable: 1) using sets of contrasting situations for sentences including 'this' and 'that' with pictures of a big item and a small item and a big 'index finger' as to show different distances to the items on the blackboard (Figure 5.5.), 2) using examples using students cards, 3) practicing saying the model sentences in chorus, and 4) giving further explanations with their own pictures to individual groups. According to the understandings or reactions of the students, different types and length of the instructions were given to each different class in an attempt to improve the instruction.

Figure 5.5. Picture cards for Karuta Activity

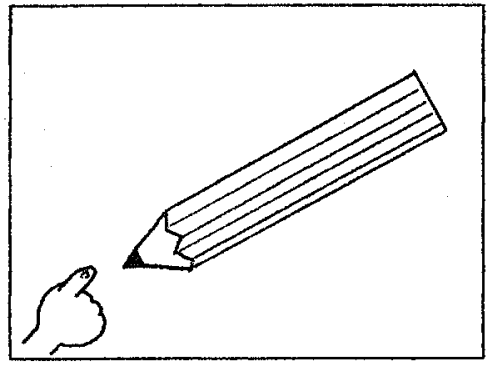

For 'This is a pencil.'

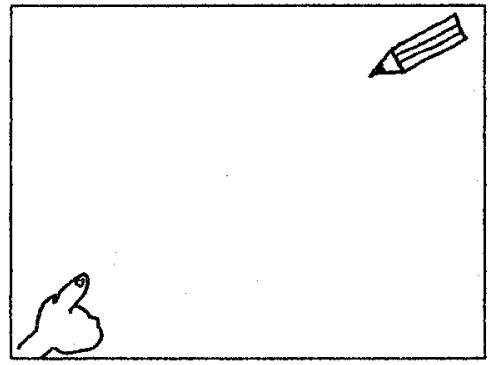

For 'That's a pencil.'

For instance, the class which received considerably long instructions was the first class which engaged in the activity, or Class 2 . What this class received as explicit instruction was all four types mentioned above with a couple of examples. However, the instruction was too long to keep some of the students' attention and patience for listening. After changing the content and length of the instruction little by little for each class, the researcher found that the most efficient, comprehensible, and stress-free way of giving 
explicit instruction was to provide teacher-centred instruction by strategy 1) above but minimized (one or two) sets of example sentences, and then to provide time for each group to talk about and teach the grammar in terms of the rules of the game to each other. While students were engaging in the process of clarifying the rules or grammar, the researcher circulated and, if needed, added further instruction by strategy 2), but by choosing examples were based on students' questions, or/and strategy 4). The difference in the instruction given to the last class from the first one is that the instruction was minimized and students initiated most of it, except for the initial teacher-centred one. Only according to students' requests did the researcher give instruction beyond the first minimum explicit instruction. The following examples illustrate a) the teacher-centred explicit instructions, b) group clarifications, and c) an example set stemming from students' questions.

\section{Class3-4-5:}

R: (Showing a picture of a dog) What's this?

SS: 'Dog'.

R: Yes. This is my dog. My dog (posting it in the middle of the blackboard and showing another picture). And, what's this?

SS: Shiro.

$\mathrm{R}$ : Yes. This is Shiro (posting it on an end of the blackboard). And, this is my $\operatorname{dog}$ (pointing at the dog with a 'big index finger' board).

S: Wow, a huge finger!

R: This is my dog. That's Shiro (pointing Shiro posted on the far end of the blackboard). That's Shiro. OK? Then, if I stand here (changing the position besides Shiro and pointing at it), I can say, "This is Shiro." And, (pointing at the researcher's dog on the other end of the blackboard) that's my dog.

After this set of examples, the researcher pointed at three sets of students close to and far from her using the expression 'this/that', and finally showed the set of the pictures in Figure 5.5, which are the same as the picture cards that students were about to use in the 
game. What was challenging for the researcher in guiding students to establish the concept was to explain the situation embedding the concept with a very limited English vocabulary that students could understand. In this case, pictures were again greatly helpful to show the situation in a way that described different distances towards the items by changing the size of the items and including an 'index finger' pointing at the items as shown in Figure 5.5. It can be observed that students have successfully got the concept whether an item is, not just 'big or small', but 'close or far', established in such group interactions as follows:

Class5-5-3:

SA: 'This is' 'That is'

SB: 'This' is for something close and 'that' is for something far, right?

Before b) group clarifications, every group was handed a set of cards and spread them on the desks. As soon as the cards came into students' hands, everybody naturally started to talk about the cards and grammar that they would need to play the game in their own group:

Class2-4-1:

SA: Is 'that' for this one? (pointing out a card.) 'That's'? Is this one for 'that's"?

SB: This one is for 'this', isn't it?

SC: 'This' is for something close.

SA: Something close?

$\mathrm{SB}$ : Then, this one is for 'this', right?

At the stage of b), some of the students noticed that there were two kinds of pictures and initiated a question about it, which led c): 


\section{Class3-4-5:}

KS1: Look. We've got big Nobita and small Nobita. ${ }^{11}$

KS2: Because these are 'this is' and 'that is'.

R: Yes. Mr. KSI has a very nice question. Do you have two pens? Do you have two pens? Did you find two pens? Do you have two pens?

KS3: Miss, we've got only one.

$\mathrm{R}$ : Only one pen? You should have two pens (going check the group). What is this? (pointing at the other card of a pen.)

KS3: Yeah!

R: Yes. Big one, for a big pen (showing the card), you can say, "This is a pen."

"This is a pen." And, for a small one, "That's a pen." "That's a pen." Do you understand?

SS: (Practicing by themselves.)

KS1: (Pointing at a picture of a 'big park') *This is park.

In this example of the interaction, KS1 first did not understand why there were two different kinds of pictures for each item, but eventually succeeded in recognizing the two in the last line; it can be seen that he had established an initial distinction for 'this/that'.

As have been discussed in this sub-section, the explicit instruction for new pronunciation and grammar features can help students to understand the English-only communicative FonF class as well as students' prior knowledge about the world and katakana and the contextual cues. In particular, explicit form instruction is necessary to start the communicative FonF activities which require students' understanding of the grammatical features involved. In this case, the instruction should be concise and supportive to establish a concept of the grammar to be taught. However, it should be always remembered that the instruction could not be enough for students to fully understand and get fully confident about recognizing the grammar. This is seen in the student interview, in which most of the students claimed that they almost understood the grammar through the explicit instruction but completely came to understand it and 
confirmed their understandings while experiencing the situation repeatedly through playing the game.

\subsection{Outcome from Communicative Fon F Activities}

In the previous section, I have discussed how students arrived at an interpretation of the English-only communicative FonF class and what kinds of resources they used in the process of understanding it. The discussion was based on analyzing what students did as a reaction to what the researcher showed and said to them. In most cases, the reaction was in Japanese or by physical responses. If students reacted correctly to the researcher's input, then it was assumed that they understood the researcher's intention or noticed the point that the researcher was attempting to say.

There are three outcomes in terms of student responses to the English-only communicative class that deserve additional comment. First, in some cases, students showed their understanding or 'noticing' by responding in English even though they were not required or forced to do so, or even taught what they had understood to peers. Secondly, slow-learners and problematic students could willingly participate in most of the activities, especially in the ones with students' physical responses involved. Thirdly, even in the case students who did not fully understand the class, their uncertainty of what they had heard cultivated their autonomy in studying by themselves. Each of these is discussed in turn below.

\footnotetext{
11 Nobita is a name of a cartoon character.
} 


\subsubsection{Students' English Use in Communicative FonF Activities}

In the communicative FonF activities used in the project, two types of students' English use occurred. The first is responding to their teacher or even taking the initiative in English in a meaningful way. The second is teaching what they have understood to peers in Japanese which also contains English words. The former tends to be found in teacher-student interactions while the latter is found in student-student interaction at the beginning level (where, in the project class, students are not required to produce English).

When students understood the researcher's utterances, they sometimes responded in English. In Question-Answer Activity, in which the researcher asked a question to them in English but students were not required to answer in English, most of the students responded with a Yes/No English answer while only a few students responded with a physical movement such as nodding or shaking their head. Besides the Yes/No answer, even in the first lesson, some students, including the key students, picked up a word or two from input, that is, the researcher's talk or what they learnt in the communicative class, and started using these words in a perfectly meaningful and situated way. Moreover, other students were able to use their understanding of the class for teaching their peers in Japanese with some English words they learnt.

The following is one of the examples for students' English use:

Class2-1-3:

R: Mr. SA, am I your friend?

SA: No!!

R: No?

$\mathrm{SA}:$ No.

KS: My teacher.

R: Yes! Your teacher. I am your teacher. 
This conversation is from part of Question-Answer Activity in which students are confirming the concept of the new word 'friend'. To the SA's response, KS added more information using the word 'teacher' he had just learnt and 'my' he had picked up. In this case, the conversation was initiated by the researcher, and the students followed the English conversation flow. On the other hand, students also took the initiative and started a conversation in English even on the first day, especially when they wanted to request or ask about something. The following was formed when a pair of students completed a set of cards in Matching Activity:

\section{Class1-1-4:}

SA: *Teacher, finish. [Miss, we are finished with this set.]

R: Finished? Did you finish it?

SB: What can we do when we finish?

R: Good. Put the cards together and put them back in the bag.

In this conversation, SA is using only the English words picked up from the researcher's input in an understandable way although the usage is not perfect, and SB is using the English word 'finish' she also picked up from the input or SA's utterance within a Japanese sentence. As the project class progressed, the frequency in students' use of English increased slightly, and at the same time more varieties of words were used. All their usage of English fitted the situation; in other words, their utterances were absolutely meaningful and situated.

In the fourth lesson, a key student's utterance became a three-word sentence with a subject and a verb when the researcher was admiring and evaluating their eager participation in Karuta Activity and awarding the small prize for the winner in each group: 
Class2-4-1:

R: Who is No. 1 in this group?

KS: *I am champion.

The sentence uttered is missing an article, but its meaning is perfectly correct in this situation (with a more complex sentence structure than a simple noun phrase which had been often seen in students' utterances) and it uses different words from those in the researcher's question. It seems that this KS had deliberately chosen the words and grammatical concepts he was using.

In addition, in the case where the researcher provided explicit formal instruction, some students who noticed and appeared to understand what was instructed taught their developing knowledge to peers. This was done mainly in Japanese but with some English words. Such peer instruction can be: 1) to just tell others what they have noticed that was different from their prior knowledge as katakana; or 2) to articulately explain what they understood. An example of the first type of the peer instruction occurred when the class was reading aloud the new phrases which they had practiced writing on the handout as their homework:

\author{
Class 1-4-4: \\ R: 'Thank you.' \\ SS: "Sank you." \\ KS: It's not "Sank you" but 'Thank you'.
}

This key student not only noticed that the researcher pronounced the phrase differently from katakana "Sank you" that other students were pronouncing, but also pronounced it correctly with his tip of the tongue sticking out of the mouth. His indication actually led the researcher's explicit instruction for the pronunciation 'th' to the class. The key student 
could show how to pronounce the phrase correctly, but did not articulate how to make the pronunciation.

For the second type of peer instruction, however, the two following examples show that some students could articulately explain what they had learnt and tried to help their peer understand it. One of the examples is Hiro from Class 2 . He is also a very energetic key student, but often misbehaves in a regular class because he just cannot sit still; he has a big curiosity with everything and wants to talk all the time. At the same time, it can be seen that he is kind of clever; his brain is always activated in a way that he can make all different kinds of connections between the things he has known and what he is seeing and hearing in the class. From the very first lesson, Hiro showed his curiosity about whatever the researcher showed and said in English and mimicked whatever he could picked up, which presumably sounded funny to him because it was different from katakana. He noticed the researcher's pronunciation of many words different from katakana, such as 'bag' [bæg] from "baggu" [ $b \wedge$ gu] and 'chair' from "cheaa" and mimicked them. After the researcher's explicit instruction of the pronunciation 'er', Hiro taught his neighbour how to make the sound as follows:

\section{Class2-1-3:}

Hiro: Toku-chan, you can get it if you put your tongue far inside of your mouth. 'Ruler'. 'Ruler'. You see?

In this instruction, Hiro's explanation is in Japanese, but he also demonstrates the word 'ruler' in English with using his understanding of the pronunciation.

Moreover, in group work, there were many more cases of peer instruction containing English; students frequently taught each other as well as asking questions about uncertain points. They instructed each other in Japanese but included English 
words as well. Whereas only a few key students tend to be able to speak up or ask a question in front of the class in order to clarify or confirm what they are assuming to be right, more students can play the same role as "key students" in group work situations. In other words, group work allows slow-learners ask a question to peers more easily than to a teacher in public and quick-learners or "sensitive-noticers" teach peers with a use of some English. It was observed in many groups in the Karuta Activity that even quiet shy students who had never spoken up in class were helping group members to understand the researcher's instruction or explanations of the form 'this/that' by using some examples, abstract concepts, and Japanese translation meanings. It is completely understandable that students are not $100 \%$ sure about what they think they have understood because it is information that they have obtained through English that they are not sure about. In a small group, however, the shy students do not have to worry that they might be wrong; instead, they can feel free to make a mistake. One such group peer instruction progressed as follows:

\section{Class 1-4-4:}

1. SA: Eh, there are two. What does that mean?

2. SB: Well, it is like a question to recognize 'this' and 'that'.

3. SA: I don't get it.

4. SB: 'that' is that, and 'this' is this.

5. SA: 'that' is ...? What did you say?

6. SC: 'that' is for something far, and ....

7. SB: 'that' is that, and....

8. SC: 'this' is this.

9. SA: Huh? I don't get it. What is 'that'? (The game is in progress.) Hey, what does it mean? What do 'that' and 'not' mean?

10. SB: 'that' is for something far, and 'this' is for something close. Do you understand?

11. SA: Not at all. 
12. SB: If, if, for example, 'that' is for "that bag" (pointing at a bag far from them), or 'this' is for "that window", or....

13. SC: You mean 'this'.

14. SB: Yeah, yeah, for "this window."

15. SA: For something far is 'that', right? OK. I'm going to memorize just that!

In this group, three students are involving in the peer instruction and they are all quiet students. SA is having a trouble with recognizing the concepts for 'this' and 'that'; meanwhile, SB and SC are trying to teach SA what 'this' and 'that' mean. First, in line 2, SB is expressing his abstract interpretation of the game, but that does not help SA. In line 4, then, SB is translating the English words 'this' and 'that' into Japanese, which still makes no sense for SA to play the game that requires the underlying concept. In line 6, SC started talking about the concept necessary for the game, but SB in line 7 brought the Japanese translations back to the conversation, and SA is still confused. Finally, in line 10, $\mathrm{SB}$ is explaining the concept of 'this' and 'that' and in lines 12-14 giving SA some examples. Consequently, SA successfully manages to grab one of the concepts and comes to participate in the game.

None of these three students had ever asked a question or spoke up about what they had not understood in public before, but in the group the slow-learner could initiate his question and the others could teach him by gradually articulating the points they had understood including the English words in their explanations in Japanese. The students who can teach others like SB and SC understand what the teacher have said, digest it, and then, at the stage of the peer instruction, put it in their own Japanese words with some of the English words that the teacher used. Without using the English words, they should not be able to teach anything to others. It can be seen in that all the lines, except lines 13 and 14 in which they are correcting a mistake in Japanese, include either 'this' or 'that'. The 
peer instruction is the place where students can show their understanding of the class in their own way, which is in Japanese with a use of some English they understood.

\subsubsection{Slower-Learners' Participation in Communicative FonF Activities}

I have already discussed how slower learners can participate in communicative group work with the help of peers in the previous sub-section, but their participations are not only in group work but also in whole-class communicative activities. In this sub-section, I am going to focus on a slow learner called Nao who willingly participated in a whole-class student-centred communicative activity.

Nao is a problematic student as well as a slow learner, as mentioned in the section 5.2.3. He has been brought up neglected in a single-mother family and did not master the basic school knowledge during his elementary school years as he skipped most of the classes. Since he entered junior high school, his homeroom teacher has been training Nao to regularly get up and come to school on time, phoning or visiting him in the morning, but he has not yet established such as habits. It is even difficult for Nao to sit at his desk over a period of 50 minutes, which is understandable concerning that he cannot understand most of the classes and is far behind the others. As a consequence, even if he can attend a class, he chats with peers, interrupts the class by doing something unusual, or does nothing by sleeping on the desk.

However, in the communicative English class, he can be at the same, or similar stage as others are; everybody is a beginner and has no basic knowledge of English. Moreover, the communicative class does not require students to read letters so much at the very initial stage - which is believed to be especially difficult for these slow or problematic learners; rather, it uses lots of visual teaching materials such as pictures and 
games which can attract them. Students do not have to rely on their background school knowledge but can also use all different kinds of contextual cues as discussed above.

In Nao's case, although he skipped almost half of the project classes, it appeared that he understood the class as mostly as others did according to his reactions in the class. One of the best activities in which Nao participated delightfully and in which he seemed to understand what was going on was the Skit Activity. In this activity, a pre-practiced student acted out a short dialogue skit with the researcher twice in front of the class. The dialogue was adapted from the prescribed textbook, as shown in Figure 5.6.

Figure 5.6. A Dialogue in Skit Activity
S: (Drops his book.)
R: (Picked it up) Excuse me.
S: Yes?
R: Your book?
S: Oh, yes! My book. Thank you.
R: You're welcome.

After the skit was acted out, the 'actor' student called on Nao as the next actor to play. In spite of researcher's misgivings, Nao did a great job with a help of his friends and made his peers laugh. He did not know what to say in the skit, but surprisingly did understand the conversation flow through watching the skit only twice and perfectly dealt with his role in his situation rather than mechanically spoke his memorized lines in a meaningless way. His participation in the activity was as follows:

\section{Class 3-2-2:}

1. N (Nao): Help me, OK? What should I say?

2. KS: Drop the book and leave. Just leave.

3. N: (Dropped it and ran out of the classroom.)

4. SS: (Laughing.)

5. R: Excuse me. Excuse me (picked it up and followed him).

(Both came back in the classroom.) 
6. R: Your book?

7. N: Not my book.

8. R: Oh, you're right.

9. SS: (Laughing.)

10. R: (Picked up Nao's file) Your file?

11. KS: (Telling Nao what to say.)

12. N: Oh, yes.

13. R: Here you are.

14. N: Thanks. Thank you.

15. R: You're welcome. You are very welcome. Good. Very good, Nao!

In line 7, Nao replied in Japanese with a use of English words 'my book,' which was perfectly understood, to researcher's question in line 6, but did not say, "Oh, yes. My book." If he said as the original line, it could be said that he actually did not understand but just memorized the line. However, in this case, Nao understood the question and meaningfully made a negative reply because the book did not belong to him but the first actor. Line 14, in which he thanked in both Japanese and English, also shows that he understood the situation and what appropriate to say in English. In brief, Nao participated well in the communicative activities, more so than expected.

Many of the slower learners or problematic students like Nao managed to understand the communicative class or the researcher's instructions, actively participated in the activities, and clearly enjoyed themselves. This is certainly a huge difference from their participation in the regular non-communicative class.

\subsubsection{Students' Autonomy in Communicative FonF Activities}

Another outcome of the communicative FonF class in terms of student responses is the development of students' autonomy. In the regular class where a teacher gives Japanese explanations to students, there is a tendency for them to passively listen to the 
explanations. All they need to do is sit still at their desk and pay attention to the explanations and sometimes read some words or sentences aloud in chorus or practice writing. In the communicative FonF class, however, students need to take the initiative to understand the class, not only paying their aural attention to the teacher's talk but also using all senses for any possibly useful clues happenings in the classroom and connecting the clues to their own knowledge. Also, they often need move their hands and body in the activities. That is to say, the communicative FonF class requires students to be very active both mentally and physically. Despite all these efforts, they are still not $100 \%$ certain about the interpretations they have reached because the device used for interpreting the information includes uncertain language, English. In contrast, this uncertainty can positively affect students' attitude in the class. One of the effects, as discussed in the section 5.2.3, is increasing students' concentration. The other is that students' uncertain feelings about what they heard in the class cultivate their autonomy.

The peer instruction discussed above is also considered part of the developing autonomy. Other signs of students' autonomy were found during the project. For example, it was seen several times that some students were looking spelling of a word up in the textbook while engaging in an activity or practicing to pronounce words by themselves while waiting for the researcher to check everyone's homework. It is important to note, also, that some of the students interviewed are aware of their development of the autonomy through the communicative activities:

\section{SI2A, June 9:}

SA: After finishing Matching Activity, while waiting for others to finish it, my pair and I were giving each other a tiny quiz like asking "How about this?" And then, we did pronunciation practice as well.

SB: She was saying something by herself too.

SA: Oh, yes. I sometimes did it alone too. 
R: Did you guys make it all up by yourselves?

SA: Yes. I've never done that before. In a regular class, I was just chatting with my friend in my spare time. l've never ever initiated to study by myself.

$\mathrm{R}$ : Why do you think you've done that in the communicative class?

SA: Because I am worried. I may get lost soon.

R: Do you think that helped?

SA: Sure. It was helpful. Now I am able to say the words by myself without teacher's models.

As seen in this SA's word, students' concern that they might get lost increased their tendency to work autonomously.

\section{Conclusion}

In this chapter, I have discussed students' perceptions of the English-only communicative FonF activities, their ability to understand the activities, and outcomes from implementing the activities. Generally, the students were in favour of the activities and succeeded in understanding what the teacher said in English and what to do in the class using various strategies and resources available in their classroom. These Japanese junior high school students were remarkable in their constant use of resources in the process of understanding the class. These resources included: 1) their knowledge of the world, 2) contextual cues including "key students" who became part of contextual cue-making, 3) their previous linguistic experience with katakana, and 4) explicit form instruction given by the teacher. Although the language input the students obtained was still limited by virtue of the foreign language setting, some students began to produce some output on their own initiative and taught what they understood to peers while "problematic students" were in many cases able to actively and willingly participate in the class. 


\section{CHAPTER}

6

\section{Discussion: Classroom Issues and Implications}

\section{Introduction}

A number of issues arose in implementing this new approach to an actual classroom, which is comprised of many different kinds of students with different personalities, expectations, abilities to understand, goals, and family backgrounds,. Some of them were expected and the researcher could prepare for them, either by avoiding them altogether or minimizing the negative effects on the class. However, some were unexpected. When an unexpected happening occurred in the class, the researcher had to spontaneously change her teaching plan in order to treat it properly and continue the class.

In this chapter, I focus on the issues that occurred in the project class which were unrelated to the students' ability to understand the communicative class. Through an examination of the data accumulated from the transcriptions of classroom interaction, Student Interviews, Student Questionnaires, Teacher Interviews, the researcher's own reflective diary, and pre-class preparation, the researcher identified the four following issues: 1) students' relationships with teachers and peers, 2) disciplinary interventions and encouragement, 3) teacher deficiencies, and 4) pressure for time. According to these categorized issues, this chapter will be divided into four sections. I also discuss some implications drawn from the research that I hope will act as suggestions for Japanese English teachers who are attempting to implement a new communicative approach in their classrooms in the future. 


\subsection{Students' Relationships with Teachers and Peers}

In the previous chapter, there was a discussion of two ways of classifying students. According to one classification, the class consists of three types of students: "excellent students" who always love class, "problematic students" who always hate class, and "middle students" who may like or dislike class. The first two are unlikely to change their minds regardless of circumstances, whereas the last type may change their minds depending on all elements of the class, including the teacher. Under the other classification, there are two types of students: influential "key students" and other "regular students." On the basis of the notion that there are these five different types of students in a classroom, the researcher has argued that one of the keys to a successful implementation of the communicative FonF activities would be to win over to the approach as many "middle students" and "key students" as possible.

However, there is an inevitable problem: some of the "key students" are identified as "problematic students" as well. In such cases, the "key students" do not always create a positive dynamic in the class; on the contrary, they may have a negative influence on the class, drawing the "middle students" into the dislike-side. One way of minimizing this danger is to establish a good relationship with the "problematic key students" outside of the classroom, hoping that such a relationship can support the students inside of the classroom. In this section, I will discuss teacher-student and student-student relationships that need to be considered when implementing communicative teaching.

\subsubsection{Teacher-Student Relationships}

Probably all teachers will agree that, whenever they attempt to bring a new activity into the class, especially when it is difficult and requires the students' full effort to be 
completed, a good teacher-student relationship can act as a solid foundation upon which to start. Trust in a teacher will convince the students that she is reliable and that in the long term doing the activity that she suggests will be good for them despite seeming as if it will give them difficulties in the short term. An attempt to implement this teaching project in a beginner class was a situation in which a good relationship between the teacher and students would be crucial. The project case was even more challenging since the researcher had such a short one-month period (the teaching itself was for two weeks). From the students' point of view, they needed a convincing reason to try a totally new learning style with an unfamiliar teacher. A good relationship with the teacher could have been an important part of that reason.

Establishing a good relationship with students requires a different amount of time and effort for each student, as no two students are the same. While for "excellent students," teachers do not need any special effort because there is already an established trust, for "middle students" and "problematic students," teachers need a certain amount of time and effort in order to establish a foundation for a good relationship. For "problematic students," it is difficult because they have already made up their minds and it is difficult to change them; yet, there is a possibility for establishing a good relationship with these students or at least encouraging them to participate in the class.

For the successful implementation of this new approach to teaching then, the researcher first made various attempts, as explained in section 3.2.2. She was trying to get to know the students by staying around their classroom and talking to them during lunch breaks and after school for as long as possible. She also participated in all the school activities and events with them and other teachers. As another preparation, the researcher asked teachers about individual student's behaviour and background. These attempts successfully led the researcher to win a fair amount of trust in the majority of the "middle students." However, the relationships that the researcher built up with a few "problematic" 
students were not consistently good or stable; one day they would act nicely towards the researcher and work hard and cooperatively in class, and on another day, they would never get up from their desk and sleep during the entire class, ignoring the researcher's kind words. There were two such students, Tatsuya and Koji from Class 1.

Tatsuya was a "key" as well as a "problematic student" He was an energetic boy who did not like the regular English class because he thought it would not be useful for his future. According to his answers in SQ1, he did not understand the class, he did not like the way the teacher called on students, he thought the teacher did not provide clear explanations, and that the teacher was simply not good. Despite his unenthusiastic comments of the English class in SQ1-6 and $7^{1}$, during the first week, Tatsuya not only participated in all the activities showing lots of interest, also understood what the researcher said in English. He was playing the role of a "key student" who led the class to help understand the teacher. The following conversation is a classroom interaction on the first day in which the researcher was explaining the Mapping Activity and in which Tatsuya involved:

\section{Class1-1-4:}

R: Do you understand? You can talk with your friends. You can talk. Jun: Eh?

Tatsuya: She said, “トーク("toh-ku")しろ(Talk)." She told us to talk.

R: Yes, you can talk with your friends.

In the Blackboard Karuta Activity carried out on the second day, Tatsuya, instead of the researcher, called out the words for which other students ran to pick up picture cards. The following is his constructive interaction with the researcher in engaging in the activity:

\section{Class1-2-5:}

Tatsuya: (In the last turn,) I wanted to say this (pointing at the picture of a

\footnotetext{
${ }^{1}$ In SQ1-6, he chose 'Other' indicating "Nothing," and in SQ1-7, he checked in both 'I am going to work at a reasonable level as usual' and 'I am going to work less than usual.'
} 
notebook), but didn't know what to say.

R: Notebook.

Tatsuya: I see.

However, on the third day, his cooperative attitude began to change. He slept on his desk from the beginning of class to the end. Comparing his reactions to the researcher's questions in the same Question-Answer Activity on the second and third day, the change in Tatsuya's attitude and mood can be seen. On the second day, he answered even in English and smiling whereas, on the third day, he was sulking. The following two interactions show his different responses to the researcher's questions.

Class1-2-5:

R: (Showing a picture of the researcher's cat.) Tatsuya, is this your cat? Your cat?

Tatsuya: Eh?

R: Your cat?

Tatsuya: (Smiling) No, no.

$\mathrm{R}:$ Good. This is my cat.

And,

Class1-3-5:

R: (Pointing at a pencil on Tatsuya's desk.) Your pencil?

Tatsuya: (Woke up from the desk but looked annoyed, pointing at the next student.)

$\mathrm{R}$ : Ah, I see. (Pointing at an eraser on his desk.) So, your eraser?

Tatsuya: (Pointing at the next student.)

R: Oh, this one too? So, how about this? (Pointing at his shirt.) Your shirt?

Tatsuya: That's enough. Leave me alone. Yes, yes.

R: Good. What's wrong?

In spite of his perfect answers which reveal his understanding of English, in the SQ2 administered after this third class, he claimed that 'he understood only less than half (30-50\%)' of what the teacher said (Q1) and of what to do (Q2), and that 'he just left it 
unsolved' when he did not understand something (Q3). Moreover, in Q4 and Q5, which asked him what made the class understandable (Q4) and enjoyable (Q5), Tatsuya chose the same items, the 'picture cards (PCs) the teacher showed,' the 'flash cards (FCs),' and the 'games.' Unfortunately, as he missed the questions about his perceptions (which were on the other side of the question sheet), it is not certain what he thought about the class and why. However, it is assumed that he liked the class since he checked most of the activities used as ones that he liked.

In spite of his favourable response to SQ2 administered after the third class, his classroom attitude started turning negative on the third class. SQ3 also reveals that the degree of both Tatsuya's understanding and his favourable impression of the class declined. In Q1 and 2, Tatsuya chose 'I understood almost nothing (10-30\%),' and when he did not understand, besides choosing 'I left it unsolved,' he indicated that 'I slept because the teacher was annoying.' In Q4, 5, and 6, the number of the items he chose as activities he thought helpful (Q4) or interesting (Q5) or he liked (Q6) declined. He chose only 'Teacher's English' for Q4, 'games' for Q5, and 'Karuta' for Q6 in SQ3. That is, for Tatsuya the class in the second week became less helpful and less interesting than it was in the first week. Moreover, in Q7, clearly Tatsuya expressed his dislike of the class by choosing 'I hate it very much'. He justified this by choosing the following 7 reasons: 'I cannot understand the video and tapes'; 'I do not understand the class'; 'Teacher is not good (circling 'not kind')'; 'Homework is too much'; 'homework is difficult'; 'it does not seem useful for future'; and 'Other (indicating 'Teacher is annoying').'

The researcher have not figured out why Tatsuya suddenly changed his attitude and his perceptions of the class. Reflecting on the fact that he actively participated in the class on the first two days, these negative reactions and comments may not have been caused by the new and unfamiliar approach, but rather his own problems with relation to his personality, behaviours, background, other teachers, and so on. Or, perhaps he was 
simply not in a good mood in the third class, and then the researcher annoyed him by waking him up and asking him questions. Nonetheless, what is clear from his indication that 'Teacher is annoying' in two questions is that the researcher failed to establish a good relationship with him, and this negatively influenced his feelings and his participation in the class.

The other student that the researcher failed to establish a good relationship with was a boy named Koji. He was also a "problematic student" but not a "key student" in the class. However, he was a good example of the possibility that exists in changing the mind of a problematic student. His attitude in class was constantly negative from start; he was sleeping on his desk for most of the time, even during games such as Blackboard Karuta and Karuta, when most other students got excited and enjoyed themselves. His attitude was the same in his regular English class. Enjoyable communicative games or cartoon pictures intended to attract students did not work for Koji. He expressed in SQ1-5 that he hated the class because he hated classes themselves. Also, in SQ1-7, he chose 'Other' indicating 'There is no way because I am not willing to work in class.' These comments can confirm that Koji is a typical "problematic student" who never changes his unfavourable impression of the class.

Koji indicated in both SQ2 and 3 that he understood almost $60-80 \%$ of what the teacher said in English and of what to do throughout the project. With regard to his perceptions of the class, in SQ2, Koji expressed his intense dislike of the class. He answered that in SQ2-7, he hated it because it was troublesome to listen to, and in SQ2-6, he chose 'Other' indicating 'I like none of these.'

However, there was only one small part that Koji seemed to like and actively participated in, and that was when the researcher brought in green curry paste and offered students an opportunity to taste it in the last class. Koji quickly got up and tasted it a few times. While other students commented that it tasted very spicy, Koji said, "It's not so 
spicy but tasty." After that, he did not go back to sleep but talked with his peers about spiciest curry that he had ever had. Although he was not working on the handout that the rest of the class was engaging in, he was part of the activity. It is not certain whether this occurrence influenced his perception of the class, but in SQ3 administered on the following day, Koji changed the degree of his dislike from 'Hate very much' to 'I dislike the class.' If there was another class, he might have gradually participated more. When the researcher reported on this happening, Koji's classroom teacher commented that Koji probably had many great experiences with food since his father, who had been a single father, was a professional cook.

In sum, teachers working in foreign language settings in particular should be aware that establishing a good relationship with students is quite important for the implementation of communicative teaching since it requires interactions. It should also be noted that establishing a good relationship with students requires a different amount of time and effort depending on the student. If this foundation is set for the communicative teaching, it is not impossible to make problematic students participate in the class, or at least encourage them to participate.

However, it is also quite common that problematic students may bring their own problems into the classroom, especially when they find the class difficult. In that case, according to Krashen $(1982,1985)$, their 'affective filter' is extremely high and they shut out what they hear in class. For such problematic students, who already have a high level of affective filter, probably extra scaffolding in Japanese outside the classroom would be needed. In these boys' cases, the researcher could have called them individually to the teachers' room and asked them what was wrong. She could have asked whether the reason for their non-participation was an inability to understand what the teacher was saying in English, and the researcher could have encouraged them to try to listen in class as well as briefly telling them in Japanese what had been done in class. Bringing something 
interesting for these unsociable problematic students in class can also be another way of seizing an opportunity to establish a relationship with them (as curry paste worked in Koji's case).

\subsubsection{Student-Student Relationships}

Another issue that should be taken account in terms of classroom relationships is the students' relationship with their peers. Whether or not students have a good peer relationship is quite crucial since the communicative FonF class has a significant amount of group/pair work, in which they are expected to talk and negotiate with each other, regardless of whether it is in Japanese or English. They need to cooperate to complete their tasks and sometimes must help and teach each other. As reported above in Chapter 5, these cooperative group interactions can be helpful and meaningful for understanding what was said in English. Moreover, with respect to problematic students, even if their teacher has not yet established a good relationship with them, peer relationships can support their participation in the class.

However, interactive activities could cause problems in the class if a student does not have a good relationship with his peers and does not know how to negotiate with them. Since most students in Japan usually study school subjects in a teacher-centered manner, they are not familiar with negotiating within a group. It could be possible if they chose their own groups, but that might also cause a problem; they might need more time to get into their groups, they might get too excited and noisy, or they might not work hard since students can sometimes get de-motivated and lazy when they work together.

Instead, when students work in a group chosen by a teacher, which is probably the most common grouping approach for managerial purposes, they can still have trouble if they do not have a good relationship. For instance, while engaging in the Karuta Activity, suddenly a boy, Daisuke, stood up sobbing, grabbed the arm of the boy next to him, Ryuta, 
and hit him. The researcher had to break up the scuffle, and ask another teacher to question them about the cause, since the researcher was in charge of the class going on. At that moment, their homeroom teacher, who knew their background better than others, was available by chance, and listened to them and brought about reconciliation between them. According to the teacher, Daisuke, who was a very quiet student, had had similar trouble several times before, in which he got nervous and panicky when he could not manage to negotiate something with his classmates. In this case, before the scuffle began, they simultaneously pointed out a card read aloud by the researcher several times, and each time other group members judged who was faster. This time, Daisuke did not agree with the members' judgment but could not verbally convince them, and in the end lifted his hand against Ryuta. Daisuke said that this was not the first time that he had disagreed with the judgment; he believed that he was faster than Ryuta several times, and the judgment was unfair. The researcher was expecting that students could deal with this kind of trouble by themselves, but indeed some could not. In order to avoid it, the researcher could have established a rule of playing 'rocks, paper, scissors,' whenever the judgment was unclear. Another issue concerning classroom relationships occurred when groups were mixed-gendered, particularly when quiet girls were grouped with non-cooperative boys. The girls felt that the boys were sometimes out of control and spoiled the group work. The girls believed that girls-only groups would allow them to work more cooperatively and productively.

SI2A, June 9:

R: (Talking about Tape Listening Activity) In Class 1, did you have boys-only and girls-only groups?

$\mathrm{S}$ : Yes, because we were grouped in a lengthways row.

R: How did you like it? Which do you prefer, separated or mixed-gendered groups?

S: Separated.

R: Why would you say so? 
S: Because everybody worked hard, concentrating on listening to points and exchanging opinions, it was easy.

Another student also said:

SI2B, June 10:

R: Was your group mixed-gendered?

S: It was the first case, and girls-only in the second case.

$\mathrm{R}$ : Which was better?

S: With girls.

R: Why would you say so?

S: Because the boys did not do anything at all, they were just being absent-minded.

R: Eh, Boy A and Boy B are in your group, aren't they? They aren't willing to do anything, are they? Then, don't you mind grouping with eager boys?

S: As for Boy A, he probably understands English, and when Teacher said something [in Karuta Activity], he said, "This one!" pointing out the card but did not take it.

R: Though he understood what I was saying, he didn't participate in the games, did he?

S: Yes. He is a killjoy, and I couldn't enjoy the game.

$\mathrm{R}$ : Then, if it was not a non-cooperative boy but a cooperative one, would you mind a mixed-gendered group?

S: I do not like it.

In contrast, girls who are not shy can cope with boys, and even sometimes put them back on a right track, playing a role just like a mother disciplining her child. The following is a comment by such a "mother" girl:

SQ2-8-1:

I want you to increase group work, and then I will be able to develop better relationships within a group and we will be able to keep the number of noisy students below about 4 or 5 .

These opinions, from both the quiet and strong girls, sound reasonable. Respecting both preferences, a good solution would be to have sometimes single-gendered and sometimes 
mixed-gendered groups.

To summarize, in order to create comfortable classroom conditions and a motivated atmosphere and that facilitates group work, teachers should be sensitive about their own relationships with individual student and peer relationships. Giving the class a simple questionnaire once a while is a way of collecting information about their problems as well as preferences. Whereas it is believed that the more interaction the better for a communicative class, it is also true that more interaction brings more chances to have interactive trouble. In order to minimize the number of such troubles, the class probably needs rules, and at the same time students need time to get used to such activities as group work. This can be said not only in group work but in any communicative activity, especially in games. I will focus on this point in the following section.

\subsection{Disciplinary Interventions and Encouragement}

There are two main concerns regarding the classroom atmosphere that teachers may need to address when implementing a communicative activity. One is how to maintain control in the classroom, and the other is how to motivate the class. During a game, for instance, students usually get more excited and often noisier. That result can be chaotic when students do not listen to the teacher and sometimes it is no longer possible to carry on the game. At this point, the class needs disciplinary intervention. However, when a class or a group has several very shy quiet students, it is also difficult to carry out a game. The class needs something to stimulate excitement or encouragement.

\subsubsection{Disciplinary Interventions}

Disciplinary intervention is more serious and important than encouragement since disaster 
can result when a class loses control. Overly excited students can often get carried away. There was a critical incident with regard to such a student in the project. It happened during the sixth period on Friday, which was the very end of the week when students tend to lose their concentration. Class 4 was engaging in the Blackboard Karuta Activity.

A boy, Yuto, sprained his ankle when he fell over the leg of another boy, Ken. Ken's leg stuck out in the alley between the desks, where Yuto came running through to pick up a picture card on the blackboard. What the researcher had noticed from the classroom behaviour of these students was that Ken was one of the most problematic students among the first-years while Yuto was one of the serious and keen students, especially good at English. Since the researcher saw that Ken deliberately try to trip other students with his friend before, she told them:

\section{Class4-2-6:}

$\mathrm{R}:$ No, no, no. That is not good. Not good. Don't do that. It's dangerous. I know you have long legs, but you can't do that. Put your legs under your desks. Everybody, put your legs under your desks. Your legs under your desk.

After this researcher's intervention, these two boys, Ken and his friend, stopped tripping others for a brief period. From this reaction, it is believed that the boys should have understood what the researcher meant from her gesture even if they might not understand English used. From their age, they also must have known that they should not have done that. However, Ken repeatedly tried to trip other classmates. Thus, the researcher stayed right beside him to watch him while the game was going on, rather than scolding and warning him in a stricter manner.

There were two reasons why the researcher did not scold Ken with stronger words at this point. The first reason was that she did not want to create an overly serious atmosphere, which would hinder the relaxed atmosphere of the game, and which consequently hinder students' language acquisition (Krashen, 1982; 1985). The attempt 
was to provide with the class was not only lots of English input but also a comfortable and pleasant classroom environment within which students' 'affective filter' remained low.

The second reason for not scolding Ken was that the researcher did not want to ruin Ken's participation in the class either. As mentioned above, he was a problematic student. He had hardly participated in class activities such as the chorus pronunciation and writing activity, and had never done his homework; instead, he slept, talked to his peers, or did not do anything related to the class. Often he would not even bring his textbook, notebook, or have his handout on his desk. He had very little motivation to study. Only in such a game activity, did Ken sometimes show his interest in what the class was doing and try to participate. Therefore, this was only his limited chance to engage in the class, and the researcher hoped that this would be the first step for him to start studying.

For these two reasons, the researcher decided not to give Ken a strict warning but to stick beside him. However, since Ken was sitting in the back row, it was impossible to stay close to him all the time. There were 33 other students to take care of, communicate with, and she needed to go back and forth to the blackboard to rearrange disordered picture cards, and congratulate the winners. When the accident happened, the researcher was in the front calling out a word for a picture to be picked. Yuto fell forward, tripping over Ken's leg suddenly stuck out in the alley, and was lying down with his ankle badly sprained when she rushed back to the spot. The homeroom teacher had to take Yuto to the hospital to see a doctor, and the class had to give up the activity and begin another that did not require students to move out of their seat. At the same time, the school phoned both parents telling what had happened in class and arranged an occasion for Ken and his parent $t^{2}$ to formally apologize to Yuto and his parents after school. In the meeting, the school, including the regular English teacher and the researcher also apologized to Yuto and his parents since any accidents in a classroom are usually considered due to teacher's

2 Ken has a single mother. 
irresponsibility; teachers were supposed to ensure that everything in the classroom was safe.

Yuto's mother blamed the school saying that the teachers in the classroom (the regular English teacher and the researcher) did not pay sufficient attention to Ken, who was a problematic student and who would always do wrong if possible. The mother also insisted that teachers should not create opportunities in the class for the students to play or have fun, since they were suppose to be studying. She said that she did not want teachers to sacrifice the proper education of other students in order to compromise for the students who tended not to study in a regular type of classroom. Many Japanese parents still believe that a class should be serious where all students quietly sit straight in a row. The mother clearly claimed that this accident was not Ken's fault but the school's because the school did not properly deal with Ken even though they had known that Ken had issues controlling his behaviour.

If the school, including the researcher, completely accepted the claim by Yuto's mother, the school would have to give up providing students with many opportunities to learn other things, such as fine arts, technical arts, and home economics in which students use a lot of tools. The school would have also had to give up teaching physical education, having school trips, or field trips, because these opportunities presented the possibility for an accident. Indeed, on the contrary, rather than merely avoiding dangerous situations, these subjects and school events have been a large part of the schooling system. The Ministry of Education, Science, Sports, and Culture, Monkasho, has valued their educational effectiveness over the potential for any problems. With respect to learning English also, the nature of this type of education should be applicable, considering that Monkasho has advocated 'participatory education' for all school subjects rather than a teacher-fronted one-way education. The school should also support the nature of the communicative approach that includes lots of interactions and physical movement. 
Because students are especially beginners who cannot express their thoughts and understandings verbally in English, they are usually required to use part of their body as a response to show their understandings of English they receive. Concerning this point, Toyota said in the interview as follows:

TI1B, Toyota, June 13:

T: I love to play a game very much although l've never done one here in this school yet. But I'm always afraid it would be really noisy for other classes around if I did it in a regular classroom. Everyone frantically participates in games, doesn't he? So, at the previous school, I used to have games in a multipurpose classroom where students can run around in a big empty space. It's not a matter of classroom size, though...

R: But, there is still a possibility of injury behind those really active games. What do you think about this point?

T: I also think this is the next problem to be solved. It depends on school, but I want to go for it because it's not fun if I do not use these games. But I guess I need preparation before that.

However, in the sense that teachers should minimize (but not completely avoid) the possibilities of any kind of danger in education, the mother's claim is right. What can or should English teachers do in order to minimize the possibility for dangerous situations in communicative class?

Fist of all, before implementing a communicative activity, the class should have established a "problem-free" policy, which means if a problem occurs during a game, then the class will give up the game. This "problem" can be any kind of problem that hinders the class to move on, for example, a few students that are too noisy and will not listen to the teacher. Under this policy, students will be responsible as a whole class to make the classroom atmosphere safe to have active games.

Teachers can suggest the policy in either Japanese or English, depending on students' understanding, at the beginning of the implementation, and also keep reminding students of this policy throughout the class. At the beginning of the class right after the 
incident, the researcher set ten minutes or so aside for an explanation of the policy in Japanese. For the explanation, the researcher used Japanese because all the students, whose ability to understand English was still extremely limited, needed to completely understand the policy. For reminders about the policy, warning in English is probably understandable and works:

Class2-4-1 (Class was engaging in Karuta Activity and very excited):

R: OK. Next one. Hello? Mr. OO, hello? Mr. OO. OK. Everyone. Hello. Listen up!

SS: (do not become quiet and would not listen to the teacher.)

R: Hello? Uh-oh... (Remaining quiet for a few seconds.)

S: Be quiet!! Otherwise we will have to give up the game.

R: No game?

Kazu: Yes.

R: OK. Let's start.

Second, teachers should make sure that there is enough space for students to move around. If available, it would be excellent to prepare another room for English class. As the number of children has been declining in Japan, most schools probably have several extra rooms that are no longer used. Besides having enough space, this special classroom will allow the teachers to arrange desks in advance to save time, create an 'English environment' with decorative ads and students' work on the wall, and to feel free to make noise by active interactions, which might disturb other classes around. However, if an English classroom or a larger classroom like a multipurpose room is not available, teachers should make sure that students have enough room to move during activities by moving their desks, removing unnecessary students' possessions, and telling students to sit properly to make enough room for others. The following is one of these instructions:

Class3-3-6 (engaging in Blackboard Karuta Activity):

S: Hey, Toru, you're in my way!

R: OK. Others!! Everyone, put your legs under your desk. Under you desk.

Takeshi: You said, “Put our legs under the desk", didn't you? 
R: Yes. Put your legs under your desk.

Third, teachers should prepare well for all the communicative activities involved in terms of the organization and the activity instructions. In cases when the class gets out of control, disasters do not result from simply students' bad behaviours but also teacher's insufficient preparation or mismanagement. During the project, for instance, in Question-Answer Activity, the class could maintain quiet listening to others for up to about ten students, but after that, students often lost their interest in listening and got noisier. Another example in teacher's mismanagement can be seen when the researcher was trying to explain grammatical points necessary for the Karuta Activity after handing cards to each group. The students had got too excited to listen to her:

\section{Class2-3-3:}

R: Spread all the cards. Yes. Are you ready?

- some interactions -

R: Hello? This is a pencil. (Closely pointing at a picture card on the blackboard.)

Shun: This is a pen.

Kazu: Shun, that's just a noise.

R: Hello? Not yet. Hello? Listen.

Kazu: (Holding a card of 'pencil') Can I keep this?

R: Listen.

Hiro: Hurry up!

Kazu: Not yet?

R: Quiet! Listen!

Kazu: Oh, all my efforts for getting this card came to nothing.

R: This is not a game yet. Not yet. This is not a game yet. OK? Not count. Not count.

Hiro: Hurry up!

R: This is a pencil. And THAT,..that's a pencil. (Pointing the card from a distance.)

SA: What does it mean?

SB: Far.

R: (Picked up two sample cards from a group and showed them to the class.)

Which is "This is a pencil"? 
SC: (Pointed at the right one.)

R: Yes. And small one, small one. That is a pencil. OK? If you are far away

(standing at the door and pointing at the 'pencil' card on the other side of the blackboard), you can say, "That's a pencil."

The result was that the researcher tried to make students repeat the example sentences after the researcher, which did not mean anything for the students and ended up with confusion:

\section{Class2-3-3:}

R: Say together. "That's a pencil."

Kazu: This isn't a rehearsal, is it?

R: "That's a pencil." Say.

Kazu: Isn't it a rehearsal?

Some students: That's a pencil.

SS: (Noisy.)

R: Quiet!!!!! (Shouted.)

SS: (Silence.)

What should be remembered in communicative English-only class is that students cannot rely on only language heard in order to understand the class, but tend to rely on all information available around them, especially visual materials in front of them. In the examples mentioned above, the students were handed a set of cards while the researcher required the students to look at the other picture cards on the blackboard and practice saying the example sentences. The researcher should not have handed the set of cards until they were ready to be used. If the flow of the units and activities involved are not well organized, then that will put students in confusion. I will discuss this point in relation to teacher deficiencies more in the following section.

Fourth, as mentioned in the previous section, group work can play a role of disciplinary intervention as well. If a game requires cooperative work in a group, especially when cooperation affects the competition of the game, members tend to 
naturally discipline each other. For example, in Class 5, the students played Blackboard Karuta as a group. In each turn, group representatives competed for points, and the points were added up for a final reward. In a turn, a boy was not listening to the teacher but playing in front of the video camera and missed a chance to start running to pick up a card called. After this, the other group members complained about his behaviour. Communicative games as group competition can stimulate students to listen to the teacher's instructions because otherwise the group would miss important information to win the game. When it works out well, teachers no longer have to discipline students. Of course, teachers should be careful about grouping members and aware of locations of bully and bullied students as well.

Finally, in an emergency case, teachers should not hesitate to use Japanese. It is important for teachers to keep in mind that they supposedly use maximal amount of English, but for the purpose of students' safety, teachers can also use Japanese.

In brief, as a disciplinary purpose in a communicative class, teachers need to prepare well-organized group activities, be aware of students' relationships, and provide necessary rules and enough space as well as can reserve the right to use Japanese in an emergency case.

\subsubsection{Encouragement}

In the meantime, for shy or modest students, even though they are interested in a game, it is not easy to express their excitement by participating actively. This tendency is more likely to be seen among girls, and they need something to encourage them. It could be a getting small reward for winning a game, having group members cheer them on, being empowerment by being group with a good friend. Or, it could be becoming simply accustomed to playing games by rehearsing or playing the same sort of a game several times. For these relatively quiet students, simple group work would also be good rather 
than a competitive game. It is assumed that, for example, some of these types of encouragement must have been there during the project activities based on two descriptions from the researcher's reflective diary on Class 1 .

\section{Reflective Diary, May 30 (on Blackboard Karuta):}

Girls in the first turn did not run to pick the card up. They did not seem to be excited either except for one who won a sticker. But in the second turn, the girls became a little bit more excited. Probably in the first turn, they did not know they could get a sticker for a prize, or they were simply too shy or modest to show their excitement or competitive spirit.

Reflective Diary, June 6 (on Tape Listening Activity):

The students were divided into 3 boy-only and 3 girl-only groups. All the groups worked really hard, rewinding and listening to the tapes many times, thinking of what the tapes said together and exchanging opinions well. Especially girls' groups concentrated on listening and cooperatively worked, I think.

In conclusion, balancing disciplinary interventions and encouragement must be another key to the successful implementation of communicative FonF activities. In order to achieve this balance, a number of suggestions have been made in this section. However, the most fundamental underlying factors in achieving this balance are the establishment supportive student-teacher and student-student relationships and the resulting supportive classroom atmosphere and dynamic. Not only will group activities be more successful in such an atmosphere, but group activities can also function as the basis and resource for both disciplinary interventions and encouragement. It is also important to remember that time for both students and teachers to become familiar with the routines and benefits of group-based teaching is needed.

\subsection{Teacher Deficiencies}

One of the biggest issues that arose in implementing communicative English-only FonF 
activities is teacher language deficiency. Researchers (e.g. Chambers, 1991; Franklin, 1990; Li, 1998; LoCastro, 1996) report with regard to foreign language teaching that many secondary school teachers feel uncomfortable using the target language as the medium of instruction. Chambers (1991) categorized teachers' managerial language use into four areas according to its purpose. These categories are organizational instructions, activity instructions, evaluation and correction of students' performance, and disciplinary interventions. The last category has already been discussed in the previous section; therefore, in this section, I will discuss the other three on the basis of the classroom interaction in the project.

It must be true that teachers' confidence in speaking the target language influences on their decision whether or not they use the language in class. However, this issue seems to be not just about the teacher's ability to use the language, but is intertwined with classroom managerial skills as well. In other words, teachers' thorough preparation for classroom management can compensate for their language deficiency.

\subsubsection{Organizational Instructions}

Chambers (1991) suggests that teaching main organizational instructions at the beginning will help teachers more easily conduct the class mostly in the target language. At the very beginning of the prescribed textbook used in the city of the research site, indeed, some of these expressions are introduced (see Table 4.5, Chapter 4) with pictures to be taught right after the page of 'greeting.'

However, these instructional expressions can also be used and taught in daily class activities relatively in a natural way because of the nature of the expressions. The following two are examples that students came to understand some of organizational instructions in the project.

The first is the organizational instruction for Homework-check Activity. 
Throughout the period of the project teaching, every class except the first one ${ }^{3}$ started with Homework-check Activity. In this activity, the researcher circulated talking to individuals, and checking whether they had done their homework and colored flowers to indicate how many times they had read new vocabulary items on the handout. The following interaction occurred in the third lesson, which means that it was only the second time that the class had their homework checked by the researcher.

\section{Class1-3-5:}

R: OK. Look at this paper. (Showing the homework sheet.) Look at this paper. Yes. You had homework to read three times. (With a gesture of "three".) Did you read three times?

SS: (Taking out their file in which the sheet was supposed to be bound.)

R: Yes.

SA: I did it three times.

R: Yes. Three times. Wow, really? Let me check. Open your homework. (Started circulating to check their homework.)

R: Very good. Very good. Where is your homework?

SB: (Took his file out of his desk and opened it.)

In this case, although it was the second time that the class had this activity, the students seemed able to understand the instructions quickly without any problem. Here there are two indications that SA and SB understood that the researcher was going to check their homework from their reactions: SA's response in Japanese and SB's physical response. However, it is not certain which information they had used to come up with the understanding, whether it was the sheet the researcher showed them, the word 'homework,' the gesture or word of 'three,' other students' reactions, the action that the researcher was carrying a stamp to put on the handout, or their memory that the class had done the same activity in the previous lesson. Nevertheless, the activity had already become routinized, and the organizational instructions had become familiar to the

3 The students had not learned a word, 'homework,' so, in the first lesson, the researcher had to explain what the students should do as their homework with a picture of 'home' rather than just using the word, 
students.

The following interaction also shows that organizational instructions can be easily understood, thus easily implemented. This example is retrieved from a preparatory unit for Karuta Activity when the class was trying to make groups of six.

Class2-3-3:

R: Now I want you to make a group. I want you to make a group.

Shun: Oh, are we going to make groups with this?

R: Yes. Move you desk. (Started moving some of students' desks.) Put six desks together (with a gesture of 'six'). Put six desks together.

S: Are we going to join desks?

R: Yes. Six desks. Six desks.

Shun: We're going to put six together, aren't we?

R: Right.

This is absolutely the first time for the students to arrange their desks in order to be grouped in the project, that is, the activity itself has not yet been routinized and the organizational instructions used were unfamiliar to the students. In addition, the students knew only a few words, such as 'desk,' 'you,' and 'I,' in the utterances used by the researcher, and might have understood the word 'group' from Japanese katakana "guruupu" and 'six' from the researcher's gesture. Nevertheless, the students could understand what the researcher said and successfully arrange their desks into a group of six in a short time.

In sum, the teachers seemed to be able to have students understand organizational instructions without extreme difficulty for at least four reasons. First, most of these instructions can be used with a gesture as for students to understand. Second, these expressions are repeatedly used, which enables students acquire them soon. Third, following the same sequences every time can routinize many of the classroom activities and the expressions involved. Once students have got accustomed with main daily 
classroom routines, then teachers actually do not need to explain in details but simply tell the students what to do. Fourth, most organizational instructions require students' immediate physical reaction as a result of their understandings, which is good particularly for beginners who cannot verbally express their understandings and for teachers who immediately need to grasp whether or not students understood in order to carry on the class. If there were no evidence that students understood, then teachers could try something else. For these reasons, it should not be so difficult for teachers to use English for the purpose of providing organizational instructions.

\subsubsection{Activity Instructions}

The language for activity instructions has much more variety and appears to be more sophisticated than organizational instructions. Yet, it is possible for teachers to make this type of instructions less sophisticated and easier to be understood by preparing in advance. These points are discussed in turn.

On the one hand, it is true that activity instructions are more complicated than organizational instructions, and therefore, teachers tend to diminish their enthusiasm for attempting to use English as the medium of instruction. In Teacher Interview, Toyota reveals this tendency:

TI3A, Toyota, June 13:

T: I think teachers need a great ability in explaining rules in English because they must make students understand. When I saw you making desperate efforts through trial and error, repeatedly asking students "Do you understand?" "Did you get it?" many, many times, I thought that would be a really hard task because it would never end by one trial, wouldn't it? I can't finish it by saying, "First of all..." That point would be hard.

$R$ : Then, what if you should do this by yourself?

T: For myself, it may be impossible to implement this [explaining rules in English]. But, if I were told to do it anyway and did it, students would get 
tired, I'm afraid.

R: Do you mean because your explanation would be tedious?

T: Yes. Because it would take a long time to get them understand. $\cdots$ [omission] $\cdots$ Rather than repeating the same things, you were saying in different ways from a variety of directions, that I think helped students feel like listening to you more and increase their concentration.

$\mathrm{R}$ : Then, what is the first reason that you said that it would be impossible although you loved to implement it?

T: I cannot explain one from various directions. I do not think I have enough vocabulary to do it, probably.... . [omission] $\cdots$ What I could do may be to use body action, or body language, and to say only such words as "Read!" "Listen!" or "Get!" if I wanted to make students really understand what to do. So, I don't know if that would be a good way to do. I think that is what I cannot do by myself. I am not confident.

Toyota is afraid that students may get bored and tired because she cannot give them precise activity instructions; to tell the truth, students are not so patient. The following interaction is from one of the Karuta Activity instructions the researcher gave to an individual group, in which a student was about to lose his tolerance within an ambiguity in the process of understanding. Before this group instruction, the researcher had already given a classroom instruction by using picture cards on the blackboard, but it seemed that most students needed more clarifications with actual game materials in their hands. So, the researcher begun to individually explain in each group:

\section{Class3-4-5:}

R: This is a park. That's a park. (Pointing at each card in a group.)

SA: Big one is "this" and small one is "that."

R: For this (pointing at a card with a small park in the corner of it), THAT'S.

That's a park.

SB: Can't get it. That's enough. Say it in Japanese! Say it in Japanese!

SB became no longer patient enough to listen to the researcher's explanation, but he had a reason for being impatient. The reason was the inefficient organization of the explanation. As mentioned above, the boy had listened to another explanation before, which was 
teacher-centered and not understandable to him. If all these explanations were better organized or prepared, he might not have needed be impatient or unhappy about it. So, how could the researcher organize the activity instructions in order to make them more understandable? In other words, how could the researcher better prepare the activity instructions in order to help students to understand them more easily?

First of all, grammar explanation should be part of the activity instructions. Communicative FonF activities should be designed to naturally pay students' attention to a grammar point. Thus, students do not need extra grammar explanation outside of the activities; rather, grammar explanation should be in the part of the rule instructions. SB in the previous interaction, who once almost lost his patience with listening to the instructions, eventually held himself back and succeeded to understand them with a help of other members' clarifications, and researcher's additional explanation and demonstration as follows:

Classe-3-4-5:

SC: "THIS" is this, and

R: Listen. When I say, "This is a park," and you'll take this (picking a card up).

SB: Uh huh!!

R: And if I say, "That's a park," then take this (picking another card up). So,

SC: Something far.

SS: (Confused murmuring voices.)

R: Listen. Listen. Quiet. Listen. So, you have THIS and THAT.

SB: Uh huh, I've got it. I've got it!

$\mathrm{R}$ : If I say, "This is a ruler," take this (picking a card up).

$\mathrm{SD}$ : If you say "THAT," this one! (Picking the right card up.)

$\mathrm{R}:$ OK. Let's play it, OK?

It is assumed that what maintained his patience up and pushed him to understand the instructions was his eagerness to play the game. Conversely, it can be said that the activity instructions, which could not be directly connected with the game in his mind, such as the 
instructions on the blackboard, were neither catchy nor useful to him, but he was patient enough to listen to the incomprehensible instructions. When he finally had a chance for a little more comprehensible and meaningful instruction in a group, he had already been tired out. Presumably, the first type of the instruction is not necessary. This is in evidence in an interview with a girl who is a very careful and patient student:

SI, June 4:

S: I think I understood what the teacher said in explanations for Karuta, but at the beginning, it was still confusing; I mixed up THIS and THAT. I almost understood [what THIS and THAT meant] in the teacher's explanation before the game, and came to really understand it by watching others got right cards. It is easier to understand it while I am playing the game because it is fun and I get really confused if the teacher explains all at once.

Similarly, most students interviewed made a comment that they understood the difference between this and that through playing the game Karuta. Meantime, some also said that examples given in an individual explanation to their group by using their own cards was very helpful.

There were four types of explanation in the activity instructions given before the game; 1) teacher-fronted explanation with 'dog' pictures, 2) teacher-fronted explanation with 'pencil' pictures, 3) teacher-fronted explanation with their own 'pencil' cards, 4) individual group explanation with their own cards. The researcher, combining these four differently, changed the amount and contents of explanations in each class; however, students' comments from the interview in all the classes were similar. The researcher reflected on this point as follows:

Reflective Diary, June 5 (on Karuta Activity):

Although I changed amount of explanations or examples to show what's different between THIS and THAT, I felt that the different amount of the explanation made no difference in students' understandings. Every class has some quick learners and some slow learners. What I found is that students 
better or more quickly understood when the explanation was with their own cards rather than it was to the whole class on the blackboard.

From these evidences, it can be concluded that grammar explanation before the activity, even if it is for the activity, may not be helpful for students to understand the grammatical point; rather, it would be easier for students to understand the point as part of the activity instructions. In other words, grammar explanation should not be an independent activity instruction, but part of the instructions for a communicative FonF activity.

Second, teachers can demonstrate and use a real example from the activity or a student from the class. Instead of just verbally explaining, visualizing the instructions with examples allows students have a concrete picture of the activity. It is better to use the same materials that students use in the activity.

Third, the activity instructions should be simple and easy to follow. This means that the procedure or rule of the activity should be also simple and easy. Teachers can make instructions simple by breaking them down into small steps, which are almost the same as organizational instructions.

Another way of simplify the instructions is to borrow a rule from other games which are familiar to students. Karuta is a good example for this. All the students have already known this card game since they were little children. However, teachers usually still need to adapt the rule a little bit and explain what is different from the original game, but giving students a familiar name of the activity allows them to have a general idea about what this activity looks like.

Fourth, as students get familiar with the basic rule, teachers can gradually add more rules, or change the task more complicated. In Karuta Activity, students came to have to say the sentence aloud when they got a card in the middle of the game. In

\footnotetext{
${ }^{4}$ More discussion on explicit form instruction is in section 5.2.3. (2) 4) as well.
} 
Vocabulary-Building Activity with Handout, first, students repeated after the teacher, and said the vocabulary items by themselves, and then, with a speed. The level of the task was gradually increased.

Fifth, group work helps students understand the instructions as well as discipline each other as discussed above. Students can clarify the instructions each other in group work. The following group interaction occurred right after the activity instructions for a new rule added in the middle of Karuta Activity:

Class2-4-1:

SA: We pick up and say the one that the teacher says, don't we?

SB: If we can say it, we can get the card. If I pick up this, and can say, "This is a board," then I can get it.

In summary, preparation can make it easier for teachers to use English for activity instructions and the kind of preparation has been suggested as important factors in helping both teachers and students. The activity instructions should be simplified and include demonstrative examples. Explicit form instruction, if needed, should be part of the activity instructions, and group work can also be a powerful tool in applying activity instructions in English.

\subsubsection{Evaluation and Correction of Students' Performance}

Since producing language is not expected from beginners particularly at the initial stage, there were only limited parts of the class in which students should perform English in the project. They were in: Vocabulary-Building; Question-Answer; Blackboard Karuta; Karuta; and Writing Activity.

On the one hand, basically the researcher tried to not to correct students? performance as long as it made sense while the class was focusing on meaning such as during a game or Question-Answer Activity. In the meantime, students' katakana-like 
pronunciation and misspelling was corrected in Vocabulary-Building Activity with practice involved, especially in choral pronunciation practice and vocabulary writing practice. Moreover, the researcher was discreet in correcting students' performance in a way that is not to embarrass students by making their individual mistake public; katakana-like pronunciation was corrected as a whole class, and misspelling was corrected on worksheet returned to individual students.

On the other hand, the researcher tried to positively evaluate and encourage students with praise as much as possible whenever she could see that individuals understood English they heard even though they expressed their understanding in Japanese. Since this English class is part of school education, the researcher admired students' efforts more than the quality of their performance. One of the examples for this evaluation is bearing a stamp on the worksheet when students have done their homework. If they handed in incomplete worksheet, the researcher bore a stamp of "Hand in Again" and returned it explaining what the stamp meant and what they should do.

In the same sense of evaluating efforts, students had a chance for self-evaluation in which they coloured 'flower' on the worksheet each time when they pronounced a whole set of vocabulary seeing pictures. The students could admire their own performance by themselves and seemed to be quite happy about seeing what they had done.

\section{Class2-3-3:}

R: Very good. Very good. You read all these one more time. So, colour one more flower. Colour one more flower.

S: May I colour again?

$\mathrm{R}$ : Yes, one more.

S: Wow!!

When the class completed the worksheet used for homework every day, a student expressed as follows: 
Class5-5-3:

R: Good. Very good. OK. Colour four flowers left. Colour four flowers because we read four times.

S: Oh, we've done this!

R: Yes. We finished it. Good. Very good. Twenty times!

This self-evaluation, or recording what students have done by themselves, actually motivated some students as well. A girl did her homework more than required:

Class3-3-6:

R: (Circulating checking students' homework and bearing a stamp.)

S: Look, Miss. I made extra flowers because I've already done all.

In the project, there was also informal peer-evaluation seen when 'actor' students were performing in front of the class for Skit Listening Activity:

\section{Class5-3-6:}

S: Oh, ohhhh, they are speaking in English!

R: Yes, they are. Very good!

SS: (Clapping hands)

I have discussed some ways in which teachers make it possible to implement English-only communicative FonF activities in terms of three types of teachers' functions: organizational instructions, activity instructions, and evaluation and correction of students' performance. It is certainly possible with thorough preparation and mental rehearsal to implement such activities. Yet, there is the fact that it is never easy either since most teachers have not learnt the language in a communicative way. As long as teachers' lack of confidence in speaking the target language negatively affects on their decision-making of its implementation, this fact should not be ignored. In the present project case, the researcher, who has been studying TESOL in Canada for more than two years, still had several incorrect usages of English in class during the project, for example, 'very south' for 'far down in south,' 'last students' for 'students in a back row,' and 'no 
count' for 'not count.' Some phrases such as 'no count' are 'Japanese-English' influenced by the existence of katakana, and the researcher relied on its convenience in order to make students understand what she meant by using Japanese- English familiar to them. Others are simply incorrect usages due to the researcher's lack of knowledge and preparation for using right expressions.

It is obvious that Japanese English teachers desperately need to be retrained in terms of their speaking skill as well as the communicative approach. The government should offer not only these opportunities to get teachers in-service or pre-service trained but also enough time for teachers to be willing to make full use of these opportunities.

\subsection{Pressure for Time}

One of the most serious issues relating to the implementation of the communicative FonF class is time management. Because language learning requires a long time, and because the curriculum is already very tight, teachers are often caught in a dilemma between communicatively teaching and systematically feeding a list of knowledge prescribed in the curriculum.

Throughout the two-week project teaching period, or 3050 -minute sessions, the researcher gave up and resorted to Japanese in order to move on only once, which was when a boy, Yuki ${ }^{5}$, was trying to convince the researcher about the way of writing his name in English in Skit Writing Activity. He insisted that his name should be written as "Yūki", which is right in Romaji (roman letters) used in Japan to describe katakana words with English alphabet because he was confused with romaji and English or simply did not know that " $\bar{u}$ " did not exist in English alphabet. The researcher already spent quite a time for explaining reasons that we write as "Yuki", but failed to convince him. Finally, the

\footnotetext{
5 Note that in this case, Yuki is pronounced as "yu:ki", not "yuki" which is a name for girls.
} 
researcher briefly, for about half a minute, explained in Japanese, and he gave up although he was not satisfied. Yuki said he understood what the researcher explained in English, but just did not want to accept it; it seemed that Japanese is simply more convincing. There are reasons for resorting to Japanese. The first reason is because the researcher no longer wanted to spend a time over this unimportant point that " $\tilde{u}$ " did not exist in English alphabet. The second is that the researcher did not want other students get confused with all Yuki was saying.

Besides this incident, the researcher was always feeling pressure for time because of the existence of the curriculum. Probably, most teachers have similar feelings to greater or lesser degrees since they must have their own teaching plan. What the researcher tried to do in implementing the communicative teaching was convince herself that whatever happened in class, everything would be English input for students. At the same time, teachers should feel free to use Japanese on an absolutely necessary occasion when they desperately need to save time as well as for students' safety reason as already discussed above. The purpose of using Japanese is, after all, to maintain the communicative FonF class.

\section{Conclusion}

In this paper, I have discussed the possibility of implementing English-only communicative FonF activities in a Japanese junior high school context. Through examining students' perceptions and responses to the activities, I reached a quite positive conclusion that Japanese English teachers can implement the activities. Students, even beginners, can understand the class organized with the activities and actively participate enjoying themselves. However, the implementation requires several conditions, which are relating to characteristics of the activities considered in designing the activities and classroom issues which arose in the project. Undoubtedly, it is not easy; teachers need a 
great deal of preparation and considerations for the implementation. But, the most necessary and powerful condition is, I believe, a time period within which both teachers and students get familiar with this new teaching/learning style. For this reason, without implementing and trying it until everybody involved in education, who are teachers, students, their parents, and authorities, get comfortable with it, there is no success for this new evolving teaching.

Although I am convinced with this conclusion, there are several limitations of this research. First, the findings cannot be generalized since the participants are convenience samples and the research site is located in such a specific context explained in Chapter 3. If it is in a school area where most residents are highly educated and concerned about entrance examinations, the result might be different. Secondly, further research regarding effectiveness of the communicative FonF activities on entrance examinations is needed. According to Toyota's comment elicited a few days later after the project teaching completed, the students, even some of the slow learners, showed in a quiz that they had acquired some vocabulary items. They could spell the items accurately although the activities included a small amount of writing exercise. Toyota also reported that the students did not take as much time and effort to learn how to write the required forms covered in the project as they usually need in the traditional grammar class. It is assumed that the reason for this may be that the students have already established concepts behind the forms through being exposed to sufficient listening input in various communicative FonF activities involved. However, these reports are not enough to support the effectiveness of the activities on grammar-oriented examination. Thirdly, in this project investigating beginners' perceptions and responses to the FonF activities, FonF could not be separated from the communicative activities, but rather it was integrated within the meaning-centered communication as Harley (1998) suggested. However, the effectiveness of FonF per se, separated from interesting communicative 
activities, needs to be investigated. Fourth, it is necessary to consider relationship between the implementation of the communicative FonF activities and the evaluation system in Japan. These are further research.

The implementation appears to require enormous work. Nevertheless, from students' perspectives, it is never impossible but desirable; they like the activities and can understand what they hear and see in the activities. As a teacher who has been taught by CLT in Canada and who has learnt about language acquisition, I am certainly confident that I can throw a small stone into at least my school, talking about and exchanging my experiences with other teachers who do not yet know about this new teaching. 


\section{References}

Asher, J. (1966). The learning strategy of the total physical response: A review. Modern Language Journal, 50, 79-84.

Asher, J. (1969). The total physical response approach to second language learning. Modern Language Journal, 53, 3-17.

Bialystok, E. (1994). Representation and ways of knowing: Three issues in second language acquisition. In N. Ellis (Ed.), Implicit and explicit learning of languages (pp. 549-569). London: Academic Press.

Breen, M., \& Candlin, C. (1980). The essentials of a communicative curriculum in language teaching. Applied Linguistics, 2, 89-112.

Burden, P. (2000). The use of 'only English' in a learner-centred university classroom in Japan. RELC Journal, 31, 139-149.

Chambers, F. (1991). Promoting use of the target language in the classroom. Language Learning Journal, 4, 27-31.

Cheung, C. (2001). The use of popular culture as a stimulus to motivate secondary students' English learning in Hong Kong. ELT Journal, 55, 55-61.

Cook, V. (2001). Using the first language in the classroom. Canadian Modern Language Review, 57, 402-423.

Cortazzi, M., \& Jin, L. (1996). Culture of learning: Language classrooms in China. In H. Coleman (Ed.), Society and the language classroom (pp. 169-206). Cambridge: Cambridge University Press.

Dörnyei, Z. (2001). Theories of motivation in psychology. In Teaching and researching motivation (pp. 18-45). Harlow, UK: Pearson Education.

Doughty, D., \& J. Williams, (Eds.). (1998). Focus on form in classroom second language acquisition. New York: Cambridge University Press.

Duff, P. A., \& Polio, C. G. (1990). How much foreign language is there in the foreign language classroom? Modern Language Journal, 74, 154-166.

Edge, J., \& Samuda, V. (1980). Methodials - The role and design of material and method. RELC Journal,

Ellis, N. (1994). Implicit and explicit language learning - An overview. In N. Ellis (Ed.), Implicit and explicit learning of languages (pp. 1-9). London: Academic Press.

Ellis, R. (1992). Second Language Acquisition and language pedagogy. Clevedon, UK: Multilingual Matters.

Ellis, R. (1994). A theory of instructed second language acquisition. In N. Ellis (Ed.), Implicit and explicit learning of languages (pp. 79-114). London: Academic Press.

Ellis, R. (1998). Teaching and research: Options in grammar teaching. TESOL Quarterly, $32,39-60$. 
Ellis, R., Basturkmen, H., \& Loewen, S. (2001). Preemptive focus on form in the ESL classroom. TESOL Quarterly 35, 407-432.

Ertmer, P. A. (1997). Common qualitative research designs. In P. Leedy, (Ed.), Practical research planning and design (pp. 155-172). Upper Saddle River, NJ: Prentice Hall.

Fathman, A. (1975). The relationship between age and second language productive ability. Language learning, 25, 245-253.

Finocchiaro, M., \& Brumfit, C. (1983). The functional-notional approach from theory to practice. Oxford: Oxford University Press.

Fotos, S. (1993). Consciousness raising and noticing through focus on form: Grammar task performance versus formal instruction. Applied Linguistics, 14, 385-407.

Fotos, S. (1994). Integrating grammar instruction and communicative language use through grammar consciousness-raising tasks. TESOL Quarterly, 28, 323-351.

Fotos, S. (2002). Structure-based interactive tasks for the EFL grammar learner. In E. Hinkel, \& S. Fotos (Eds.), New perspectives on grammar teaching in second language classrooms (pp. 135-154). Mahwah, NJ: Lawrence Erlbaum Associates.

Franklin, C. E. (1990). Teaching in the target language: Problems and prospects. Language Learning Journal, 2, 20-24.

Gorsuch, Greta. (1993, August 2). "Brave use of English pays off." The Daily Yomiuri, p. 9.

Gorsuch, G. (2000). EFL educational policies and educational cultures: influences on teachers' approval of communicative activities. TESOL Quarterly, 34, 675-709.

Harley, B. (1998). The role of focus-on-form tasks in promoting child L2 acquisition. In C. Doughty, \& J. Williams (Eds.), Focus on form in classroom second language acquisition (pp. 156-174). New York: Cambridge University Press.

Herman, R. L., \& Flanigan, B. O. (1995). Adding grammar in a communicatively based ESL program for children: Theory in practice. TESL Canada Journal, 13, 1-16.

Hinkel, E., \& Fotos, S. (2002a). From theory to practice: A teacher's view. In E. Hinkel, \& S. Fotos, (Eds.), New perspectives on grammar teaching in second language classrooms. Mahwah, NJ: Lawrence Erlbaum Associates.

Hinkel, E., \& S. Fotos, (Eds.). (2002b). New perspectives on grammar teaching in second language classrooms. Mahwah, NJ: Lawrence Erlbaum Associates.

Hino, N. (1988). Yakudoku: Japan's dominant tradition in foreign language learning. JALT Journal, 10, 45-55.

Kasajima, J., Asano, H., Shimomura, Y., Makino, T., Ikeda, M., et al. (2002). New horizon, English course 1. Tokyo: Tokyo Shoseki.

Keller-Cohen, D. (1981). Input from the inside: The role of a child's prior linguistic experience in second language learning. In R. W. Anderson (Ed.), New dimensions in second language acquisition research. Rowley, MA: Newbury House 
Publishers.

Kobayashi, Y. (2001). The learning of English at academic high schools in Japan: Students caught between exams and internationalisation. Language Learning Journal, 23, 67-72.

Kowal, M., \& Swain, M. (1998). From semantic to syntactic processing: How can we promote it in the immersion classroom? In C. Doughty, \& J. Williams (Eds.), Focus on form in classroom second language acquisition (pp. 284-309). New York: Cambridge University Press.

Krashen, S. (1980). The input hypothesis. In J. Alatis (Ed.), Current issues in bilingual education (pp. 144-158). Washington, D. C.: Georgetown University Press.

Krashen, S. (1982). Principles and practice in second language acquisition. London: Pergamon.

Krashen, S. (1985). The input hypothesis: Issues and implications. New York: Longman.

Krashen, S. D. (1994). The input hypothesis and its rivals. In N. Ellis (Ed.), Implicit and explicit learning of language (pp. 45-77). London: Academic Press.

Krashen, S. D. (1999). Seeking a role for grammar: A review of some recent studies. Foreign Language Annals, 32, 245-257.

Krashen, S., \& Terrell, T. (1983). The natural approach. Oxford: Pergamon.

Li, D. (1998). "It's always more difficult than you plan and imagine": Teachers" perceived difficulties in introducing the communicative approach in South Korea. TESOL Quarterly, 32, 677-703.

Lightbown, P. M. (1992). Getting quality input in the second/foreign language classroom. In C. Kramsch, \& S. McConnell-Ginet (Eds.), Text and context. Cross-disciplinary perspectives on language study (pp. 187-197). Toronto: D. C. Health and Company.

LoCastro, V. (1996). English language education in Japan. In H. Coleman (Ed.), Society and the language classroom (pp. 40-59). Cambridge: Cambridge University Press.

Long, M. H. (1991). Focus on form: A design feature in language teaching methodology. In K. de Bot, R. Ginsberg, \& C. Kramsch (Eds.), Foreign language research in cross-cultural perspective (pp. 39-52). Amsterdam: John Benjamins.

Long, M. H., \& Robinson, P. (1998). Focus on form: Theory, research, and practice. In C. Doughty, \& J. Williams (Eds.), Focus on form in classroom second language acquisition (pp. 15-41). New York: Cambridge University Press.

Loschky, L., \& Bley-Vroman, R. (1993). Grammar and task-based methodology. In G. Grookes \& S. Gass (Eds.), Tasks and language learning: Integrating theory and practice (pp. 122-167). Clevedon: Multilingual Matters.

Maxwell, J., \& Miller, B. (1992). Two aspects of thought and two components of qualitative data analysis. International Journal of Qualitative Studies in Education, 
3, 7-20.

Maykut, P., \& Morehouse, R. (1994). Qualitative data analysis - using the constant comparative method. In Beginning qualitative research: $A$ philosophical and practical guide (pp. 126-149). London: Falmer.

Medgyes, P. (1994). The non-native teacher. London: Macmillan.

Ministry of Education (Monbusho). (1989). Chugakkou gakushu shidonyouryo: Gaikokugohen [The course of study for junior high schools: foreign languages English]. Tokyo: Tokyo Shoseki.

Ministry of Education, Science, Sports, and Culture (Monkasho). (1998a). Chugakkou gakushu shidouyouryo: Gaikokugohen [The course of study for junior high schools: foreign languages - English]. Tokyo: Tokyo Shoseki.

Ministry of Education, Science, Sports, and Culture (Monkasho). (July 12, 1998b). National Curriculum Standards Reform fro Kindergarten, Elementary School, Lower and Upper Secondary School and Schools for the Visually Disabled, the Hearing Impaired and the Otherwise Disabled - Synopsis of the Report. Retrieved December 15, 2002 from http://www.mext.go.jp/english/news/1998/07/980712. htm.

Ministry of Education, Science, Sports, and Culture (Monkasho). (1999). Chugakkou gakushu shidouyouryo kaisetsu: Gaikokugohen [A commentary on junior high school education guidelines: foreign languages - English]. Tokyo: Tokyo Shoseki.

Oyama, S. (1976). A sensitive period for the acquisition of a non-native phonological system. Journal of Psycholinguisitc Research, 5, 261-285.

Patkowski, M. S. (1980). The sensitive period for the acquisition of syntax in a second language. Language Learning, 30, 449-472.

Peirce, B. N., Swain, M., \& Hart, D. (1993). Self-assessment, French immersion, and locus of control. Applied Linguistics, 14, 25-42.

Polio, C.G., \& Duff, P. A. (1994). Teachers' language use in university foreign language classrooms: A qualitative analysis of English and target language alternation. Modern Language Journal, 78, 313-326.

Rolin-Ianziti, J., \& Brownlie, S. (2002). Teacher use of learners' native language in the foreign language classroom. Canadian Modern Language Review, 58, 402-426.

Rounds, P. (1996). The classroom-based researcher as fieldworker: Strangers in a strange land. In S. Gass \& J. Schachter (Eds.), Second language classroom research: Issues and opportunities (pp. 45-59). Mahwah, NJ: Lawrence Erlbaum Associates.

Sarantou, L. (1998). Using games in the Japanese high school English classroom. On JALT '97: Trends and transitions, 207-212.

Schmidt, R. (1990). The role of consciousness in second language learning. Applied Linguistics, 11, 129-158. 
Schmidt, R. (1995). Consciousness and foreign language learning: A tutorial on the role of attention and awareness in learning. In R. Schmidt (Ed.), Attention and awareness in foreign language learning. Hawaii: Second Language Teaching \& Curriculum Center, University of Hawaii.

Scovel, T. (1981). Discussion of "Exceptions to critical period predictions: A sinister plot". In R. W. Andersen (Ed.), New dimensions in second language acquisition research (pp. 58-61). Rowley, Mass.: Newbury House Publishers.

Scovel, T. (1988). A time to speak: A psycholinguistic inquiry into the critical period for human speech. New York: Newbury House.

Scovel, T. (2000). A critical review of the critical period research. Annual Review of Applied Linguistics, 20, 213-223.

Seliger, H. W. (1981). Exceptions to critical period predictions: A sinister plot. In R. W. Andersen (Ed.), New dimensions in second language acquisition research (pp. 47-57). Rowley, Mass.: Newbury House Publishers.

Sheen, R. (2002). 'Focus on form' and 'focus on forms.' ELT Journal, 56, 303-305.

Singleton, D. (1995). A critical look at the critical period hypothesis in second language acquisition research. In D. Singleton, \& Z. Lengyel (Eds.), The age factor in second language acquisition (pp. 1-29). Clevedon: Multilingual Matters.

Spada, N., \& Lightbown, P. M. (1993). Instruction and the development of questions in L2 classrooms. Studies in Second Language Acquisition, 15, 205-221.

Thompson, G. (1996). Some misconceptions about communicative language teaching. ELT Journal, 50, 9-15.

Tomlin, R., \& Villa, V. (1994). Attention in cognitive science and second language acquisition. Studies in Second Language Acquisition, 16, 182-203.

Tovell, R., \& Hawkins, R. (1994). The observable phenomena of second language acquisition. In Approaches to second language acquisition (pp. 7-16). Clevedon: Multilingual Matters.

Turnbull, M. (2001). There is a role for the L1 in second and foreign language teaching, but.... Canadian Modern Language Review, 57, 531-540.

Turnbull, M., \& Arnett, K. (2002). Teachers' uses of the target and first languages in second and foreign language classrooms. Anmual Review of Applied Linguistics, 22, 204-218.

VanLier, L. (1988). The methods of classroom research. In L. van Lier, The classroom and the language learner (pp. 36-70).

VanPatten, B. (1990). Attending to content and form in the input: an experiment in consciousness. Studies in Second Language Acquisition, 12, 287-301.

VanPatten, B. (1993). Grammar teaching for the acquisition-rich classroom. Foreign Language Annals, 26, 435-450.

VanPatten, B., \& Cadierno, T. (1993). Explicit instruction and input processing. Studies 
in Second Language Acquisition, 15, 225-243.

VanPatten, B., \& Sanz, C. (1995). From input to output: Processing instruction and communicative tasks. In F. Eckman, D. Highland, P. Lee, J. Mileham, \& R, Weber (Eds.), Second language acquisition theory and pedagogy (pp. 169-186). Hillsdale, NJ: Lawrence Eribaum Associates

White, J. (1998). Getting the learners' attention: A typographical input enhancement study. In C. Doughty, \& J. Williams (Eds.), Focus on form in classroom second language acquisition (pp. 85-113). New York: Cambridge University Press.

Williams, J. (1999). Learner-generated attention to form. Language Learning, 49, 583-625. 
School ro.l

\section{Appendix 1}

Unit:

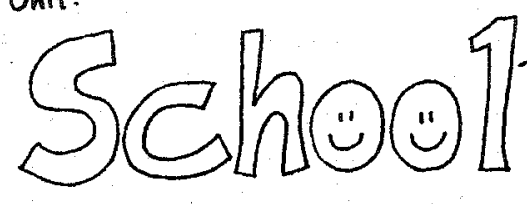

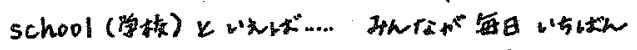

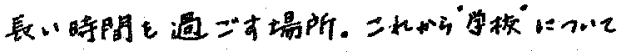

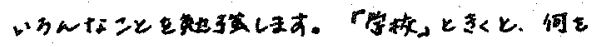

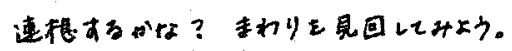

一何心ちかが?

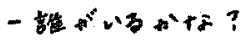

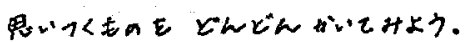

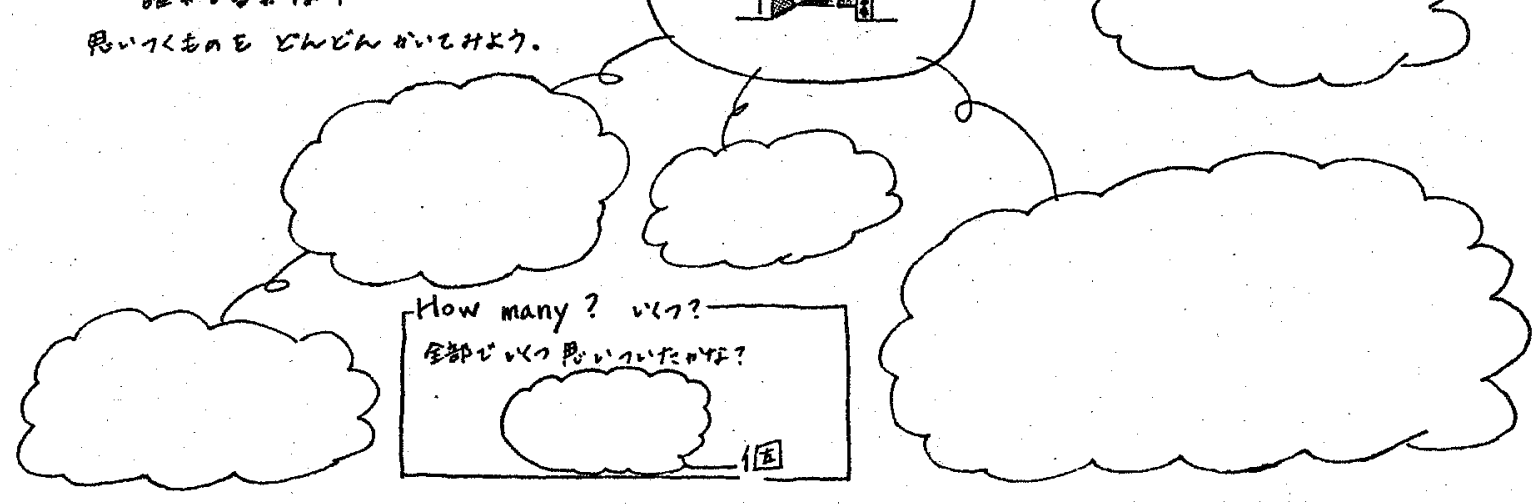

\section{Appendix 2}

School No.2 lasbe, no. (, name (

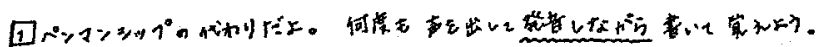
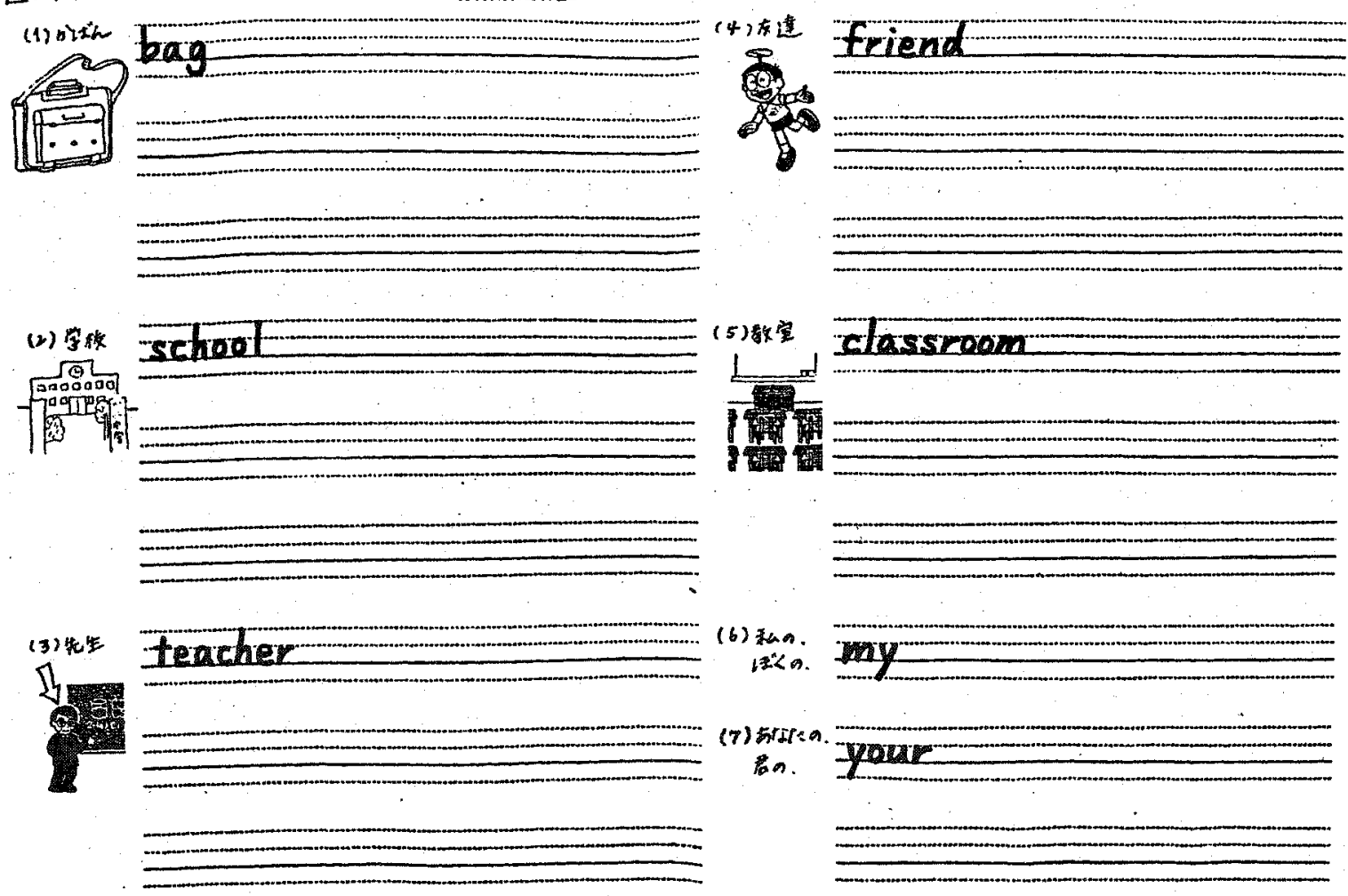

(b) 私a .

12<a.

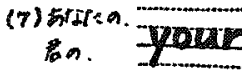

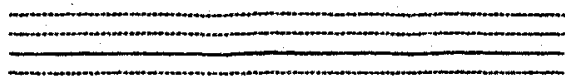




\section{Appendix 3}

School No.3 class( he.,

圭しもし……落としましたよ。

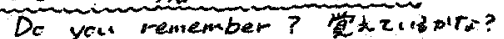

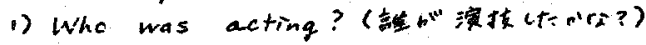

(1)

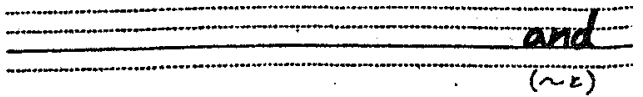

(2)

(1)

2) What were they saying? (何e to.tt=n'ts?)

(1) FXevre wit. (木भまん.)

(2)

$=\frac{}{(1 \pm n ?)}$

(3)

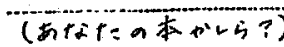

(4)

-

(たカーそうてす。

(ポフ日本)

(6)

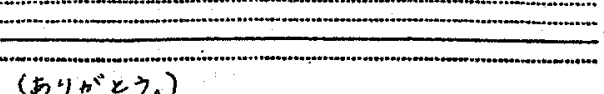

(2)

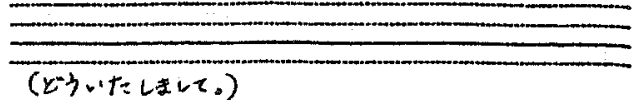

3)練㥜しよク

Excuse

Thankyou.

\section{You're welcome.}

\section{Appendix 4}

\section{School No. 4}

class() no. ()

name (

Listen to Ritsuko's friends. (Wn=o o

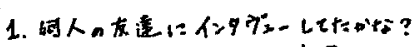
How many friends did Ritsuko interview? frierds.

2. Listen to the tope and fill in the blanks with your friends in your group. (₹-T0E

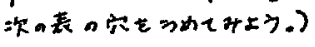

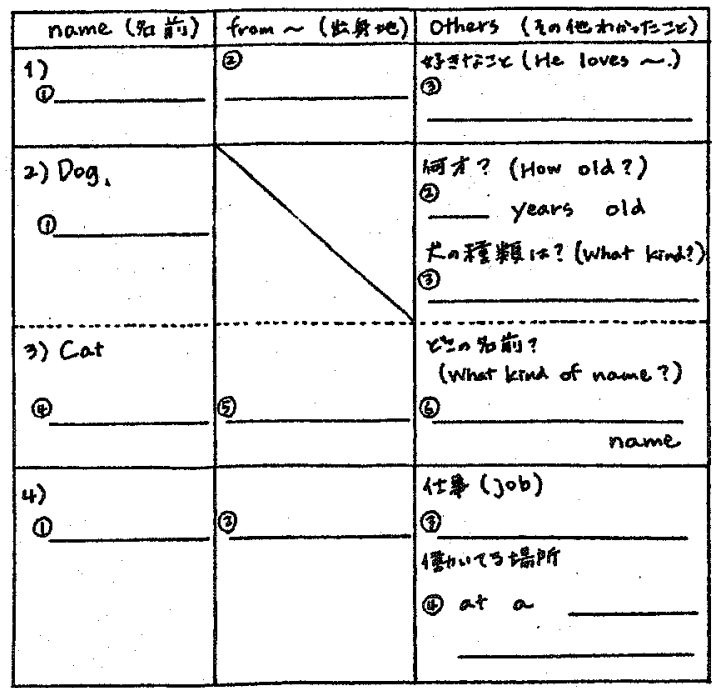

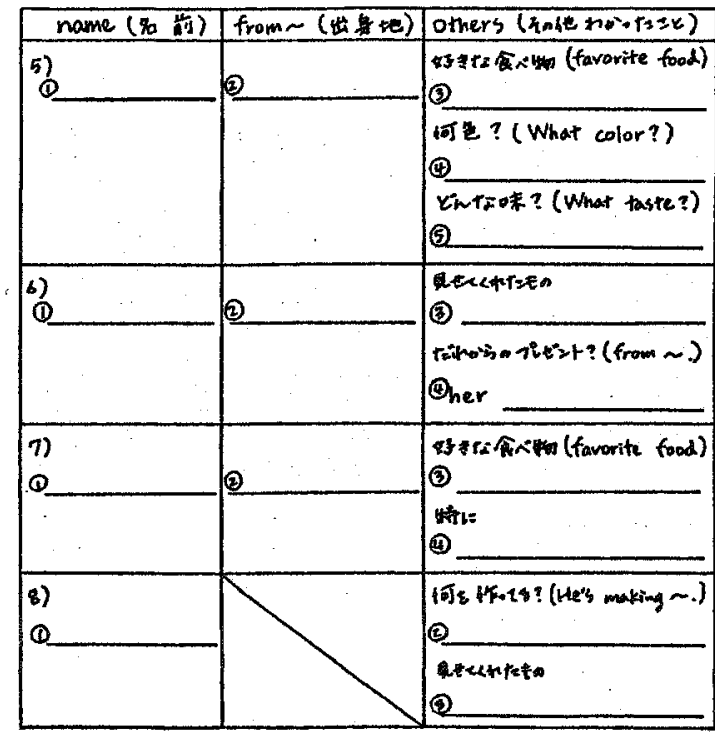

Tole ants 


\section{Appendix 5}

Let's read!" No., class( ) no. ( ' name (

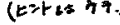

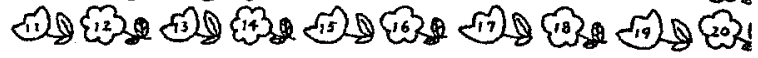

〜'school"version (学校糄) 〜 $\sim$ "your town"version (
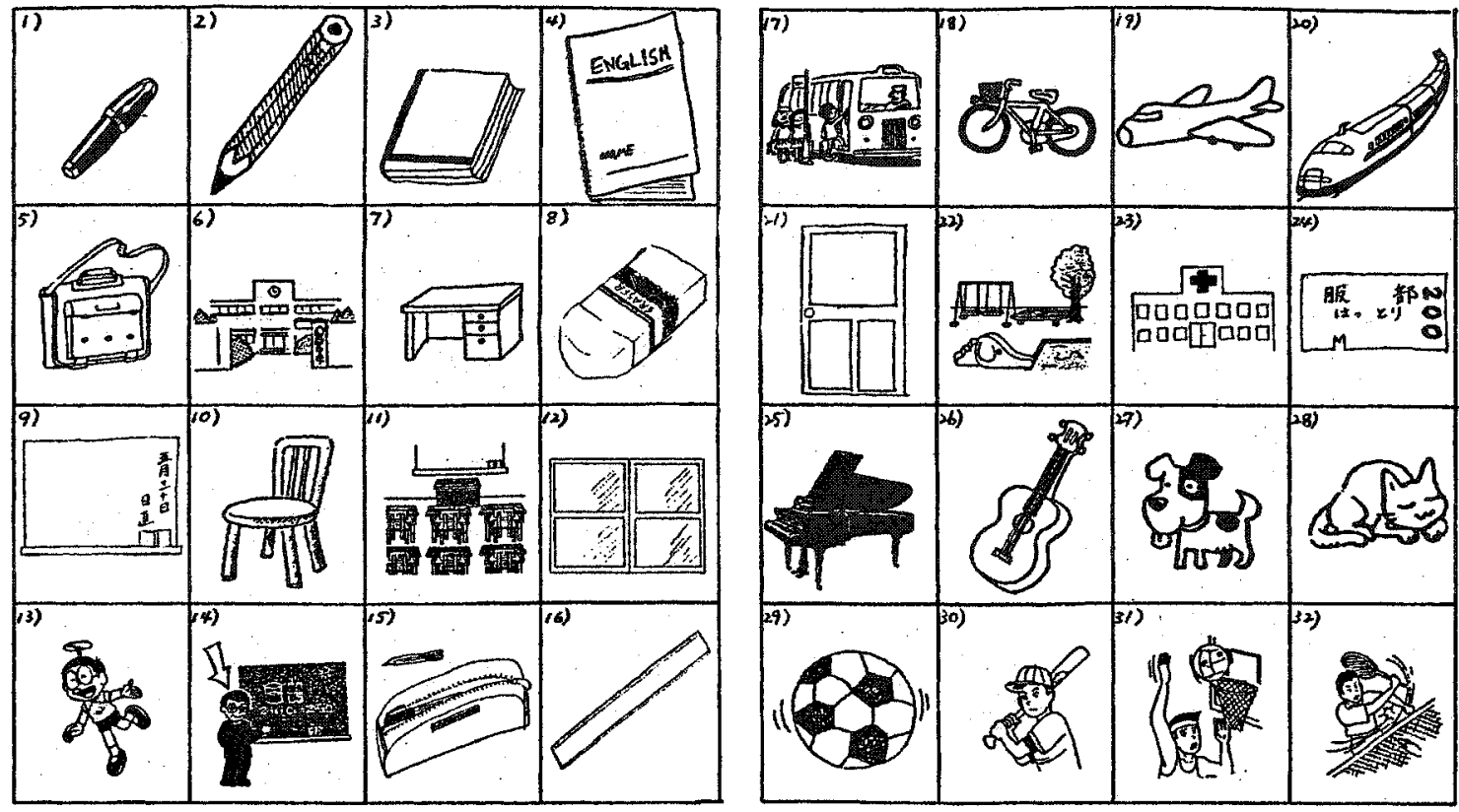


\section{Appendix 6}

\section{Student Questionmaire 1}

\section{(English Version)}

No. ( ) Name (

Before starting the English class conducted only in English, please answer the questions below. Your answers will be used only for a study exploring "a better approach to teaching English", but not for any other purpose, and will not influence your grade and mark at all. So, please do not worry and answer honestly.

Read the questions below, and circle one which best describes your case.

1. Have you ever been to any other country rather than Japan? Yes / No

2. Have you ever lived in any other country rather than Japan? Yes / No

$\rightarrow$ If your answer is "Yes,"

(1) Which country was it? The name of the country (

(2) How old were you?

years old )

3. Have you ever studied English before junior high school? Yes / No

$\rightarrow$ If your answer is "Yes,"

(1) How old were you? Circle all that apply.

Grade 6 Grade 5 Grade 4 Grade 3 Grade 2 Grade 1 Before elementary school

(2) Where did you study it? Circle all that apply.

School Cram School English Conversation School Tutor Home with family Other (specify

(3) How often did you study it?

Once a month Once 2 weeks Once a week Twice a week 3 times a week or more

(4) How long per class did you study it?

Half an hour 1 hour 1.5 hours 2 hours More than 2 hours

(5) Did you like the English class?

Yes / No

And why? (

4. Do you take any other English class outside of junior high school?

Yes / No

$\rightarrow$ If your answer is "Yes,"

(1) Where do you study English besides school? Circle all that apply.

Cram School English Conversation School Tutor Home with family

Other (specify

(2) How often do you study it?

Once a month Once 2 weeks Once a week Twice a week 3 times a week or more

(3) How long per class did you study it?

Half an hour 1 hour 1.5 hours 2 hours More than 2 hours 
(4) Did you like the English class?

I like it very much. I like it. I dislike it. I hate it very much.

(5) If you chose "I like it very much" or "I like it" in Question 4, why? Circle all that apply.

( ) Because it is fun.

( ) Because it covers the same content with school English class and useful for it.

( ) Because it covers the different content from school English class and I can study something new.

( ) Because it is easy to understand.

( ) Because the teacher explains well.

( ) Because the teacher is good (funny / kind).

( ) Because it helps me do my homework from school.

( ) Because it gives me no (or a little) homework.

( ) Because I can see my friends.

( ) Other (specify

(6) If you chose "I dislike it" or "I hate it very much" in Question 4, why? Circle all that apply.

( ) Because it is not fun.

( ) Because it covers the same content with school English class; it is boring.

( ) Because it covers the different content from school English class; it is not useful for school.

( ) Because it is difficult to understand.

( ) Because the teacher does not explain well.

( ) Because the teacher is not good (not funny / kind).

( ) Because it gives me lots of homework.

( ) Because it cuts the time for me to play with my friends.

( ) Other (specify

5. Do you like English class at school?

I like it very much. I like it. I dislike it. I hate it very much.

(1) If you chose "I like it very much" or "I like it", why? Circle all that apply.

( ) Because I can study something new; it is fun.

( ) Because I can play games; it is fun.

( ) Because I can do something different from what I do in other classes, for example, listening to a tape.

( ) Because it is helpful for my future.

( ) Because it is easy to understand.

( ) Because the teacher does not often call on a student.

( ) Because the teacher explains well.

( ) Because the teacher is good (funny / kind).

( ) Because the teacher encourages me with praise.

( ) Because it gives me no (or a little) homework.

( ) Other (specify 
(2) If you chose "I dislike it" or "I hate it very much", why? Circle all that apply.

( ) Because it is not fun.

( ) Because it is not serious with games.

( ) Because it covers the same content with cram school; it is boring.

( ) Because it is not useful for my future.

( ) Because I have to pronounce English aloud.

( ) Because it is difficult to understand.

( ) Because the teacher often calls on a student.

( ) Because the teacher does not explain well.

( ) Because the teacher is not good (not funny / kind).

( ) Because the teacher does not encourage me with praise.

( ) Because it gives me lots of homework.

( ) Other (specify

6. What do you think of taking English-only English class? Circle all that apply.

( ) I'm excited because it sounds like I can do something different from usual.

( ) I'm nervous because the teacher is different from usual.

( ) I'm afraid I cannot understand the class.

( ) Other (specify

7. Prior to taking English-only class, what is your expectation of yourself?

( ) I am going to work harder than usual.

( ) I am going to work as hard as usual.

( ) I am going to work at a reasonable level as usual.

( ) I am going to work less than usual.

( ) Other (specify 


\section{Appendix 7}

\section{Student Questionmaire 2}

(English Version)

No. ( ) Name (

After taking English-only class 3 times, please answer the questions below regarding how you feel and what you think about. Your answers will be used only for a study exploring "a better approach to teaching English", but not for any other purpose, and will not influence your grade and mark at all. So, please do not worry and answer honestly.

1. Did you understand what the teacher was saying? Circle one.

( ) I understood almost all. (80-100\%)

( ) I generally understood it. (60-80\%)

( ) I understood about half of it. (50-60\%)

( ) I only understood less than half. (30-50\%)

( ) I did not understand most of it. (10-30\%)

( ) I did not understand at all. (0-10\%)

2. Although you might not have understood some English, did you understand what to do in class? Circle one.

( ) I understood almost all. (80-100\%)

( ) I generally understood it. (60-80\%)

( ) I understood about half of it. (50-60\%)

( ) I only understood lesss than half. (30-50\%)

( ) I did not understand most of it. (10-30\%)

( ) I did not understand at all. (0-10\%)

3. What did you do when you did not understand something? Circle all that apply.

( ) I carefully listened to teacher's English.

( ) I asked the teacher in English.

( ) I asked the teacher in Japanese.

( ) I asked peers.

( ) I watched what other peers were doing.

( ) I guessed by myself.

( ) I left it unsolved.

( ) Other (specify

4. Which do you think is helpful to easily understand the class? Circle all that apply.

( ) Teacher's English

( ) Pictures shown by the teacher

( ) Word cards (Flash cards)

( ) Talk with neighbours or peers in a group

( ) Games

( ) Other (specify 
5. Which do you think is helpful to make the class fun? Circle all that apply.

( ) Teacher's English

( ) Pictures shown by the teacher

( ) Word cards (Flash cards)

( ) Talk with neighbours or peers in a group

( ) Games

( ) Other (specify

6. Which activity do you like? Circle all that apply.

( ) Mapping Activity in the first class

( ) Listening Activity with picture cards

( ) Pronouncing Activity with picture cards

( ) Pronouncing Activity with flash cards

( ) Matching Activity (cards in the envelope)

( ) Blackboard Karuta (picking up a picture/word on the blackboard listening to English)

( ) Skit shown by your classmates

( ) Karuta

( ) Word-Writing Exercise with handout

( ) Other (specify

7. Do you like this English class? Circle one.

I like it very much. I like it. I dislike it. I hate it very much.

(1) If you chose "I like it very much" or "I like it", why? Circle all that apply.

( ) Because I can study something new; it is fun.

( ) Because I can play games; it is fun.

( ) Because its atmosphere is casual.

( ) Because I can work actively myself, besides listening to the class.

( ) Because I can talk to peers.

( ) Because there is group work.

( ) Because it is easy to understand.

( ) Because there is only a few "writing" activities with the use of a notebook or handout.

( ) Because the teacher often calls on a student.

( ) Because the teacher explains well.

( ) Because the teacher is good (funny / kind).

( ) Because the teacher encourages me with praise.

( ) Because it gives me no (or a little) homework.

( ) Because the homework is easy.

( ) Because it gives me homework.

( ) Because it seems helpful for my future.

( ) Other (specify 
(2) If you chose "I dislike it" or "I hate it very much", why? Circle all that apply.

( ) Because it covers the same content with cram school; it is boring.

( ) Because it is not fun.

( ) Because it is not serious with games.

( ) Because I have to work actively myself, rather than only listening to the class.

( ) Because I am not good at working with neighbours or peers in a group.

( ) Because I have to pronounce English aloud.

( ) Because it is too difficult to understand.

( ) Because there is only a few "writing" activities with the use of a notebook or handout.

( ) Because the teacher often calls on a student.

( ) Because the teacher does not explain in Japanese well.

( ) Because the teacher is not good (not funny / kind).

( ) Because the teacher does not encourage me with praise.

( ) Because it gives me lots of homework.

( ) Because the homework is difficult.

( ) Because it does not seem useful for my future.

( ) Other (specify

8. If you have any request for the coming class, indicate what you want. 


\section{Appendix 8}

\section{Student Questionmaire 3 \\ (English Version)}

No. ( ) Name (

After taking English-only class 6 times, please answer the questions below regarding how you feel and what you think about. Your answers will be used only for a study exploring "a better approach to teaching English", but not for any other purpose, and will not influence your grade and mark at all. So, please do not worry and answer honestly.

1. Did you come to understand what the teacher was saying? Circle one.

( ) I understood almost all. (80-100\%)

( ) I generally understood it. (60-80\%)

( ) I understood about half of it. (50-60\%)

( ) I only understood less than half. (30-50\%)

( ) I did not understand most of it. (10-30\%)

( ) I did not understand at all. (0-10\%)

2. Although you might not have understood some English, did you come to understand what to do in class? Circle one.

( ) I understood almost all. (80-100\%)

( ) I generally understood it. (60-80\%)

( ) I understood about half of it. (50-60\%)

( ) I only understood less than half. (30-50\%)

( ) I did not understand most of it. (10-30\%)

( ) I did not understand at all. (0-10\%)

3. What did you do when you did not understand something? Circle all that apply.

( ) I carefully listened to teacher's English.

( ) I asked the teacher in English.

( ) I asked the teacher in Japanese.

( ) I asked peers.

( ) I watched what other peers were doing.

( ) I guessed by myself.

( ) I left it unsolved.

( ) Other (specify

4. Which do you think is helpful to easily understand the class? Circle all that apply.

( ) Teacher's English

( ) Pictures shown by the teacher

( ) Word cards (Flash cards)

( ) Talk with neighbours or peers in a group

( ) Games

( ) Video

( ) Tapes

( ) Other (specify 
5. Which do you think is helpful to make the class fun? Circle all that apply.

( ) Teacher's English

( ) Pictures shown by the teacher

( ) Word cards (Flash cards)

( ) Talk with neighbours or peers in a group

( ) Games

( ) Video

( ) Tapes

( ) Other (specify

6. Which activity do you like? Circle all that apply.

( ) Listening Activity with picture cards

( ) Pronouncing Activity with picture cards

( ) Rhythmical-Pronouncing Activity with pictures on the handout

( ) Pronouncing Activity with flash cards

( ) Writing Exercise with handout

( ) Activity in which the teacher asked a question in English to individuals

( ) Teacher's explanation about this and that with pictures

( ) Karuta

( ) Video

( ) Tape-Listening Activity in a group

( ) Check-It-Out Activity in which the whole class was listening to the tapes again

( ) Other (specify

7. Do you like this English class? Circle one.

I like it very much. I like it. I dislike it. I hate it very much.

(1) If you chose "I like it very much" or "I like it", why? Circle all that apply.

( ) Because I can study something new; it is fun.

( ) Because I can play games; it is fun.

( ) Because I can watch a video.

( ) Because I can listen to English tapes.

( ) Because its atmosphere is casual.

( ) Because I can go to a different classroom than usual.

( ) Because I can work actively myself, besides listening to the class.

( ) Because I can talk to peers.

( ) Because there is group work.

( ) Because it is easy to understand.

( ) Because there is only a few "writing" activities with the use of a notebook or handout.

( ) Because the teacher often calls on a student.

( ) Because the teacher explains well.

( ) Because the teacher is good (funny / kind).

( ) Because the teacher encourages me with praise.

( ) Because it gives me no (or a little) homework.

( ) Because the homework is easy. 
( ) Because it gives me homework.

( ) Because it seems helpful for my future.

( ) Other (specify

(2) If you chose "I dislike it" or "I hate it very much", why? Circle all that apply.

( ) Because it covers the same content with cram school; it is boring.

( ) Because it is not fun.

( ) Because it is not serious with games.

( ) Because I do not like to move to another classroom.

( ) Because I cannot understand videos and tapes.

( ) Because I have to work actively myself, rather than only listening to the class.

( ) Because I am not good at working with neighbours or peers in a group.

( ) Because I have to pronounce English aloud.

( ) Because it is too difficult to understand.

( ) Because I cannot ask a question to the teacher.

( ) Because there is only a few "writing" activities with the use of a notebook or handout.

( ) Because the teacher often calls on a student.

( ) Because the teacher does not explain in Japanese well.

( ) Because the teacher is not good (not funny / kind).

( ) Because the teacher does not encourage me with praise.

( ) Because it gives me lots of homework.

( ) Because the homework is difficult.

( ) Because it does not seem useful for my future.

( ) Other (specify

8. Do you think we had better have more "writing" activities in class? Circle one.

Yes / No

9. Why do you think so? Write your reason.

10. If this English-only class continues, do you agree or disagree?

Agree Tend to agree Tend to disagree Disagree

11. Why do you agree / disagree? Write your reason.

12. What would be your problem if English-only class continued? 


\section{Appendix 9}

\section{Teacher Questionnaire}

(English Version)

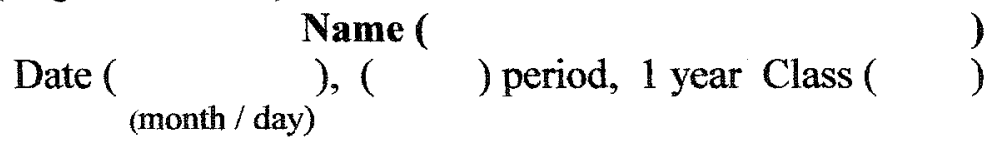

Thank you for observing the project class despite your busy work. If you do not mind, could you give me feedback?

1. What do you think about English class organized with communicative activities and conducted only in English? Circle all that apply.

( ) A. It looks easy for students to get familiar with.

( ) B. It looks easy for students to understand.

( ) C. It is good because it is taking a participatory style.

( ) D. It is good because it is what the new national curriculum is requiring.

( ) E. It seems to prepare students for entrance examinations.

( ) F. It seems to foster students' conversation competence for their future.

( ) G. It is too casual.

( ) H. It has a lack of seriousness.

( ) I. It is noisy, and I'm afraid that it may bother other classes.

( ) J. It does not seem to make students understand well enough.

( ) K. It may not foster students' communicative competence.

( ) L. It may not prepare students for entrance examinations.

( ) M. Other (specify

2. Do you agree with continuing this type of class? Choose one.
Agree
Tend to agree
Tend to disagree
Disagree

3. Which one best describes your reason for the answer to Question 2? Choose one from the items provided in Question 1.

4. What do you think about students' reactions or responses? Choose one.

Very good Relatively good Relatively bad Very bad

5. If you chose "Very good" or "Relatively good" in Question 4,

(1) specify in which activity you had the impression?

(2) Why do you think so? Circle all that apply.

( ) Because the activities were clear

( ) Because the activities were enjoyable themselves.

( ) Because the examples used were good.

( ) Because the explanations and instructions were clear so that students could understand well.

( ) Because the students were well motivated.

( ) Other (specify 
6. If you chose "Relatively bad" or "Very bad" in Question 4,

(1) specify in which activity you had the impression? (

(2) Why do you think so? Circle all that apply.

( ) Because the activities were complicated

( ) Because the activities were boring.

( ) Because the examples used were appropriate.

( ) Because the explanations and instructions were not clear, and then students did not understand.

( . ) Because the students were not motivated.

( ) Other (specify

7. To what extent do you think the students understood teacher's instruction and what to do in class?

( ) $80-100 \%$ (They seemed to understand almost all.)

( ) $60-80 \%$ (They seemed to generally understand it.)

( ) $50-60 \%$ (They seemed to understand more than half of it.)

( ) $30-50 \%$ (They seemed to understand only less than half of it.)

( ) $! 0-30 \%$ (They did not seem to understand most of it.)

( ) $0-10 \%$ ( They did not seem to understand at all.)

8. Please indicate whatever you noticed or felt in terms of the contents of the class, students' reactions, and so forth. I would appreciate if you give me suggestions or comments. 


\section{Appendix 10}

Teacher Interview Schedule (English Version)

\begin{tabular}{|c|c|c|c|}
\hline Activity & $\begin{array}{l}\text { Students' understanding, reactions, interactions, } \\
\text { etc. }\end{array}$ & $\begin{array}{l}\text { The possibility for } \\
\text { implementation }\end{array}$ & $\begin{array}{l}\text { Reasons, } \\
\text { etc. }\end{array}$ \\
\hline $\begin{array}{l}\text { Introducing } \\
\text { new vocab. } \\
\text { with PCs } \\
\text { (Listening } \\
\text { Activity) }\end{array}$ & & $\begin{array}{l}\text { A. Already used } \\
\text { B. Can use it } \\
\text { C. Can use it partly } \\
\text { D. Want but cannot } \\
\text { E. Do not want }\end{array}$ & \\
\hline $\begin{array}{l}\text { Verbal } \\
\text { practice of } \\
\text { vocab. } \\
\text { with PCs }\end{array}$ & & $\mathrm{A}, \mathrm{B}, \mathrm{C}, \mathrm{D}, \mathrm{E}$ & \\
\hline $\begin{array}{l}\text { Verbal } \\
\text { practice of } \\
\text { vocab. } \\
\text { with FCs }\end{array}$ & & $\mathrm{A}, \mathrm{B}, \mathrm{C}, \mathrm{D}, \mathrm{E}$ & \\
\hline $\begin{array}{l}\text { Mapping } \\
\text { Activity }\end{array}$ & & $\mathrm{A}, \mathrm{B}, \mathrm{C}, \mathrm{D}, \mathrm{E}$ & \\
\hline $\begin{array}{l}\text { Matching } \\
\text { Activity } \\
\text { (Pair work) }\end{array}$ & & $\mathrm{A}, \mathrm{B}, \mathrm{C}, \mathrm{D}, \mathrm{E}$ & \\
\hline $\begin{array}{l}\text { Blackboard } \\
\text { Karuta }\end{array}$ & & $\mathrm{A}, \mathrm{B}, \mathrm{C}, \mathrm{D}, \mathrm{E}$ & \\
\hline $\begin{array}{l}\text { Skit with } \\
\text { a student } \\
\text { for new } \\
\text { grammar }\end{array}$ & & $\mathrm{A}, \mathrm{B}, \mathrm{C}, \mathrm{D}, \mathrm{E}$ & \\
\hline $\begin{array}{l}\text { Question to } \\
\text { individuals } \\
\text { in English }\end{array}$ & & $\mathrm{A}, \mathrm{B}, \mathrm{C}, \mathrm{D}, \mathrm{E}$ & \\
\hline $\begin{array}{l}\text { Explanation } \\
\text { of new } \\
\text { grammar in } \\
\text { English } \\
\text { (incl. PCs \& } \\
\text { gestures) }\end{array}$ & & $\mathrm{A}, \mathrm{B}, \mathrm{C}, \mathrm{D}, \mathrm{E}$ & \\
\hline $\begin{array}{l}\text { Grammar } \\
\text { Karuta }\end{array}$ & & $\mathrm{A}, \mathrm{B}, \mathrm{C}, \mathrm{D}, \mathrm{E}$ & \\
\hline Video & & $\mathrm{A}, \mathrm{B}, \mathrm{C}, \mathrm{D}, \mathrm{E}$ & \\
\hline $\begin{array}{l}\text { Tape- } \\
\text { Listening } \\
\text { Activity } \\
\text { (class/group) }\end{array}$ & & $\mathrm{A}, \mathrm{B}, \mathrm{C}, \mathrm{D}, \mathrm{E}$ & \\
\hline
\end{tabular}




\begin{tabular}{|l|l|l|l|}
\hline \multicolumn{1}{|c|}{ Activity } & $\begin{array}{l}\text { Students' understanding, reactions, interactions, } \\
\text { etc. }\end{array}$ & $\begin{array}{l}\text { The possibility for } \\
\text { implementation }\end{array}$ & $\begin{array}{l}\text { Reasons, } \\
\text { etc. }\end{array}$ \\
\hline $\begin{array}{l}\text { English } \\
\text { Instruction } \\
\text { of rules for } \\
\text { Games and } \\
\text { Activities }\end{array}$ & & $\mathrm{A}, \mathrm{B}, \mathrm{C}, \mathrm{D}, \mathrm{E}$ & \\
\hline $\begin{array}{l}\text { Jap. / Eng. } \\
\text { translation } \\
\text { of the learnt } \\
\text { contents } \\
\text { with handout }\end{array}$ & & $\mathrm{A}, \mathrm{B}, \mathrm{C}, \mathrm{D}, \mathrm{E}$ & \\
\hline
\end{tabular}




\section{Appendix 11}

\section{Student Interview Schedule}

1. About their perceptions of activities/class

Do you like the activity that we did today? Why?

How do you like the class that we had today? Why?

Did it make you feel tired/bored?

Which part was fun?

How do you like the English-only class? Why?

Which activity do you like the best? Why?

2. About their ability to understand teacher's English and what to do

Did you understand what your teacher was saying/what to do?

To what extent did you understand it?

When and how did you come to understand it?

What helped you come to understand the class?

What did you do when you did not understand it?

Do you think you improved yourself?

3. About group work

Do you like working with a friend/friends in a group? Why?

Was your group boys-/girls-only, or mixed? Do you like it? Why?

Did your friend help you?

Did you help your friend?

If you have group work all the time in your class, how do you like it? Why?

4. About studying in another classroom

Do you like moving to another classroom? Why?

Is it good or not? Why?

*Note that most of the questions were asked about a particular activity pointed out first; the students responded to the questions based on their concrete experiences in the class, rather than general impressions. 